Ann. Abeilles, I964, 9 (2), I03-I59.

\title{
LES TECHNIQUES DE CONDITIONNEMENT ET DE COMMERCIALISATION DU MIEL AU CANADA ET AUX U.S.A.
}

\author{
R. BORNECK, R. GAUTHRON, F. GLIRAUTE, P. HORGUELIN, \\ J. LOUVEALX, A. PEDELUCQ \\ Documents rassemblés et coordonnés par J. Louveaux, \\ Station de Recherches sur l'Abeille et les Insectes sociaux, \\ Bures-sur-Yvette (Seine-et-Oise)
}

\section{SOMMAIRE}

Les auteurs, membres d'une mission d'étude envoyée en mars 1963 au Canada et aux U. S. A. pour recueillir des renseignements d'ordre technique et économique sur les méthodes de conditionnement et de commercialisation du miel utilisées en Amérique dı Nord, présentent les principaux résultats de leur encuuête. Ils font tout d'abord le point des techniques de préparation du miel pour la vente et décrivent le matériel utilisé dans les entreprises visitées, ainsi que les bâtiments où se fåzit le conditionnement du miel. Après une étude économique du fonctionnement des coopératives apicoles, ils concluent sur les possibilités de transposition au marché français du miel des données recueillies.

\section{INTRODUCTION}

Les difficultés économiques rencontrées par 1'Apiculture française au cours de ces dernières années ont montré à l'évidence que la profession apicole ne pourra surmonter la concurrence des miels étrangers que si elle opère un redressement technique et commercial complet. La création de Coopératives apicoles dans un grand nombre de régions au cours des trois ou quatre dernières années correspond à ce désir de renouveau et d'organisation sur des bases nouvelles de la commercialisation du miel abandonnée jusqu'ici au hasard de circuits plus ou moins compliqués et généralement peu satisfaisants pour le producteur.

Mais si la création de coopératives apicoles répond à un besoin, la mise au point des modalités de fonctionnement de ces organismes demande une étude préalable 
très poussée. Les principes selon lesquels on peut envisager le traitement et la commercialisation du miel sous la forme coopérative sont connus depuis des années et nous avons déjà exposé les uns ou les autres les grandes lignes du processus. La miellerie expérimentale de 1'I. N. R. A, à Montfavet a fait la démonstration concrète de possibilités offertes par les techniques modernes du conditionnement du miel. Il n'en reste pas moins vrai que de nombreux détails du fonctionnement des grandes chaînes de conditionnement restaient à mettre au point; il en allait de même pour tout ce qui concerne la commercialisation.

C'est donc dans le but d'épargner aux coopérateurs des erreurs matérielles coûteuses que les dirigeants de la profession apicole ont entrepris, vers la fin de I962, d'organiser une mission d'étude dans les pays d'Amérique ayant montré jusqu'ici le plus grand dynamisme dans le domaine de la coopération apicole, le Canada et les fitats-Unis, et d'examiier sur place les plus belles réalisations.

Afin d'assurer à la mission le maximum d'efficacité, il fut décidé de lui donner une composition telle qu'elle réunisse des spécialistes venus d'horizons différents et à même d'en tirer le maximum de profit. M. HoRgUEL,IN, président de l'Union nationale de l'Apiculture française, se chargea d'établir les contacts avec nos collègues américains et mit au point un programme précis pour toutes les visites de Coopératives et d'entreprises commerciales.

M. Louveaux, Directeur de la Station de Recherches sur l'Abeille et les Insectes sociaux, fut chargé de coordonner les activités des membres de la mission et d'en assurer le compte rendu final. M. BORNEck, Président de 1'Union des groupements apicoles français et M. PEDELucQ, Président de la Coopérative apicole de Tartas, furent plus spécialement chargés des questions commerciales tandis que M. Guiraute, Ingénieur du Génie rural et M. Gauthron, Architecte de la Coopérative apicole de Pithiviers, avaient pour mission, chacun dans leur spécialité, de rassembler la documentation technique relative à l'appareillage et aux bâtiments.

Le financement de la mission fut assuré par des contributions multiples venues de la profession apicole, du Service du Commerce extérieur, des Coopératives apicoles, du Ministère de l'Agriculture et de l'Institut national de la Recherche agronomique.

Sur le continent américain, l'organisation des visites fut laissée aux soins du Pr Townsend (Guelph) pour le Canada et du Dr J. HAMbLeton pour les U. S. A. Un programme particulièrement chargé nous amena de Montréal à Toronto puis à Guelph, Winnipeg, Saint-Paul-Minneapolis, Sioux-City, Chicago, Colombus, Ithaca et New York. Ce périple réalisé en moins de I $_{5}$ jours nous permit, grâce à la rapidité des déplacements par avion, de visiter :

-- à Montréal : les Services de l'Apiculture du Québec. La firme "Doyon and Doyon ». La firme Lallemand;

- à Toronto : la Coopérative apicole de 1'Ontario et la “ Billy-Bee »;

- à Guelph : le laboratoire apicole de 1'Université de 1'Ontario ;

- à Winnipeg : la Coopérative apicole du Manitoba;

- à Saint-Paul-Minneapolis : 1e laboratoire apicole de 1'Université. Les établissements Bankers, à Canon Falls (Minn.) ;

- à Sioux-City : la "Sioux-Bee, " Coopérative apicole;

- à Chicago : la firme Straub;

- à London (Ohio) : les établissements apicoles Dunham; 
- à Ithaca : le laboratoire apicole de l'Université Cornell. La Coopérative apicole de Finger Lake. La firme "Honey-Butter".

$\mathrm{Au}$ cours de ces visites, nous avons photographié les installations, relevé le plan des locaux et pris des notes abondantes complétées par des documents de toute nature qui nous furent remis par nos hôtes que nous avons soumis, par ailleurs, à un questionnaire serré et quelque peu indiscret. Grâce à l'extrême obligeance de tous ceux qui nous ont reçus, nous sommes en possession d'une masse d'informations dont il importe que nous fassions bénéficier tous les apiculteurs français soucieux d'organiser des coopératives. Le but du présent rapport est de leur fournir un exposé objectif et complet des résultats obtenus par notre mission. Respectant la répartition des tâches qui fut celle que nous avons adoptée pendant notre voyage, nous vous apportons, chacun dans notre domaine, le fruit de nos observations et de nos réflexions.

\section{I. - PRODUCTION ET COMMERCIALISATION DU MIEL EN AMÉRIQUE DU NORD — GÉNÉRAIITÉS}

\section{A. - IA PRODUCTION}

Comme toutes les autres branches de l'Agriculture, l'Apiculture est sous la dépendance étroite d'un ensemble de facteurs qui constituent ce qu'il est convenu d'appeler le milieu, c'est-à-dire essentiellement le sol et le climat. Ces deux éléments agissent, bien entendu, en premier lieu sur la flore, laquelle conditionne à son tour pour une large part les possibilités de récolte du miel. La production dépend en second lieu du peuplement humain, de l'utilisation du sol et, finalement, des méthodes mises en ouvre par les producteurs.

Nous examinerons donc successivement et, nous nous en excusons, de façon très sommaire, les différents facteurs de la production du miel dans la partie nord du continent américain.

\section{I) Le milien}

Il serait assez artificiel de procéder à une étude séparée du Canada et des ÉtatsUnis en ce qui concerne les conditions de milieu. En effet, seule la partie méridionale du Canada, c'est-à-dire celle qui est située au sud de la grande zone forestière boréale, présente un intérêt apicole; ce territoire se rattache si étroitement du point de vue géographique et agricole aux régions contiguës des U.S. A. qu'il est préférable, pour notre étude, de considérer l'ensemble du continent nord-américain jusqu'à la frontière mexicaine. Cet immense secteur présente, bien entendu, une très grande diversité de climats et de sols, done de flores, et seul un effort de simplification nous permettra d'y reconnaître, grosso modo, huit grandes régions apicoles.

\section{Le Nord-Est.}

Les sols de cette région sont surtout d'origine glaciaire. Le climat est continental et la pluviométrie dépasse généralement $\mathrm{I} 000 \mathrm{~mm}$ par an. L'hiver est rude. Sur terrains calcaires, la principale ressource mellifère est constituée par le Trèfle blanc 
(Trifolium repens) Trèfle alsike (Trifolium hybridum). Sur le relief et notamment sur les terrains acides ou neutres des Adirondacks et des montagnes Blanches les abeilles récoltent en abondance le nectar des Framboisiers (Rubus idaeus) et des Épilobes (Epilobium sp.).

\section{Les Appalaches.}

Cette région très humide porte encore de vastes forêts dont certaines esssences sont d'un grand intérêt apicole : Tilleul (Tilia sp.), Robinier (Robinia peudacacia), Liriodendron tulipifera, Oxydendron arborea, Magnolia sp., etc. Certaines de ces plantes ne se retrouvent dans aucune autre région des tats-Unis; en conséquence, les miels produits sont souvent très particuliers, tels le miel d'Oxydendron qui passe pour l'un des meilleurs miels américains.

\section{La plaine côtière atlantique.}

Cette région, qui s'étend jusqu'au golfe du Mexique est à la fois chaude et humide. Les zones marécageuses $\mathrm{y}$ abondent et on $\mathrm{y}$ rencontre diverses espèces du genre Nyssa qui sont à l'origine des fameux miels de Tupelo, riches en lévulose et qui restent liquides presque indéfiniment. Signalons encore comme plantes mellifères des plaines côtières atlantiques Ilex glabra, et, sur des millions d'hectares, le Cotonnier. Cette dernière plante fournit un miel de qualité très variable, cristallisant rapidement.

\section{Les plaines du centre.}

Cette immense région s'étend à la fois sur le Canada et les U. S. A. : c'est la prairie. Le sol y est constitué d'un loess très fertile amené surtout par le vent à la fin de la période glaciaire. Le climat est encore continental mais la pluviométrie est plus faible que dans l'Est. C'est le domaine du Trèfle blanc (Trifolium repens) et du Mélilot (Melilotus alba). Dans les vallées, les abeilles récoltent le nectar de nombreuses Composées : Bidens, Helianthus, Aster, etc.

\section{Les hautes plaines à l'est des montagnes Rocheuses.}

Ces plaines sont semi-arides, coupées de canyons et hérissées de buttes. Le sol y est d'origine tertiaire. Le climat est caractérisé par le grand écart des températures diurnes et nocturnes ainsi que par une pluviométrie généralement inférieure à $65^{\circ} \mathrm{mm}$. La seule végétation naturelle intéressante pour l'apiculture est constituée par les Sauges (Salvia sp.). La production du miel, essentiellement concentrée entre les mains des apiculteurs professionnels, dépend surtout des cultures irriguées de Luzerne (Medicago sativa) et de IIélilot blanc (Melilotus alba). Avec l'augmentation incessante des surfaces irriguées, cette région est devenue l'une des plus importantes pour la production du miel. Cette production est caractérisée par ailleurs par sa régularité.

\section{Les montagnes Rocheuses.}

La flore mellifère de ces régions très boisées est assez pauvre: Conifères, Peupliers (Populus sp.), Saules (Salix sp.). Cependant, dans les vallées fertiles, les cultures irriguées de Luzerne et de Mélilot donnent de très fortes récoltes de miel. I a partie sud des montagnes Rocheuses est peu peuplée en abeilles. D'une façon générale, le développement printanier des colonies présente des difficultés. 


\section{Le désert épineux.}

C'est la région située à l'Ouest des Rocheuses et à 1'Eist de la Sierra Nevada. La partie nord de cette région est recouverte pour les 9/1o par des Sauges (Salvia sp.) et la partie sud par des Cactacées. L'apiculture est florissante dans les régions irriguées où se cultive la Luzerne.

\section{La côte du Pacifique}

La côte du Pacifique présente du point de vue géologique et du point de vue climatique des caractères très différents du reste des États-Unis. Sa flore est très riche et très particulière. Du nord au sud, on récolte des miels d'oranger (Citrus), de Sauge (Salvia), de Luzerne (Medicago sativa), de Sarrasin (Fagopyrum esculentum), de Trè̀le ladino (Ttrifolium repens latum), de Coton (Gossypium) et d'Eucalyptus.

\section{2) L'apiculture}

Les premiers recensements concernant la production apicole aux États-Unis datent de 1932. Depuis cette époque, des mises à jours sont périodiquement publiées par le Ministère de 1'Agriculture, Bureau of A gricultural Economics. La lecture de ces documents ne permet pas de connaitre la répartition du cheptel entre les diverses catégories d'apiculteurs, ce qui leur enlève une grande partie de leur intérêt. Il semble, compte tenu des renseignements que nous avons pu recueillir, que la proportion d'apiculteurs professionnels soit plus élevée qu'en France.

TABI,EAU I

Production canadienne du miel

\begin{tabular}{|c|c|c|c|c|}
\hline Années & Apiculteurs & Colonies & $\begin{array}{l}\text { Récolte } \\
\text { par colonie } \\
\text { (en } \mathrm{kg} \text { ) }\end{array}$ & $\begin{array}{c}\text { Récolte } \\
\text { totale } \\
\text { (en tonnes) }\end{array}$ \\
\hline 1951 a 1960 & $1 \div 760$ & $3+1=00$ & 35,25 & 13000 \\
\hline 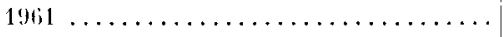 & 11660 & 336910 & 46,80 & 15759 \\
\hline 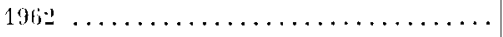 & $105 \div 0$ & $3417: 30$ & 40,05 & $1: 3: 0$ \\
\hline
\end{tabular}

Le nombre des colonies d'abeilles est d'environ 4500 ooo depuis un assez grand nombre d'années. La répartition, état par état, est connue d'une manière assez satisfaisante. Le volume de la production est d'environ roo ooo tonnes par an. La production par ruche qui était de $20, I_{4} \mathrm{~kg}$ dans la décade I9I3-I922 est passée à $20,23 \mathrm{~kg}$ pour les années $1955^{-1961}$ ( $20,36 \mathrm{~kg}$ en I960, année favorable). Ces chiffres montrent que la production du miel par colonie n'a pour ainsi dire pas changé en près de 40 ans, ce qui d'ailleurs ne signifie pas que la productivité soit restée la même puisque le nombre d'heures de travail d'apiculteur par ruche n'est pas connu. Il est hautement vraisemblable que les améliorations de la production se sont faites dans le sens d'une réduction de la main-d'œuvre nécessaire à la production du kilo de miel. 
La production canadienne se situe aux environ de I5 ooo tonnes. Les statistiques disponibles montrent une stagnation de la production par ruche et du nombre des colonies exploitées mais également une forte réduction du nombre des apiculteurs (tabl. I). Il est donc vraisemblable que, comme aux États-Unis, on a assisté à une augmentation du nombre des ruches nécessaires pour faire vivre une exploitation. C'est ainsi que le nombre moyen de ruches des adhérents de la Coopérative de 1'Ontario est de I ooo. Sur l'ensemble de l'Amérique du Nord, les méthodes d'exploitation et le matériel se sont beaucoup améliorés et modernisés. La mécanisation est intervenue comme dans les autres secteurs de l'Agriculture. I'abondance et la puissance du matériel d'exploitation permettent à l'apiculteur professionnel américain de conduire seul un millier de colonies d'abeilles, c'est-à-dire le double de son confrère français. Il n'est pas rare de trouver des apiculteurs amateurs possédant plusieurs centaines de ruches ainsi que le prouve d'ailleurs la répartition des tonnages de

TABLEAU 2

Coopérative "Sioux Bee » : valeur (en poids) des apports des adhèrents en $196 \mathrm{I}$

\begin{tabular}{|c|c|c|}
\hline \multicolumn{2}{|r|}{$\begin{array}{c}\text { Production (en tonnes) } \\
\text { de miel }\end{array}$} & \multirow{2}{*}{$\begin{array}{l}\text { Nombre d'adhérents } \\
\begin{array}{c}\text { ayant fourni } \\
\text { cette production }\end{array} \\
31\end{array}$} \\
\hline 0 & $0,5 \ldots \ldots \ldots \ldots \ldots \ldots$ & \\
\hline 0,5 & à $\quad 2,5 \ldots \ldots \ldots \ldots \ldots \ldots$ & 89 \\
\hline 2,5 & à $\quad 5 \ldots \ldots \ldots \ldots \ldots \ldots \ldots$ & 68 \\
\hline 5 & à $\quad 12,5 \ldots \ldots \ldots \ldots \ldots \ldots$ & 117 \\
\hline 12,5 & à $\quad 25 \ldots \ldots \ldots \ldots \ldots \ldots$ & 74 \\
\hline 25 & à $\quad 37,5 \ldots \ldots \ldots \ldots \ldots \ldots$ & $5 t$ \\
\hline 37,5 & $\dot{a} \quad 50 \ldots \ldots \ldots \ldots \ldots \ldots$ & 26 \\
\hline 50 & à $75 \ldots \ldots \ldots \ldots \ldots \ldots$ & 50 \\
\hline 75 & à $100 \ldots \ldots \ldots \ldots \ldots \ldots$ & 18 \\
\hline 100 & à $125 \ldots \ldots \ldots \ldots \ldots \ldots$ & 15 \\
\hline 125 & à $150 \ldots \ldots \ldots \ldots \ldots \ldots$ & 5 \\
\hline 150 & à $175 \ldots \ldots \ldots \ldots \ldots$ & 11 \\
\hline 175 & à $200 \ldots \ldots \ldots \ldots \ldots \ldots$ & 6 \\
\hline 200 & à $225 \ldots \ldots \ldots \ldots \ldots \ldots$ & 1 \\
\hline 225 & à $375 \ldots \ldots \ldots \ldots \ldots \ldots$ & 2 \\
\hline 375 & à $500 \ldots \ldots \ldots \ldots \ldots \ldots$ & 0 \\
\hline 500 & et plus $\ldots \ldots \ldots \ldots \ldots \ldots$. & 1 \\
\hline \multicolumn{2}{|c|}{ Total } & 568 \\
\hline
\end{tabular}

niel apportés par les adhérents de la Coopérative apicole "Sioux Bee " (tabl. 2.)

Les principaux miels de table produits en Amérique du Nord proviennent des différents Trèfles, de la Luzerne, du Mélilot, des Agrumes et des Sauges. D'autres miels sont produits en quantités moindres mais sont cependant d'excellente qualité bien que souvent plus colorés; ce sont les miels de Tilleul, d'Oxydendron, de Tupelo (Nyssa sp.), de Houx, de Coton, etc. Il existe enfin des miels foncés, généralement considérés comme miels d'industrie et qui entrent dans la fabrication de nombreux produits alimentaires. 


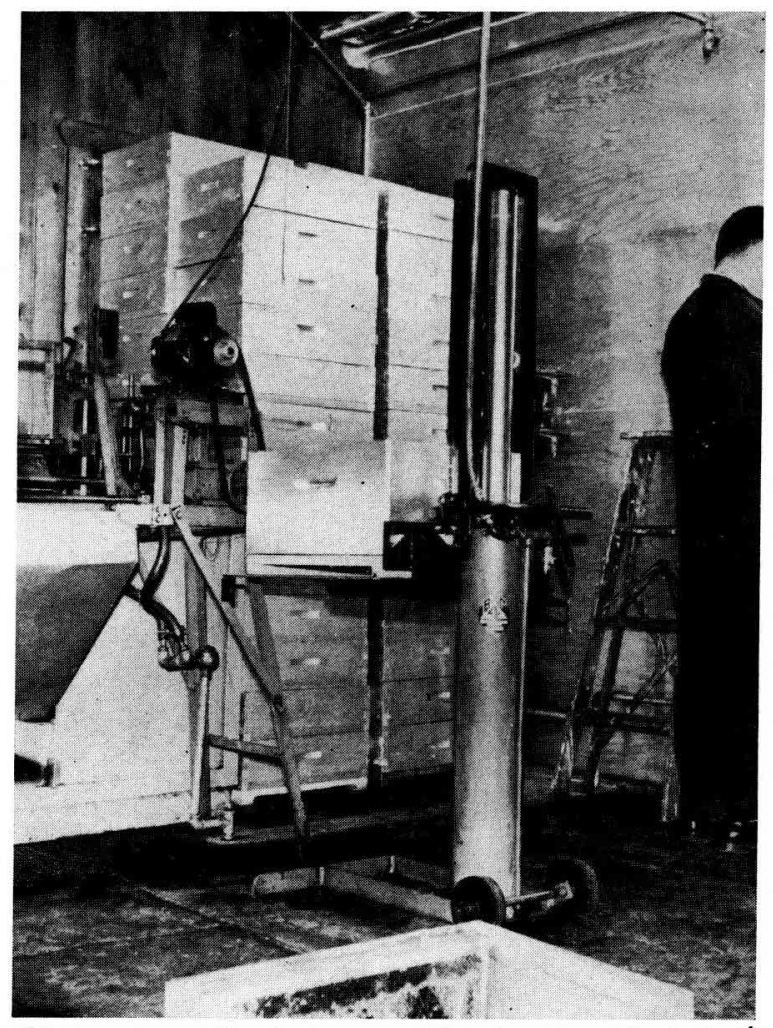

FIg. I. - Appareïl èlèvateur pour pïles de hausses utilisẻ dans la miellerie des Etablissements Dunham à London (Ohio). Cet appareil permet à l'opérateur de maintenir toujours à bonne hauteurla hausse dont on passe les cadres à la machine à désoperculer.

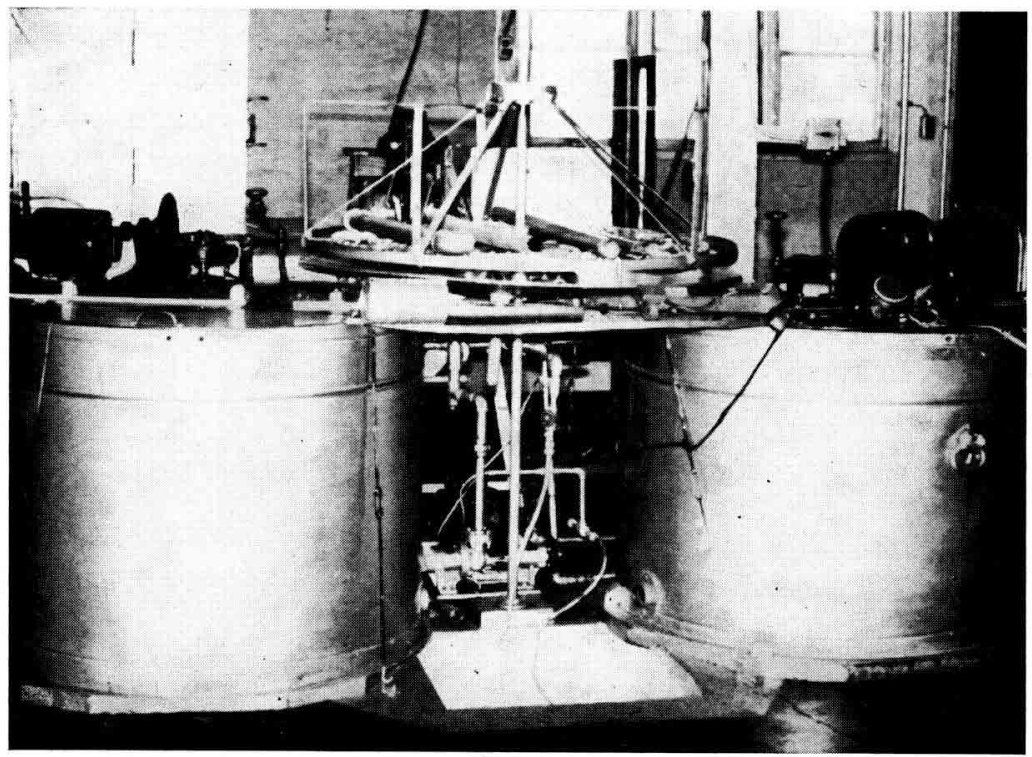

FIG. 2. - Batterie de deux extracteurs centrifuges aux Etablissements Dunham. On remarque entre les deux appareils le manège sur lequel on dépose les cadres après désoperculation. En bas, la tosse de réception du miel exirait qui est réchauffé avaut d'étre pompé. On remarquera au centre le "carrousel "ou sont déposés les cadres désoperculés en attente. 


\section{B. - IA COMMERCIALISATION}

Nous ne possédons pas de données nous permettant de déterminer de façon précise la quantité de miel vendue sur le marché américain par les circuits commerciaux normaux. Dans son ensemble, le miel produit est livré en emballages de grande capacité chez les conditionneurs, lesquels sont, soit des négociants, soit des Coopératives. Cependant le nombre des apiculteurs qui commercialisent eux-mêmes au détail leur production n'est pas négligeable.

Aux U.S. A., les Coopératives traitent à elles seules environ $\mathrm{I} / 3 \mathrm{du}$ miel commercialisé. La "Sioux Bee ", qui est la plus importante des coopératives apicoles d'Amérique, a conditionné en I $96 \mathbf{I}$ dans ses 7 usines le I/6 de la production du pays. Au Canada, 1'Union des Coopératives conditionne et vend au moins $\mathrm{I} / 3$ de la récolte canadienne.

Dans les régions où la densité du peuplement humain le permet, et notamment dans 1'Est, il existe une importante vente au détail de l'apiculteur au consommateur. Des stands et des chalets de dégustation sont établis le long des routes touristiques. Ians les secteurs ruraux les apiculteurs pratiquent beaucoup la vente directe aux détaillants en alimentation.

Négociants, coopératives et apiculteurs-conditionneurs utilisent pour la vente des systèmes commerciaux identiques à ceux des pays européens. Sauf en ce qui concerne parfois les ventes à des chaînes de distribution très importantes du type super market, on a recours à des représentants dont la rétribution est assurée par un pourcentage sur les ventes qui est soit égal soit supérieur à ceux qui sont pratiqués en France (de 5 à 7,5 p. Ioo).

Dans la commercialisation du miel, le producteur américain est soutenu par deux dispositions particulières d'ordre économique. Le Service des marchés du Ministère de l'Agriculture publie deux fois par mois un bulletin intitulé Honey market new's qui fournit des renseignements détaillés sur les cours du miel et sur 1a production. D'autre part, 1'Agricultural Act de I949 (section 20I, titre II) a institué pour le miel un système de soutien des prix fonctionnant sous l'autorité de 1'A. S. C.C.O (Agricultural Stabilization and Conservation Committee Office). Cet organisme consent des prêts ou bien il fournit des agréments d'achat (voir à ce sujet l'American Bee Journal, oct. I960, p. 404).

\section{II. - LES TECHNIQUES DE CONDITIONNEMENT DU MIEL}

\section{A. - LES BASES LÉGAIES DU CONDITIONNEMENT}

Que ce soit au Canada ou aux U. S. A., la législation concernant la vente du miel ne présente guère de points communs avec la législation similaire des pays européens, tout au moins dans son esprit. La loi américaine a surtout pour objet de préserver le consommateur contre certains défauts que peut présenter le miel : teneur en eau excessive, malpropreté, fermentation, gontts parasites, addition de corps étrangers. Il en résulte que la loi est muette sur le chapitre des appellations 
d'origine. Le miel américain est classé d'après ses caractères physico-chiniques dans l'une des trois catégories prévues et qui correspondent à trois qualités commerciales ; par contre, son origine géographique et son origine florale sont considérées comme accessoires. Tous les traitements ayant pour but de clarifier, d'épurer, de débarrasser le miel des microorganismes qu'il peut contenir, sont considérés comme bénéfiques. Aucune attention n'est accordée par la loi à la présence ou à l'absence des diastases ni à la teneur en HMF (1). Un miel ayant subi une ultra-filtration et un chauffage prolongé à $80^{\circ}$, n'aurait plus aux yeux de la loi européenne le droit de porter le nom de miel. En Amérique, le résultat de l'opération est le classement du produit dans la catégorie $n^{0}$ I. Parfaitement épuré, limpide comme de l'eau, pratiquement stérile, c'est devenu un produit de luxe.

Cette différence fondamentale entre l'esprit des lois américaines et celui des lois européennes a une origine profonde. Pour l'Américain, le miel est un produit sucrant, au même titre que le sucre de canne ou le corn syrup. Il ne lui demande donc que de sucrer les aliments alors que le consommateur européen aurait volontiers la tendance de demander au miel de le préserver de toutes les maladies. Savoir lequel des deux a raison dans cette querelle est, dans le fond, d'importance assez secondaire. L'essentiel est d'avoir conscience d'une différence de mentalité qui explique pourquoi l'Européen attache tant d'importance à tous les particularismes et pourquoi l'Américain recherche par goût le produit standardisé et de qualité rigoureusement constante.

\section{B. - Principes gúnéraux du Conditionnement de Miel}

L'étude de l'ensemble des installations de conditionnement que nous avons pu visiter tant au Canada qu'aux U. S. A., nous permet de dégager un certain nombre de règles générales. Si nous avons observé des variantes dans les opérations de conditionnement, il n'en reste pas moins vrai qu'elles ne portent que très rarement sur les principes mais presque toujours sur des détails que l'on peut négliger dans un exposé qui s'efforce d'être synthétique. Nous partirons du miel récolté par l'apiculteur pour aboutir au magasin d'alimentation de détail.

\section{Préparation du miel en vue de la livraison.}

Les miels étant payés en fonction de leur qualité, l'intérêt du producteur est de fournir à la Coopérative ou au négoce un produit de valeur aussi élevée que possible. La qualité étant le plus souvent, en Amérique, fonction de la coloration, le producteur procède au moment de l'extraction à un triage des cadres de façon à éviter de déprécier un lot de miel clair par un mélange maladroit avec quelques kilogrammes de miel foncé. De même, il évite de passer à l'extracteur une proportion trop élevée de cadres non operculés, ceux-ci étant susceptibles de relever dangereusement la teneur en eau du lot de miel à livrer, donc de lui faire perdre de sa valeur. La plupart des coopératives tiennent compte de la propreté du miel qui leur est fourni pour en fixer le prix. Le producteur a donc intérêt à procéder au moins à une filtration sommaire sur une toile de nylon qui arrête les particules de cire jusqu'à $20 \mathrm{ou}$ 3/ro de min.

(1) IIMF = hydroxyméthylfurfurol.

Annules de libeille. - 1964 . 


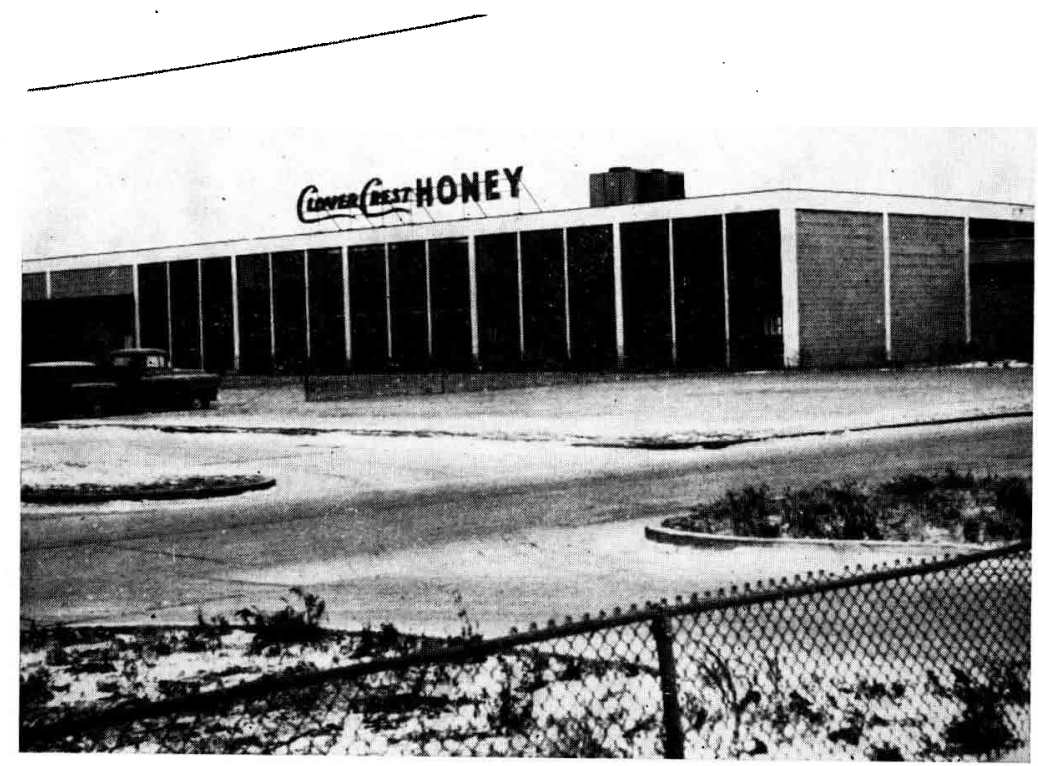

FIG. 3. - La facade principale da batiment de la "Clouer-Crest "i Winnipeg

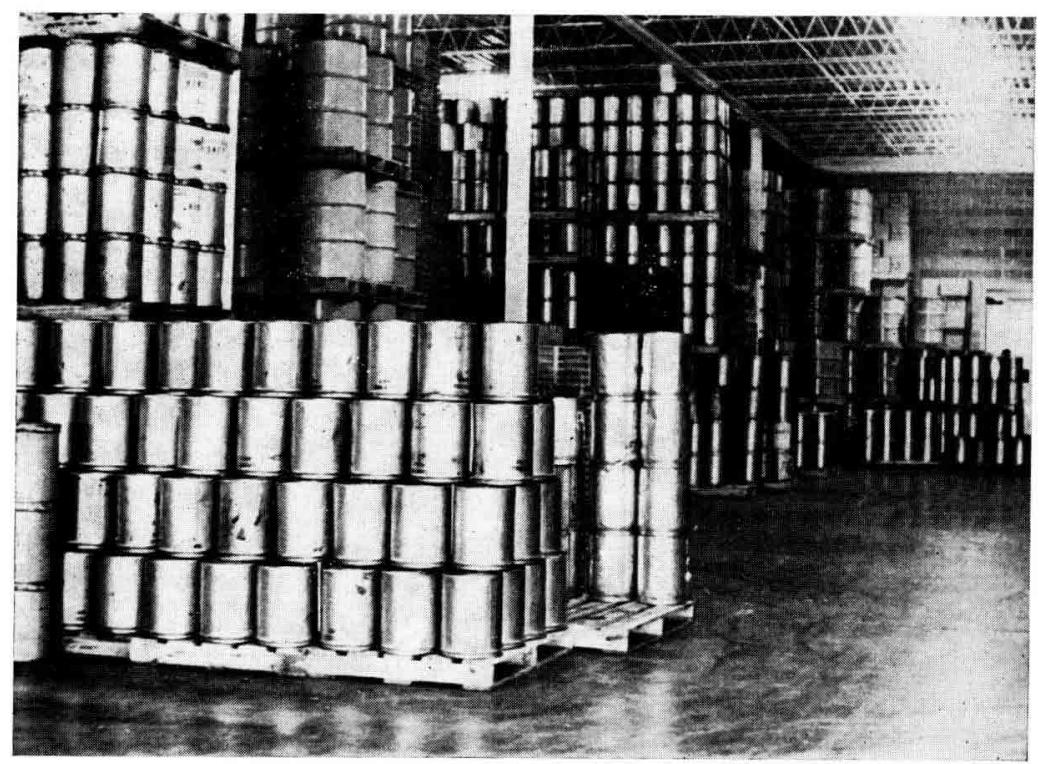

Fig. 4. - Mall de stockage les miels ì l'arrité à la "Clover-Crest" à Winnipeg 


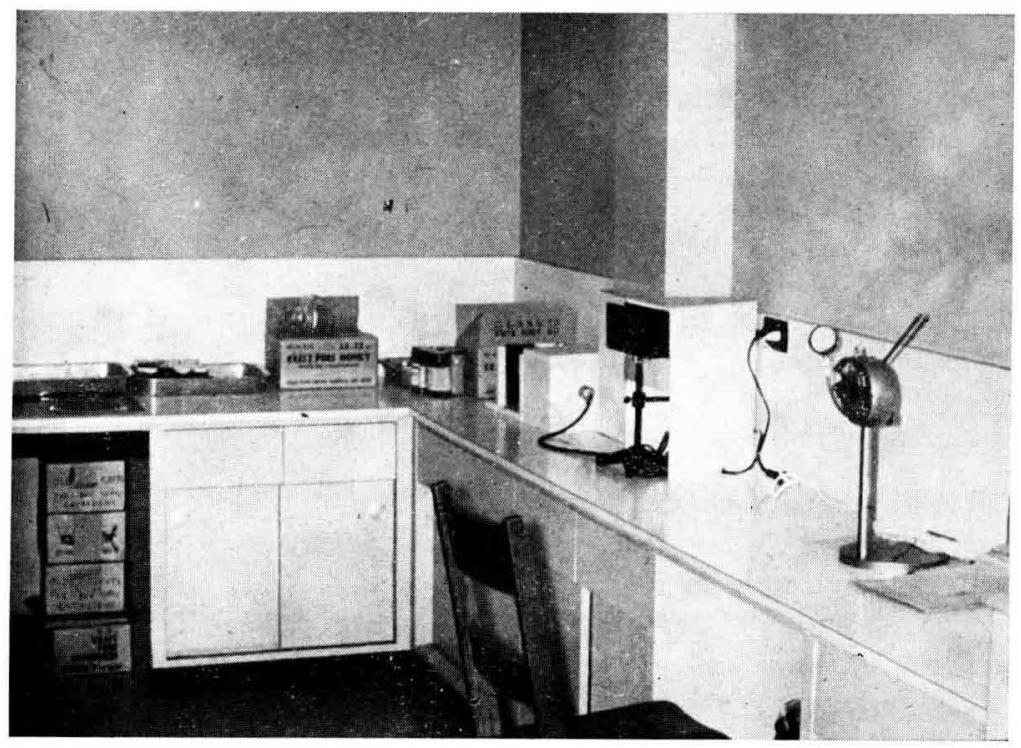

TIC. 5. - Le laboratoire de controle de la "Clover-Crest "à Winnipeg. On remarque sur la paillasse un réfractomètre et un Pfund Grader.

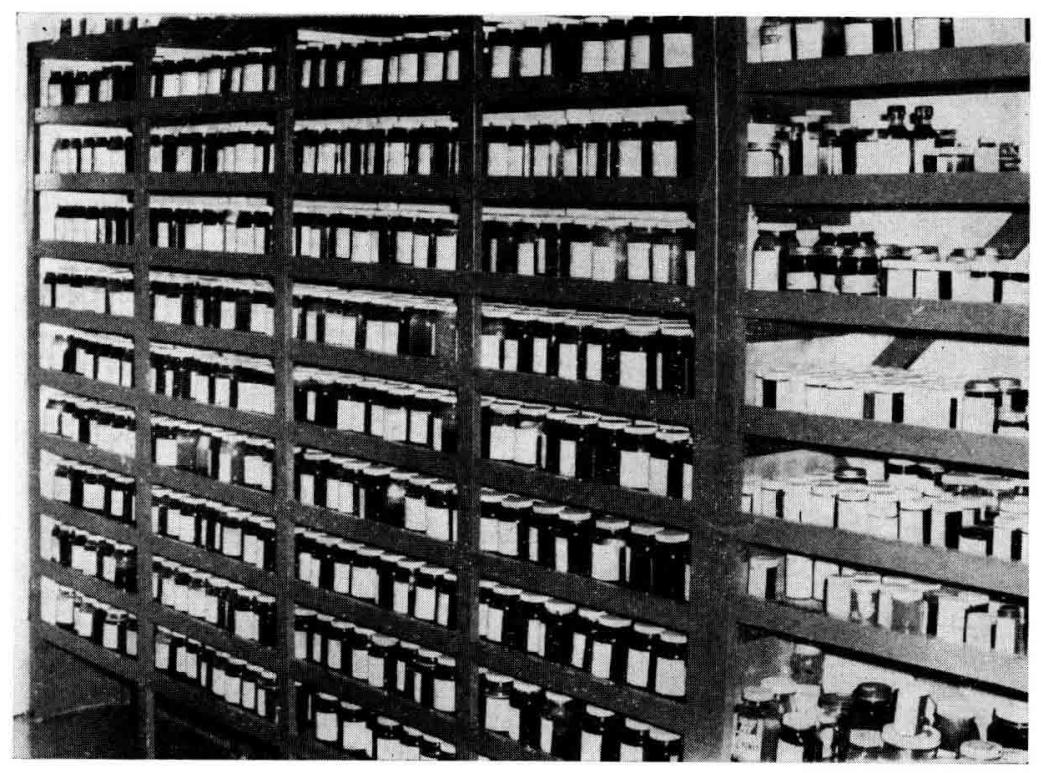

FIa. 6. - Une partie de la collection d'échantillons de miel de la Coopérative "Sioux Bee " a Sioux-City 
C'est donc un miel trié et sommairement filtré qui est livré aux Coopératives ou au négoce. Cette livraison se fait de plus en plus dans des fûts de $300 \mathrm{~kg}$. L'estagnon de fer blanc d'une vingtaine de kilos, les fûts de 50 , 60 et $70 \mathrm{~kg}$ et tous les différents modèles de contenants qui ont pu être utilisés jusqu'ici sont en voie de remplacement par le fût de $300 \mathrm{~kg}$ à revêtement interne en peinture alimentaire.

\section{Réception des miels.}

Chaque fût de miel livré à la Coopérative est tout d'abord pesé. Il est ouvert et, au moyen d'une sonde, un échantillon de quelques dizaines de grammes est prélevé en vue des opérations de classement.

\section{Examens de laboratoire.}

L'objectif principal de la Coopérative étant de "fabriquer " un miel standardisé, semblable à lui-même d'un bout à l'autre de l'année et conforme à la loi, il importe que le contenu de chaque fût de miel soit examiné au laboratoire. Cette opération est également rendue indispensable par le principe du paienent du miel au producteur en fonction de sa qualité, laquelle fait intervenir essentiellement la coloration, la teneur en eau et la propreté.

Les échantillons prélevés dans les fûts au moment de la réception sont passés à l'étuve pendant quelques heures pour permettre leur retour à l'état liquide. La teneur en eau est ensuite mesurée et la coloration est appréciée. La propreté ne fait pas l'objet d'un test précis mais elle est notée d'une façon sommaire. Enfin, le miel est gôtité pour s'assurer qu'il n'a aucun gồt parasite et qu'il peut être mélangé sans inconvénient à la cuvée.

\section{Manutention et stockage des miels.}

Toutes les manutentions de fûts de miel se font par des moyens mécaniques. Jamais un fût de $300 \mathrm{~kg}$ n'est transporté autrement qu'au moyen de l'un quelconque de ces chariots qui peuvent saisir soit un fût isolé (et souvent le basculer) soit un chargement posé sur une palette. Chaque organisme de conditionnement dispose toujours d'un vaste local couvert, généralement de grande hauteur sous plafond, et où il est possible de stocker des fûts représentant souvent plusieurs centaines de tonnes de miel.

\section{Classement des lots.}

Au cours du stockage, les fûts sont groupés selon la catégorie du contenu. Le classement est fonction du résultat des examens de laboratoire. Les miels appartenant à une même catégorie par leur coloration et leur teneur en eau sont groupés ensemble, ce qui facilite leur emploi ultérieur en vue de la fabrication d'une cuvée.

\section{Refonte de miel cristallisé.}

Les miels étant susceptibles de rester en stock pendant des périodes assez longues, il est rare qu'au moment du conditionnement ils ne soient pas cristallisés dans les fûts. Le problème de la refonte se pose donc toujours et il nécessite des installations appropriées. 


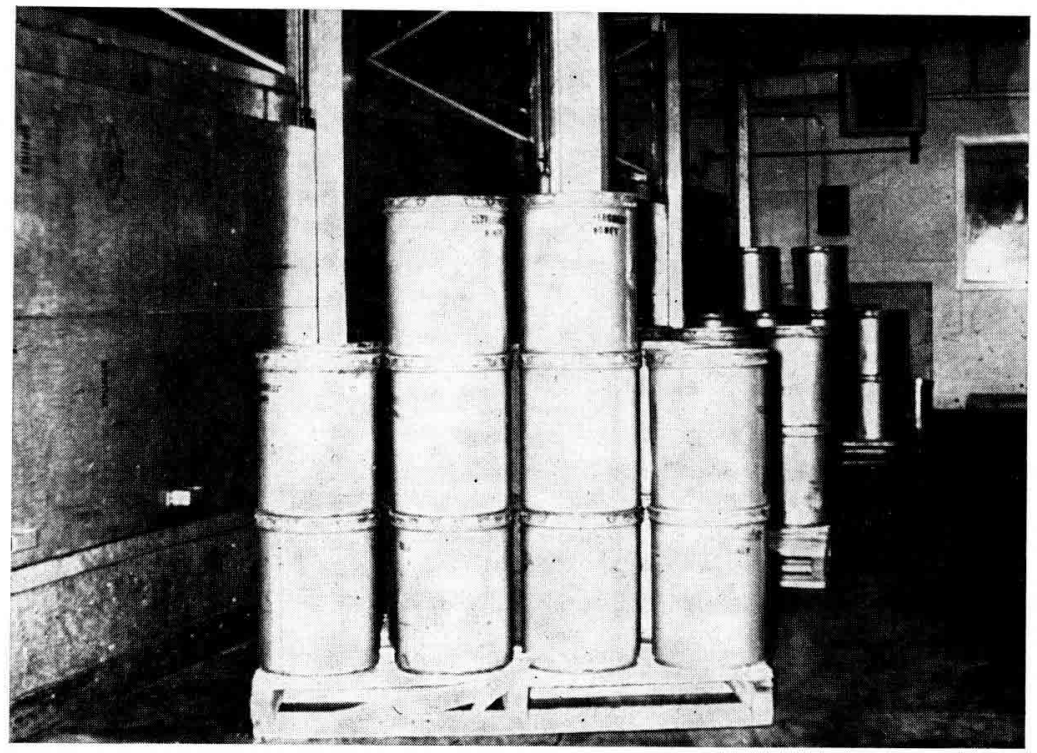

FIG. 7.--- La salle de velonte du miel a la "Clover-Cresl" (Winnipeg). On distingue sur la gauche la partie centrale de la chambre qui est maintenue a haute température et qui contient le système d'égoutlage du miel par renversement des bidons. Au premier plan des lots de miel sur palette sont en préchauff age d $40^{\circ}$. Ils entreront ensuite dans le tunnel de fonte ceniral. On apercoit au jond l'un des aérothermes servanl au chauffage de la chambre

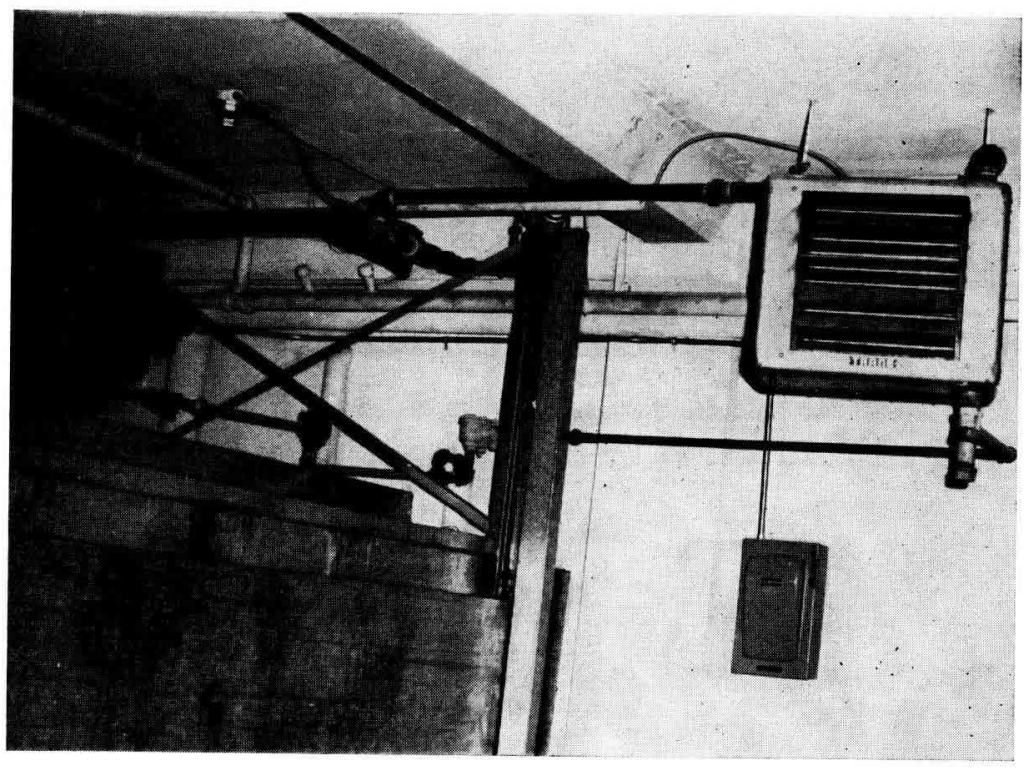

FIa. 8. - Détail de l'installation des aérothernes visibles sur la figure 9. On notera également la présence du système de conlrepsills qui commande l'ouzerhure des portes du tunnel de fonte central 
Pour refondre un lot de miel, on commence par le préparer avec soin. Le but étant par exemple de préparer 5 tonnes d'un miel à $I 7$ p. Ioo d'eau et de coloration comprise entre Io et I 2 au colorimètre de Pfund, on apportera dans la chambre de refonte une combinaison de miels dont le mélange soit susceptible de répondre à l'objectif fixé. Les miels trop riches en eau seront corrigés par mélange avec des miels secs. On opèrera de la même façon en ce qui concerne la coloration et, dans une certaine mesure, le goût final recherché.

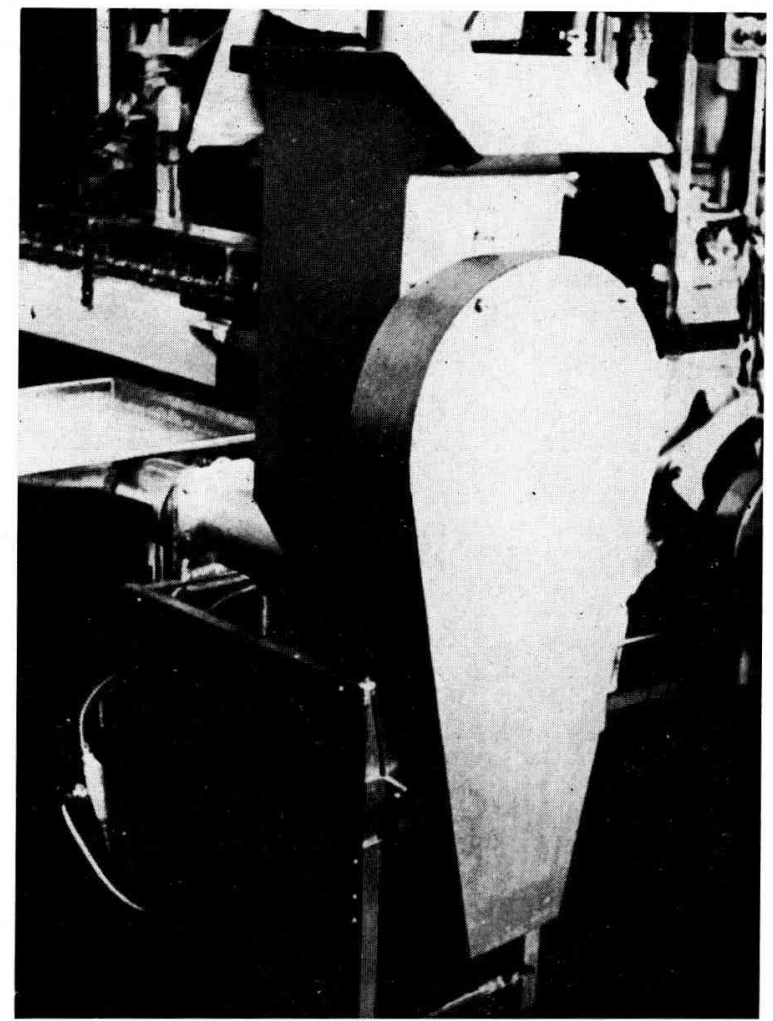

Fic. o. - "Clover Crest" (Winnipeg). Le broveur à semence destiné à fluidifier le miel à cristallisation fune avant son injection dans le circuit de préparalion du miel crème

Les chambres de refonte les mieux conçues comprennent généralement deux sections différentes. Ia première constitue un bloc de préchauffage oì le miel est porté progressivement à $40^{\circ} \mathrm{C}$ environ, les fûts restent en position verticale et non ouverts. Il s'agit en somme de l'antichambre du local de refonte proprement dite qui repose, par contre, sur le principe d'un chauffage intense mais avec écoulement continu du miel fondu et évacuation rapide par gravité ou par pompage vers un autre local. Dans la chambre de refonte proprement dite, les fûts de miel préchauffé sont mis en position couchée ou en position franchement renversée, ce qui permet à leur contenu de s'écouler librement au fur et à mesure de la refonte, dans des récipients appropriés disposés en dessous. La chute de blocs de miel encore solides 
est évitée par la présence de grilles métalliques contre lesquelles s'appuie 1'ouverture des fûts. Dans la chambre de refonte proprement dite, la température est généralement de 60 à $70^{\circ} \mathrm{C}$ et il existe une circulation forcée de l'air chaud entre les fûts.

La capacité des chambres de refonte courante est au moins de 5 tonnes par 24 heures.

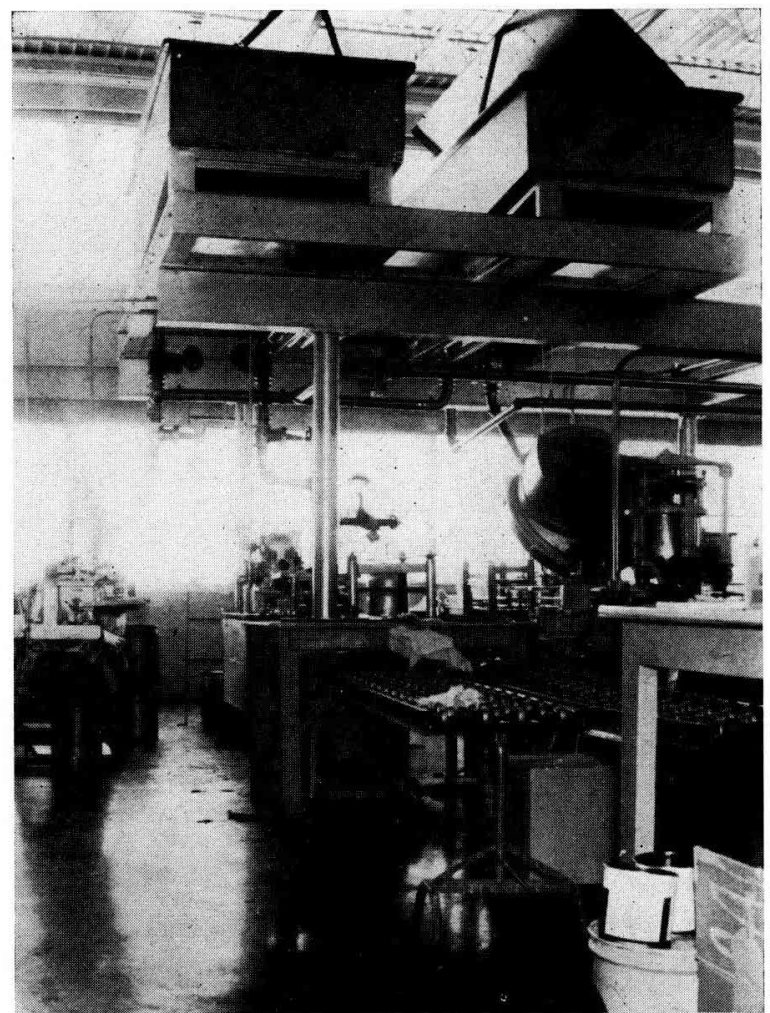

FIG. 10. - "Clover Crest" (Winnipeg). Vue d'ensemble de la chaine de mise en pot surmontée des deux cuves tampon qui permettent d'équilibrer le débil de la chaine de conditionnement el celui de la chaine d'emborteillage

Mélange.

Lres miels refondus qui sortent de la chambre chaude sont forcément assez hétérogènes. Recueillis dans des cuves de grande capacité, ils y sont maintenus à $40^{\circ}$ environ et brassés pendant quelques heures par un mélangeur à hélice ou à palettes. Les cuves de mélange sont très souvent en acier inoxydable avec chemisage d'eau chaude. Les mélangeurs sont soit verticaux et fixés à la partie supérieure de la cuve sur une traverse d'acier, soit fixés directement au bord de la cuve, ce qui constitue la solution la plus moderne. L'industrie du matériel pour laiteries fournit des cuves convenant assez bien pour le miel, mais il faut cependant noter qu'elles ne présentent qu'une ouverture supérieure de taille insuffisante. 


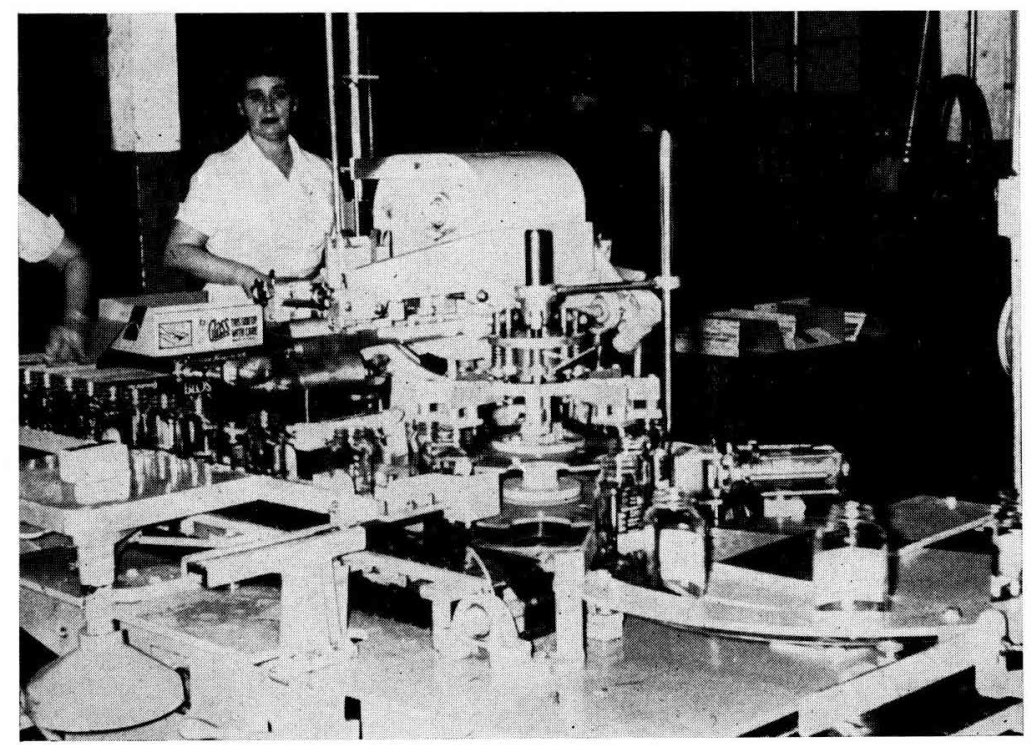

FIG. II. - Chaine d'embouteillage pour le miel liquide à la Coopérative "Sioux Bee "à Sioux-City

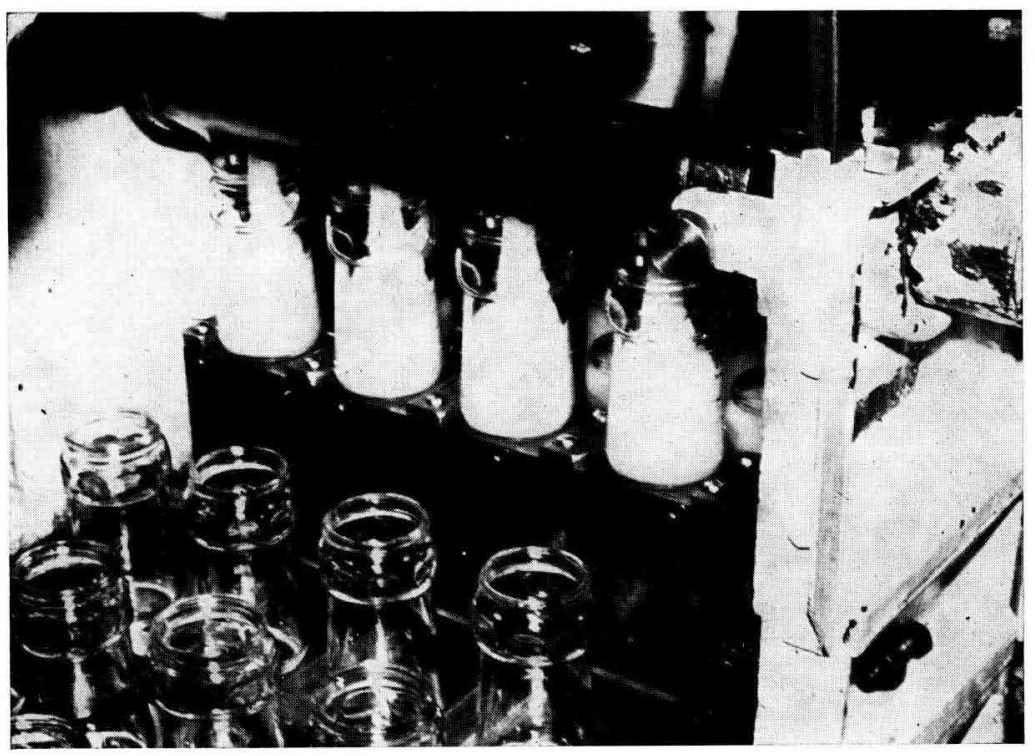

FIG. I2. - Chaîne d'embouteillage à grande capacité pour le miel crème à la Coopérative "Clover Crest "a Winnipeg 


\section{Préfiltration.}

Au sortir de la cuve à mélange, le miel est repris par une pompe et envoyé dans un circuit sous pression, presque continu jusqu'à la mise en pots. Ce circuit constitue la chaîne de conditionnement proprement dite. La première étape du circuit est la préfiltration. Son but est d'éliminer toutes les particules de cire et les débris divers d'une taille supérieure, à o, I $\mathrm{mm}$ environ. L,es filtres utilisés fonctionnent sous pression et à une température de l'ordre de 40 à $45^{\circ}$. Ils sont cons.. titués par des manchons de toile métallique ou des piles de plateaux filtrants. Dans les installations les olus perfectionnées, il existe deux filtres installés en parallèle et qui sont mis alternativement en service pour permettre le nettoyage. Il existe également des dispositifs de nettoyage automatique.

\section{Pasteurisation.}

Au sortir du circuit de préfiltration, le miel passe dans un pasteurisateur qui est presque toujours un appareil à plaques du modèle le plus classique utilisé en laiterie. La température de pasteurisation est le plus souvent de $78^{\circ}$. Quant au temps de pasteurisation, il est variable et, chose assez curieuse, il n'est généralement pas connu avec précision. Il doit être en moyenne de 5 à Io minutes. Le circuit de chauffage et le circuit de refroidissement sont alimentés respectivement en eau chaude et en eautiède par des dispositifs complets de conditionnement comportant une régulation indépendante. Cette solution permet de sortir le miel à $40^{\circ}$ environ sans aucune difficulté technique.

\section{Filtration.}

Un filtre à terre de diatomées est régulièrement intercalé entre le circuit de chauffage et le circuit de refroidissement du pasteurisateur. C'est donc à $78^{\circ}$ environ et sous pression que le miel passe sur les plateaux du filtre où il se débarrasse, non seulement de ses impuretés mais aussi de tous ses constituants solides ou colloïdaux. Les filtres utilisés sont, soit des filtres-presses horizontaux, soit des filtres verticaux à plateaux. Pour mettre en fonctionnement le filtre, on commence par faire circuler en circuit fermé une petite quantité de miel mélangé de terre de diatomées (Célite). Peu à peu, cette terre se dépose sur les feuilles de papier-filtre qui recouvrent les plateaux et constitue une couche filtrante homogène qui est utilisable pendant un temps assez long. Une batterie de deux filtres en parallèle est souvent utilisée pour permettre le nettoyage sans interruption du travail.

Nous reviendrons ultérieurement sur ce procédé de filtration qui a pour conséquence, associé au chauffage, de modifier profondément la nature du miel. Le produit finalement obtenu est d'une limpidité totale mais on peut s'interroger sur l'intérêt de cette qualité physique étant donné les conséquences biologiques de l'opération.

Pasteurisation et filtration ont pour but principal d'éliminer du miel tous les microorganismes qu'il contient normalement et de garantir sa conservation indéfinie à l'état liquide. Il semble que ce but soit parfaitement atteint. Nous reviendrons plus loin sur cette question.

\section{Préparation du miel-crème.}

Le miel américain est conditionné sous deux formes principales : miel pasteurisé liquide et miel-crème (cream-honey). Le circuit de conditionnement du miel liquide s'achève après la pasteurisation et la filtration dans la machine à mettre en pots. 
Celui du miel-crême est quelque peu plus compliqué. Au sortir du circuit de refroidissement du pasteurisateur, le miel est tout d'abord ramené à $25^{\circ}$ environ et malaxé avec un miel à cristallisation très fine qui sert de semence. Ce n'est qu'après ce malaxage qu'il est mis en pots et porté à $14^{\circ}$, température idéale pour la prise en masse par croissance rapide des cristaux de glucose. La fabrication du miel-crême présente assez de difficultés pour qu'on ne trouve pas encore, à l'heure actuelle, un processus de préparation bien uniformisé. Chaque entreprise utilise un appareillage qui lui est propre et qui est plus ou moins perfectionné.

La proportion de semence injectée est de Io p. Ioo en moyenne. Avant son injection, la semence passe dans un broyeur qui la rend assez fluide pour passer dans le mécanisme d'injection sans la réchauffer.

Le miel-crème a pour avantage commercial essentiel de représenter un produit facilement utilisable pour étaler sur les toasts et d'un grain très agréable au palais.

\section{Embouteillage et empaquetage.}

Qu'il s'agisse de miel-crème ou de miel liquide, l'embouteillage se fait au moyen de doseuses à grand débit n'utilisant qu'une main-d'œuvre réduite. Signalons que dans toutes les chaînes de conditionnement, nous avons noté la présence de récipients tampons entre la préparation du miel et la mise en pots. Ces récipients de quelques centaines de kilogrammes de capacité amortissent les variations de débit et régularisent le travail. Ils sont généralement placés juste au-dessus de la machine à mettre en pots. Les verres ne sont pas lavés mais très souvent dépoussiérés à l'air comprimé, ce qui semble suffisant pour éliminer les germes parasites de recristallisation.

\section{Conservation.}

La température idéale de conservation du miel est de $\mathrm{I} 4^{\circ}$. C'est à cette température que la croissance des cristaux de glucose est la plus rapide. Le miel ensemencé s'y transforme en quelques jours en une masse homogène du plus bel aspect. Par ailleurs, le miel liquide, tel qu'il est conditionné ne risque guère de reprendre en masse; par contre, il est protégé contre les altérations de coloration qui résultent d'un stockage à la température ordinaire.

Les Coopératives disposent presque toutes de vastes chambres froides $\left(+4^{\circ}\right.$ à $+\mathrm{I} 4^{\circ}$ ) oì le miel est conservé avant son expédition.

\section{Expédition.}

Comme à l'arrivée, toute la manutention des cartons renfermant le miel en pots se fait mécaniquement, y compris le chargement des camions. Lorsque la disposition des lieux le permet, le chariot va déposer les cartons à l'intérieur même du camion de livraison.

Des échantillons sont conservés par la Coopérative qui peut ainsi suivre l'évolution du produit dans le temps, après en avoir contrôlé les qualités essentielles.

\section{L'OUTILLAGE UTILISÉ}

\section{Appareils de laboratoire.}

L'équipement en matériel de laboratoire est fonction du format des installations. L,es coopératives d'importance moyenne (2 à $3000 \mathrm{t}$ ) possèdent les appareils 


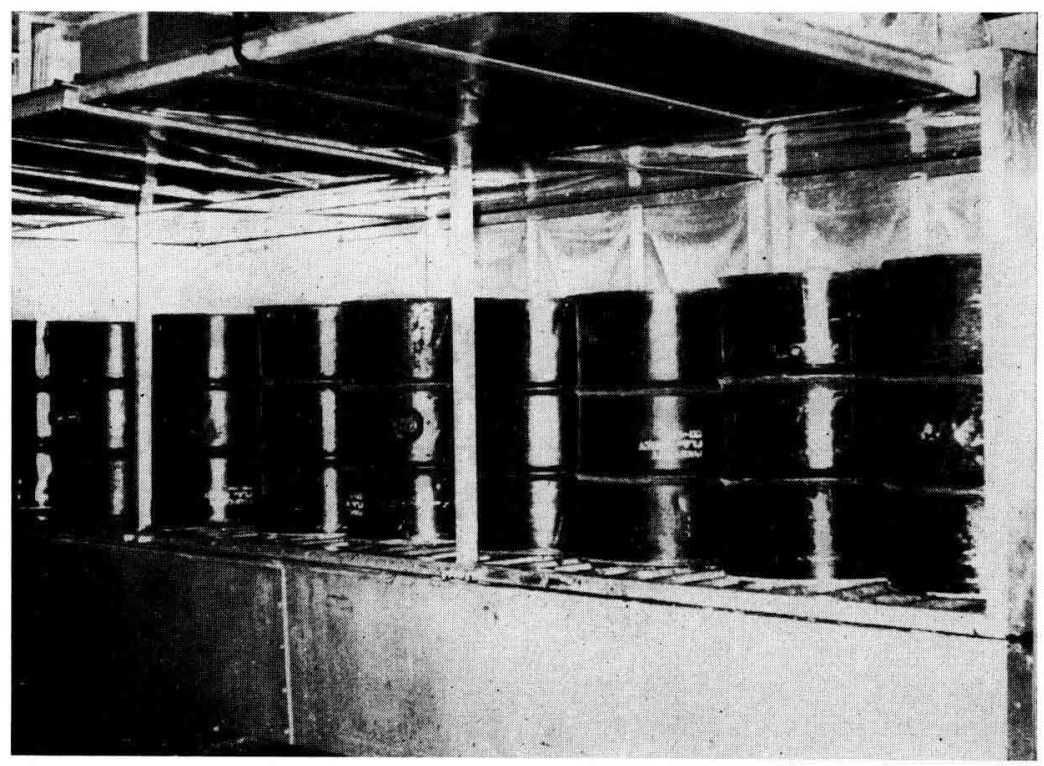

FIG. I3. - Refonte du miel en bidons de $300 \mathrm{~kg}$ dans une étuve de grande capacité à la coopérative "Sioux Bee". Les bidons sont en position renversée et le miel refondu s'écoule directement dans le bac situé d la partie in férieure ou il est repris par pompage

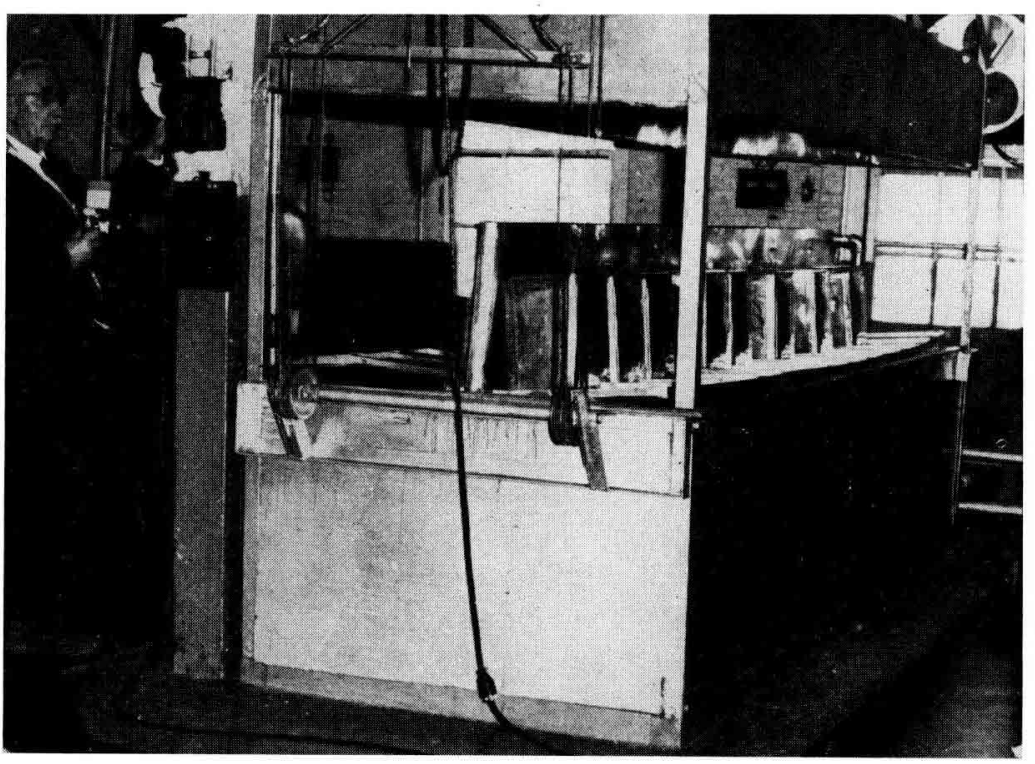

FIG. I4. - Rejonte du miel en bidons de $27 \mathrm{~kg}$ dans une étuve-cloche de petite capacilé à la Coopérative "Sionx Bee ". Le couvercle de l'étuve est équilibré par des contrepoids, ce qui permet de le relever sans effort. Le principe d'évacuation du miel fondu est le même que figure 7 
nécessaires à la détermination des paramètres (hygrométrie, couleur) qui permettront 1e classement des miels et la constitution des prix à la production : détermination de la teneur en eau par le réfractomètre $\left({ }^{1}\right)$, de la colcration par le Pfund grader $\left({ }^{2}\right)$. La plupart des Coopératives ont établi des barèmes, en fonction de ces paramètres. Une coopérative de format exceptionnel ("Sioux Bee ", U. S. A., I5 000 t) a la possibilité d'amortir un laboratoire orienté, en partie, vers la recherche et doté en conséquence (microscope, appareils de précision, etc.).

\section{Matériels de manutention.}

Ils assurent la réception des produits bruts, les transports à l'intérieur des usines, l'entreposage, le chargement pour l'expédition des produits finis. Les appareils les plus courants sont les élévateurs à fourche $\left({ }^{3}\right)$ dont la puissance varie de $500 \mathrm{~kg}$ à 2 tonnes, dotés de batteries et actionnés par des moteurs électriques. Le chargement est posé sur palette en bois :

$$
\begin{aligned}
& 0,60 \times \mathrm{I}, 20=2 \text { fûts de } 300 \mathrm{~kg} \\
& 0,90 \times \mathrm{I}, 20=24 \text { fûts de } 27 \mathrm{~kg} .
\end{aligned}
$$

Les appareils de $I, 5$ t. à 2 t. permettent de gerber les fûts de $300 \mathrm{~kg}$ sur 5 niveaux dans des bâtiments de $6 \mathrm{~m}$ de hauteur sous plafond. De même, les miels empaquetés peuvent être palétisés pour l'entreposage en chambre froide, ou le chargement en camion. Le transport des produits sur palette est confié au matériel d'une puissance supérieure à $\mathrm{x}$ tonne; les élévateurs de $500 \mathrm{~kg}$ assurent la manipulation des fûts isolés, notamment lors du chargement des chambres de chauffe. A noter, un dispositif qui permet de basculer les fûts : les fourches de l'appareil sont dotées de deux mâchoires semi-circulaires, mobiles autour d'un axe horizontal, permettant tous les mouvements verticaux, horizontaux, et de rotation par commande hydropneumatique.

\section{Chambres de refonte du miel.}

On peut les classer en trois types :

$$
\begin{aligned}
& \text { le type " armoire ", } \\
& \text { le type " tunnel ", } \\
& \text { le type " chambre ". }
\end{aligned}
$$

Le premier type correspond à une capacité de 2 à 5 t. Le chargement s'opère, soit par un élévateur à fourche, soit par un palan électrique, en se plaçant frontalement à la chambre. Les fûts reposent sur un bâti en profilé à $0,80 \mathrm{~m} \mathrm{du}$ sol sur un ou deux niveaux. A la partie inférieure, un bac dont le volume correspond au chargement journalier recueille le miel qui est évacué par pompage. Les parois de 1'armoire, construites en contreplaqué, sont calorifugées en laine de verre (épaisseur $4 \mathrm{~cm}$ ). Le chauffage est assuré par aérotherme ou serpentin, dans lequel circule de la vapeur basse-pression.

Ce type de chambre de chauffe existe dans les installations qui traitent 200 à 500 tonnes par an.

(1) Généralement le réfractomètre Zeiss.

(2) Constructeur : Koeler instrument Co. 168, Douglas Avenue, Jamaïca (N. Y.).

$\left({ }^{3}\right)$ Élévateurs Clark. 
Le type "tunnel "permet de traiter des tonnages plus importants, de l'ordre de Io à $I 5 \mathrm{t}$. par jour. On distingue les tunnels avec ou sans préchauffage. Le tunnel avec préchauffage comprend une partie centrale destinée à la chauffe elle-même et, parallèlement de part et d'autre, deux aires de stockage des fûts en préchauffage. Le tunnel est chargé latéralement; les fûts, en position inclinée, s'appuient sur un grillage à maille de I" renforcé par des profilés. Le miel s'écoule dans une gouttière vers l'étage inférieur ou dans un bac en tôle galvanisée à niveau. L'ouverture des portes se fait verticalement quand elles sont rigides. Elles s'appliquent au plafond quand elles sont constituées de lattes articulées. I'ensemble est isolé en polystyrène (épaisseur $4 \mathrm{~cm}$ ). Le chauffage est du type à convection forcée par batterie chauffante à la vapeur, ventilateur, chambres de mise en pression et de retour, gaîne de reprise de l'air chaud. Ce type d'installation de refonte semble valable pour les projets de Coopératives de I ooo à 3 ooo t. par an.

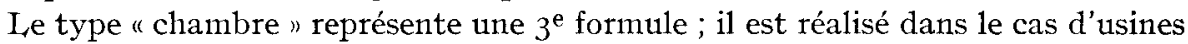
à deux niveaux; les fûts sont disposés horizontalement, le miel s'écoulant dans des caniveaux en tôle et, par gravité, vers des cuves tampons. Le chauffage est du type sans convection par aérothermes. Les détails technologiques sont analogues à ceux vus précédemment. Dans tous les cas, les températures sont asservies par thermostat, avec différentiel de $1^{\prime}$ ordre de $3^{\circ} \mathrm{C}$, agissant sur des vannes solénoïdes du circuit vapeur.

\section{Les pompes.}

Elles interviennent pour l'alimentation des appareils en eau de refroidissement, eau glacée, et pour le transport du miel en canalisations sous pression.

Les premières sont du type centrifuge et n'appellent pas de commentaires particuliers. Le pompage du miel nécessite des pompes adaptées aux liquides visqueux : pompes P.C.M., pompes à vis, pompes à palette.

- Les pompes françaises Moineau ou P.C.M. (1) sont construites sous licence aux U. S. A. ; le liquide est aspiré à une extrémité de l'arbre et refoulé à l'autre ; si on augmente la longueur du rotor et du stator, on réalise plusieurs étages de refoulement, ce qui permet d'augmenter la pression. Le pompage est engendré par le mouvement relatif des deux surfaces hélicoïdales du rotor et du stator. Le débit de ces pompes varie de 200 à $20001 /$ heure.

- Les pompes à vis sont essentiellement constituées par deux vis de pas égaux et opposés, dont les filets hélicoïdaux sont en prise et dont les axes sont entrainés en sens inverse par l'intermédiaire d'engrenages placés en bout d'arbre, à l'extérieur du corps de pompe. Ces pompes sont utilisées en amont des circuits de pasteurisation ou des échangeurs Votator et travaillent sous $6 \mathrm{~kg} / \mathrm{cm}^{2}$ de pression — débit I ooo à $20001 /$ heure $\left({ }^{2}\right)$.

- Les pompes à palette sont utilisées dans quelques cas où la pression d'utilisation est faible (extraction de la semence du broyeur à semence).

Il convient de noter que, dans tous les cas, les pompes pour le transport du miel tournent à quelques dizaines de tours/minute et qu'un réducteur à engrenage s'intercale entre la pompe et le moteur. Les ponpes sont protégées dans les circuits par

(1) Société Générale de Mécanique et de Métallurgie, 7 , rue E. Laval-Vanses (Seine).

(2) Constructeur : Waukesku Fonndry (ompany, Sanilary Pomp, a Yaukeska (1:. A. A.). 


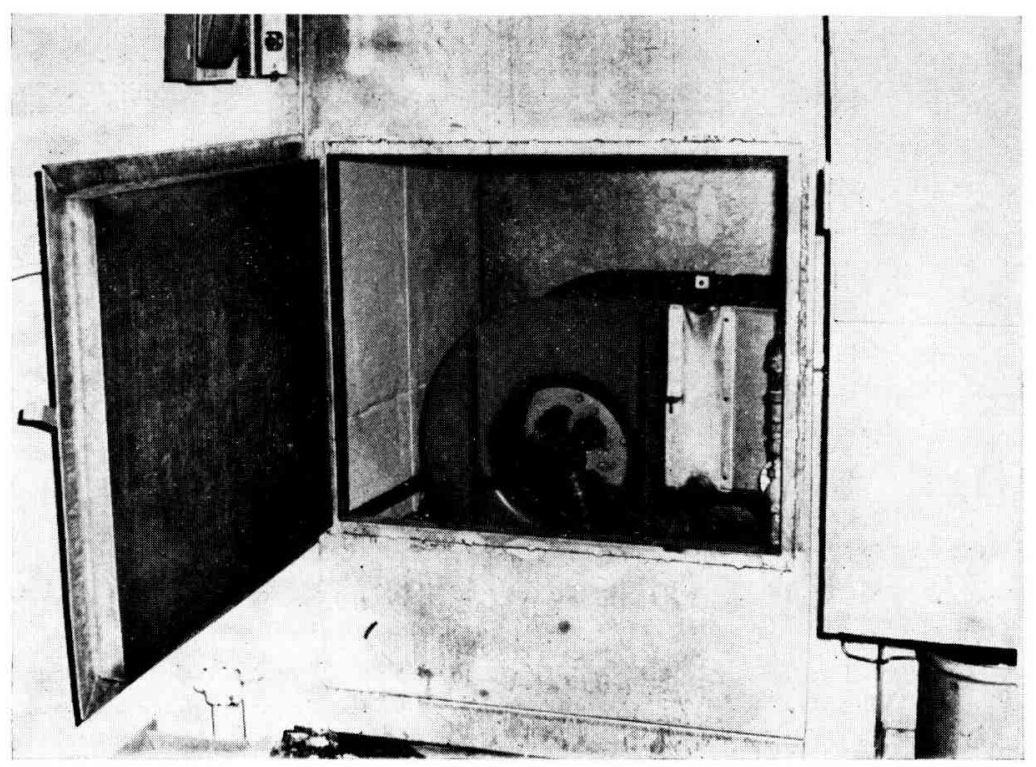

FIG. 15. -- Ventilateur brassunt lair chaud dans le tunnel de fonte central (roir figures 9 et 10)

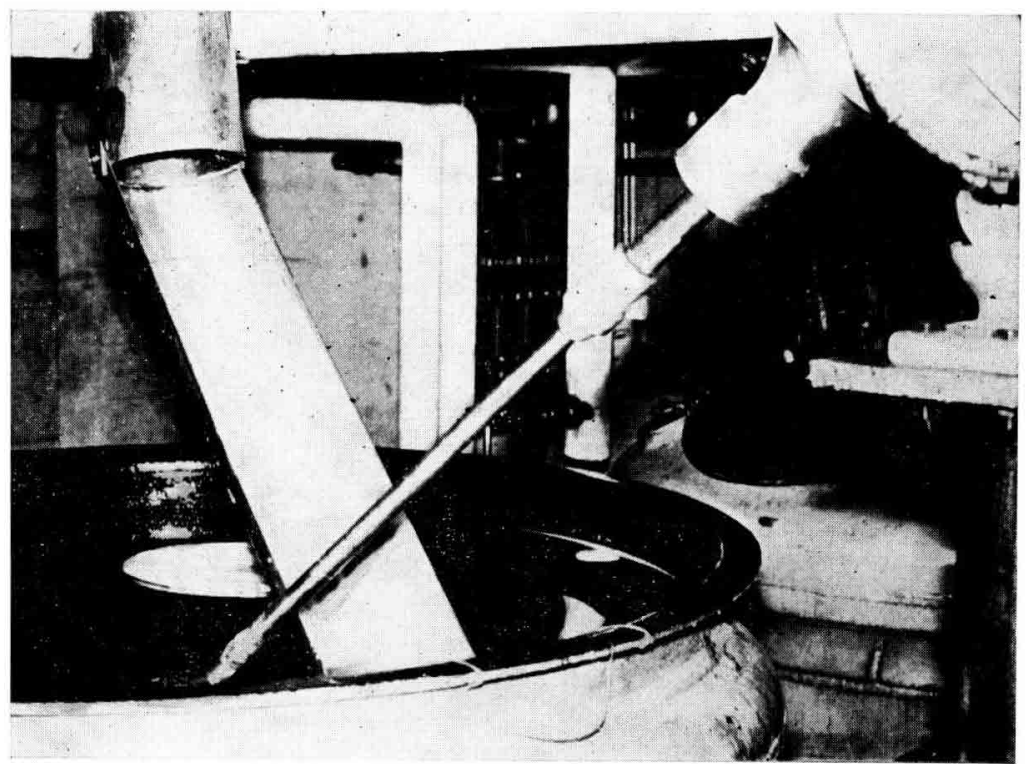

Fic. 16. - "Clover Crest" (Winnipeg). Gouttière d'amenée du miel refondu. Le miel s'écoule dans un tank de garde de grande capacité où il est homogénéisé par brassage au moyen de l'agitateur placé à droite 
des pressostats qui arrêtent l'installation dans le cas de pressions anormales. Parfois, un relai commande un by-pass et la pompe débite alors en circuit fermé, à l'amont d'un filtre par exemple.

\section{Les canalisations.}

L'eau circule dans des canalisations en acier galvanisé classique, la vapeur en canalisation acier, qualité vapeur. Le matériau choisi pour les canalisations en vue $\mathrm{du}$ transport du miel est l'acier inoxydable clont le prix est relativement bas au Canada et aux U. S. A. Les canalisations par éléments de 2 à 3 mètres sont assemblées par joints filetés. Le diamètre utilisé pour un débit de $20001 /$ h. est celui de $2 "$, ce qui correspond à une vitesse $d u$ miel de $0,30 \mathrm{~m} / \mathrm{s}$; dans les circuits, on a pu constater la présence d'éléments transparents de $0,30 \mathrm{~m}$ de longueur en pyrex, ce qui permet de voir directement le niel au passage.

Les filtres.

On distingue les systèmes de filtration suivants :

sous pression faible ou nulle et basse température;

sous pression de 2 à $6 \mathrm{~kg} / \mathrm{cm}^{2}$ et haute température.

Dans le premier groupe, on range :

- un système de dégrillage constitué par des tôles perforées dont les trous ont un diamètre de l'ordre de $5 \mathrm{~mm}$ et qui sont placées généralement à l'aval des chambres de refonte du miel. Elles sont destinées à éliminer les corps étrangers qui pourraient détériorer les pompes de reprise ;

- des filtres en aval des extracteurs ou des chambres de refonte, dont le but est d'assurer un préfiltrage, avant de placer le miel dans les maturateurs. Ce sont les filtres type O.A.C. (Ontario A griculture College) (1).

Dans le deuxième groupe, se placent les filtres destinés à la préfiltration et la filtration.

Dans une chaîne de conditionnement, les préfiltres précèdent le pasteurisateur. Ils sont constitués par une enveloppe cylindrique en acier inoxydable (diamètre $0,40 \mathrm{~m}$, hauteur $0,60 \mathrm{~m}$ ). Le miel pénètre dans le bas, dans la partie centrale, traverse 3 tamis cylindriques en métal Monel dont la dimension des mailles diminue successivement de Io mailles à 30 mailles au pouce. Le miel s'évacue par le haut vers le pasteurisateur $\left({ }^{2}\right)$.

On notera un modèle assez particulier utilisé à la "Sioux Bee " où le filtre à toile est mis en pression pneumatiquement : débit I $5_{5}$ ooo litres à l'heure $\left({ }^{3}\right)$.

Les filtres sont intercalés entre le circuit de chauffage et le circuit de refroidissement du pasteurisateur. On distingue les types suivants :

Filtres cylindriques. - Diamètre $0,30 \mathrm{~m}$, hauteur $0,70 \mathrm{~m}$; enveloppe en acier inoxydable, circulation verticale. La filtration est assurée dans le cas du filtre Sparkler par 25 plaques de toile métallique dont la dimension des mailles correspond à 200 mesh; ces plaques, dont la forme rappelle celle des assiettes d'écrémeuses,

(1) On trouvera la description complète de ces filtres dans le no 544 de la Revue française d'Apiculture.

(2) Constructeur : Sparkler International Limited, Toronto, model Strainer.

(3) Constructeur : Chicago Stainless Equipment Corporation, $500 \mathrm{I}$ North Ellon Avenue. Chicago 30. 


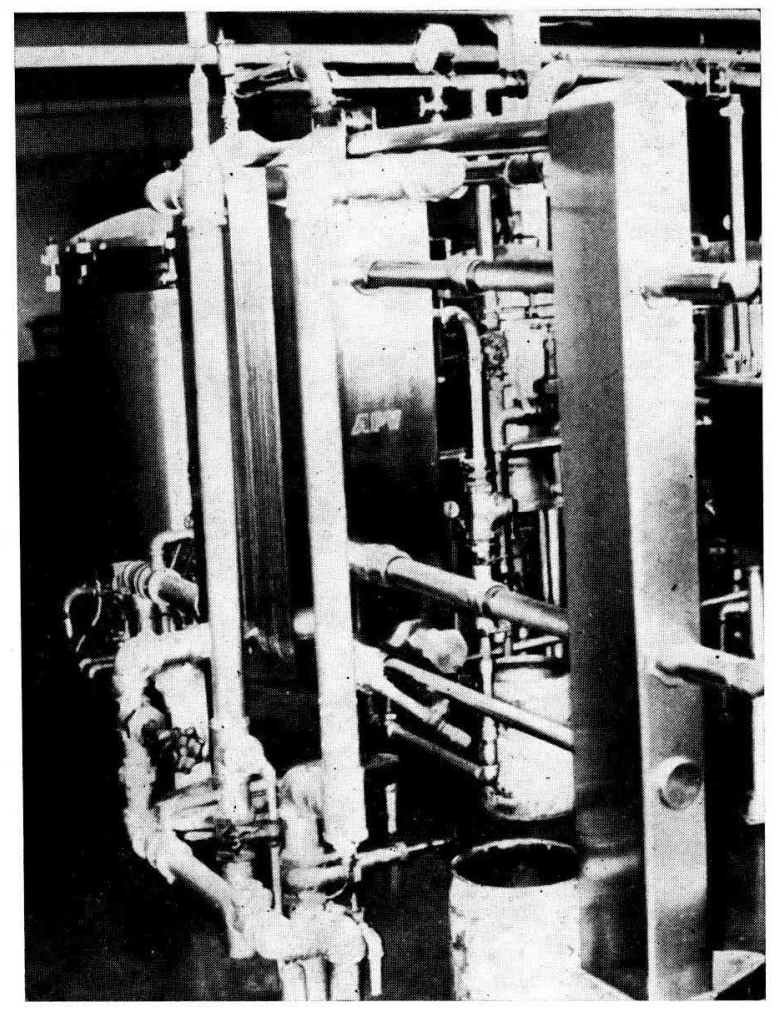

Fig. 17. - "Cloner Crest" (Winnipeg). Pasteurisation A.P.V. dans la salle de conditionnement du miel. A l'arrière plan ì gauche, in filtre

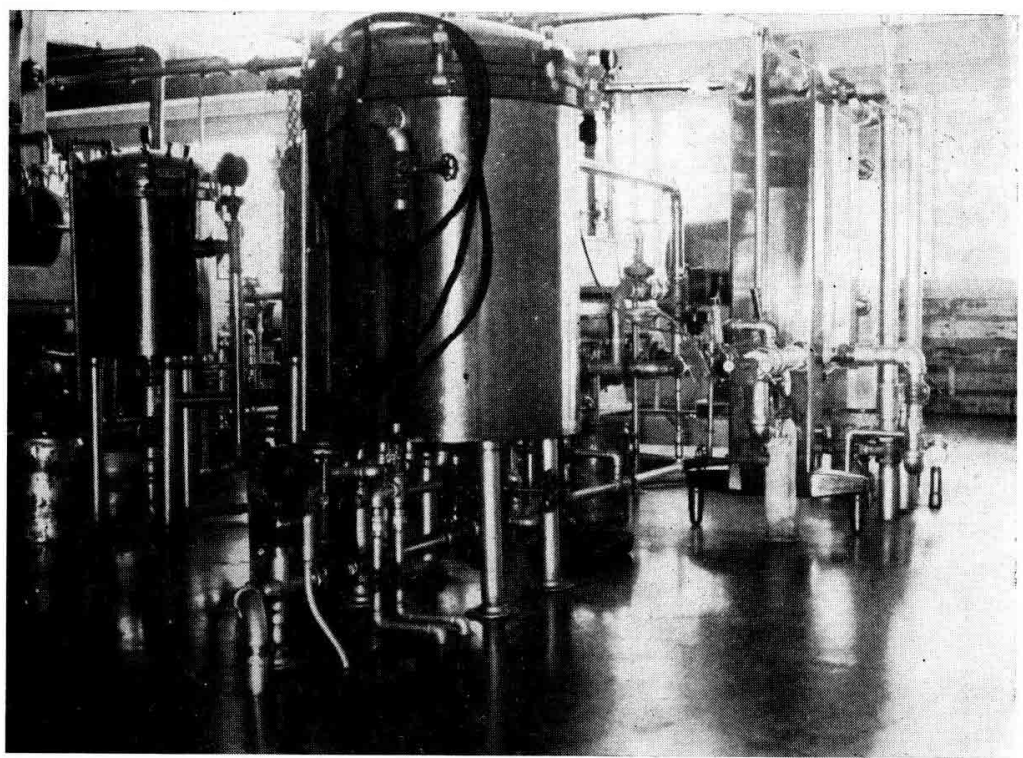

Fig. 18. - "Clover Crest" (Wimipeg). Sulle de conditionnement du miv?. Lu premier plan un filtre. A gauche un second filtre. A droile, le pasteurisateur A.P.V. déja présenl sur la figure $\mathrm{x} 3$. On remarquera que les arvivées de fhides et de miel id traiter se jont par le sol 


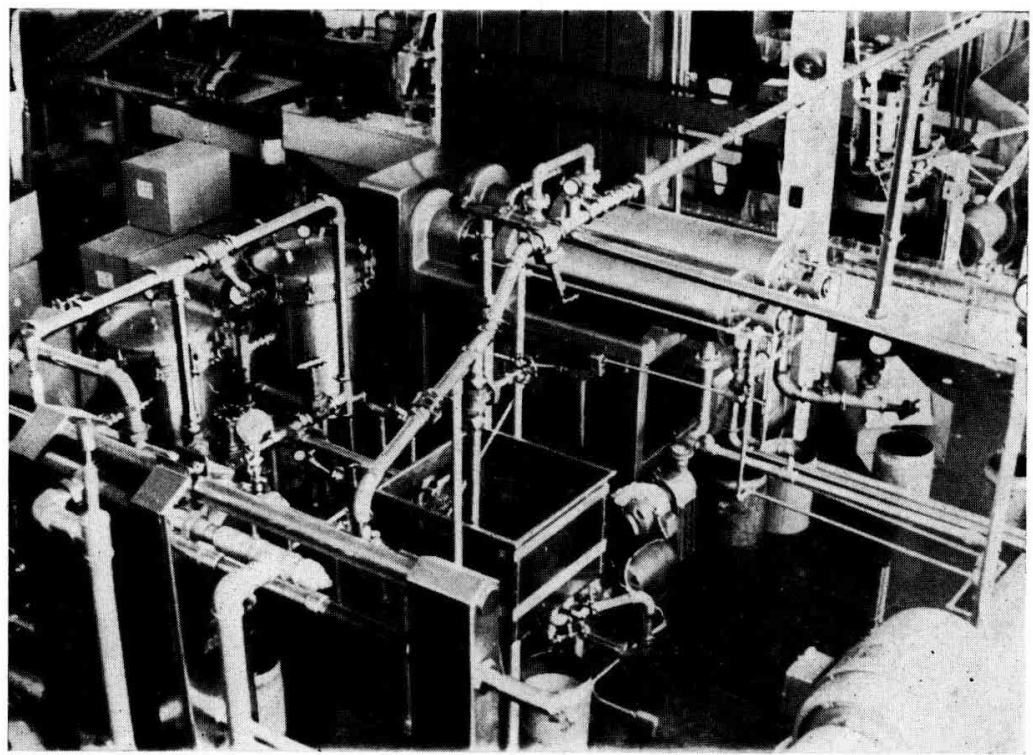

FIG. I9. - "Clover Crest" (Wimnipeg). Celte vue est prise depuis la vitre de la salle de réunion du Conseil d'administration (voir fig. 3). On distingue deux des fltres, le pasteturisateur A.P.V. est un Votator. La mise en pots se fait plus loin à droite; on reconnait d"ailleurs la chaine amenant les emballages vides

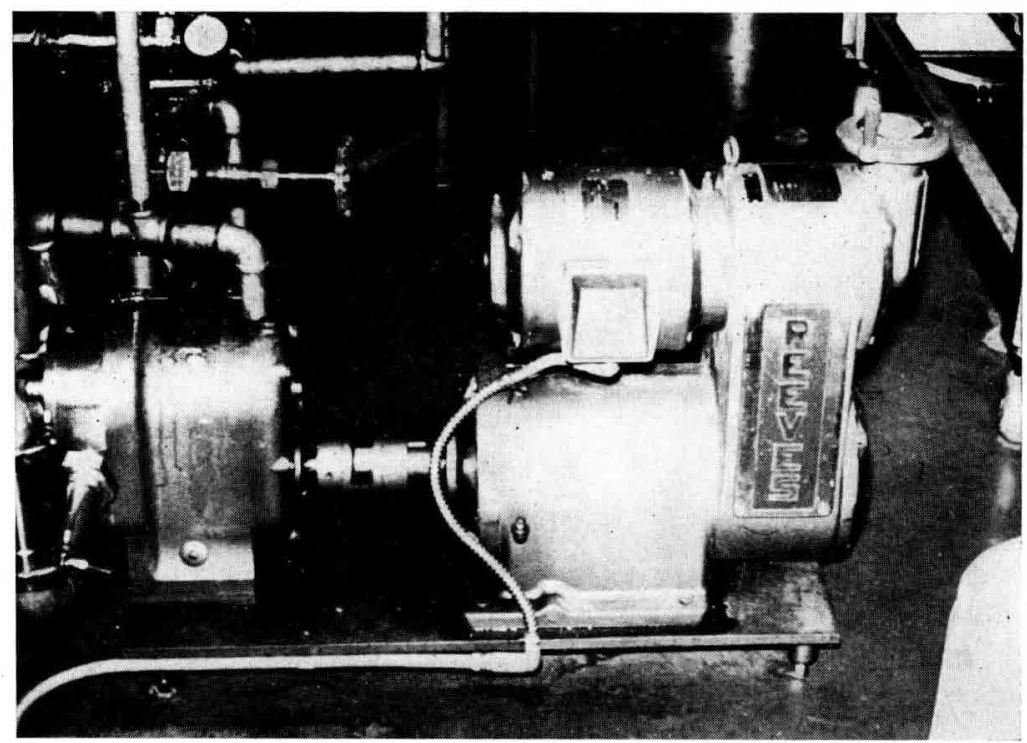

Fic. 2o. -- "Cloner Crest" (Wimipes). Croupe de pompage pour le miel. Ce mêne gronpe se retronte en tous les points ait ane mise c'n pression est néccssaive. 
sont empilées les unes sur les autres et colmatées dans une opération préalable par un passage de miel chargé de célite. Le débit atteint couramment $20001 / \mathrm{h}$.

- Filtres à sable. - (Filtres O.A.C., voir plus haut). Débit : 60o 1/h.

- Filtres bougie. - Diamètre $0,20 \mathrm{~m}$, hauteur $\mathbf{1}, 00 \mathrm{~m}$. Utilisé dans le cas d'une installation fabriquant uniquement du miel-crème.

- Filtres-presses horizontaux. - Remarques dans les installations anciennes. Leur utilisation appelle de sérieuses réserves, développées par ailleurs.

Les pasteurisateurs.

Les pasteurisateurs observés se groupent en deux catégories :

les pasteurisateurs à plaques ;

les pasteurisateurs échangeurs.

Les pasteurisateurs à plaques sont du type classique utilisé en industrie alimentaire. Ils comportent deux sections : la section chauffage, la section refroidissement, mais sans circuits de récupération ou de chaleur ou de froid. Les appareils débitent couramment I 500 à $20001 / \mathrm{h}$.

Le miel est mis en température de pasteurisation par de l'eau réchauffée par injection de vapeur; la régulation est assurée par thermostat agissant sur des vannes solénoïdes. Il en est de même pour le circuit de refroidissement. La technologie de ces appareils n'appelle pas de commentaires; des appareils analogues existent sur le marché français $\left({ }^{1}\right)$. Certains constructeurs préconisent d'ailleurs une pasteurisation par chauffage vapeur sous vide, avec limite $\pm 0,25^{\circ}$, que nous n'avons trouvée ni aux U. S. A., ni au Canada.

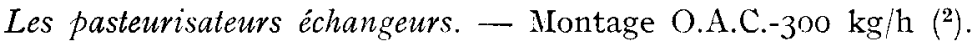

On citera pour mémoire les cuves à " pasteuriser " où le miel est chauffé pendant un temps suffisant à la température de $78^{\circ} \mathrm{C}$ (DunhaM, London). Ces cuves cylindriques possèdent une double enveloppe ; l'eau chaude circule dans la partie extérieure annulaire, le miel dans la partie centrale. Ces cuves présentent un diamètre extérieur de $0,40 \mathrm{~m}$, hauteur de I $\mathrm{m}$ environ. Avec un débit de $5001 / \mathrm{h}$, le temps de pasteurisation serait de l'ordre de $7 \mathrm{mn}$ (vitesse d'avancement du miel de $2 \mathrm{~mm} / \mathrm{s}$ dans le corps de l'appareil). Cet appareil apparaît d'une extrême simplicité, mais la "pasteurisation " ainsi obtenue appelle certaines réserves. Il n'en reste pas moins que c'est le seul dispositif peu coûteux pouvant être avantageusement utilisé par l'apiculteur conditionnant sa production.

Les cuves de mélange.

Les cuves interviennent dans les circuits, soit en vue d'obtenir des mélanges, soit pour servir de capacités tampons. Filles sont dotées en général d'agitateurs. La capacité des cuves varie de $500 \mathrm{~kg}$ à 7 tonnes. Elles sont de forme cylindrique avec fond plat ou parfois en calottes sphéricues. La plupart d'entre elles présentent un diamètre supérieur à leur hauteur. L'ouverture est largement dimensionnée. Les cuves sont construites en tôle d'acier, quelquefois en acier inoxydable. Elles présentent une double paroi pour la circulation d'eau chaude. I,es cuves en acier inoxydable s'apparentent par leurs caractéristiques aux tanks de garde utilisés en laiterie.

(1) Constructeur (pour la majorité des appareils en service) : A. P. V. Cherry Burrel Company, Chicaso, et 88 , Avenue Kléber. P’aris $\left(\mathrm{I} 6^{\mathrm{e}}\right)$.

( $\left.{ }^{2}\right)$ Voir tous les détails concernant cet appareil dans le $n^{\circ} 5+4$ de la Rezue francaise d'Apiculture. 
Les agitateurs munis de palettes ou plutôt d'hélices travaillent soit verticalement, soit obliquement, soit horizontalement. Les moteurs qui les entraînent sont accouplés à des réducteurs; la vitesse de rotation des agitateurs varie de ro tours par minute pour les agitateurs à palette, à 20 tours par minute pour les agitateurs à hélice. Les agitateurs peuvent travailler alternativement sur 2 cuves placées côte

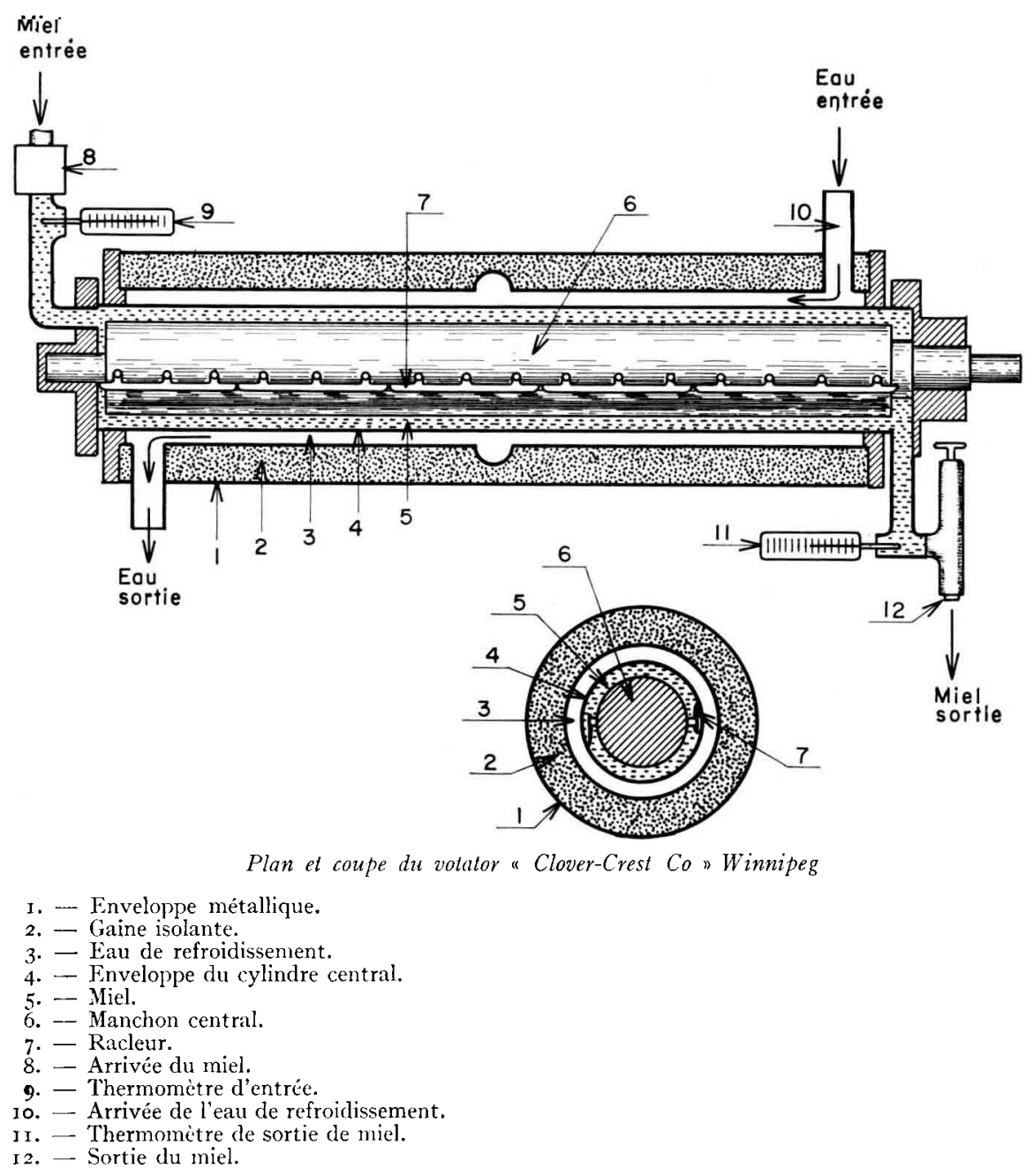

à côte. Le moteur de l'agitateur étant placé sur un bâti où il peut pivoter, il suffit de déverrouiller l'axe, de l'amener dans la $2^{\mathrm{e}}$ cuve et de le mettre en position d'entrâ̂nement.

Les échangeurs de température pour le miel-crème.

Le problème posé par la fabrication du miel-crème repose sur le refroidissement du miel filtré liquide qui sort à $50^{\circ}$ du pasteurisateur et qu'il faut amener à $24^{\circ}$, température de l'ensemencement. Il convient, en effet, d'injecter et de mélanger la 
semence à une température inférieure à $25^{\circ}$, température à laquelle commencerait la dissolution des cristaux.

Le pasteurisateur, appareil échangeur de température à plaques minces et à passage pelliculaire, ne peut pas assurer un refroidissement du miel au-dessous de $40^{\circ}$, avec un débit suffisant.

Divers appareils, off rant un plus grand passage à un miel plus refroidi et devenant visqueux, sont utilisés, et parmi lesquels les échangeurs "Votator" (1).

Dans ces appareils, le miel poussé par la pompe, circule de l'entrée vers la sortie entre deux longs cylindres. L,e plus grand, refroidi extérieurement par de l'eau à la température ordinaire - qui, elle, circule en sens inverse - est fixe. L,e cylindre intérieur est rotatif et entraîne le miel en un mouvement lent. Il porte, de plus, deux lames racleuses, montées en génératrice, opposées, qui empêchent toute adhérence du miel refroidi sur la paroi du cylindre extérieur refroidisseur.

Le montage utilisé à la "Clover Crest" est le suivant :

Le miel venant du pasteurisateur $\left(5^{\circ}\right)$ est repris par une pompe $\left(8 \mathrm{~kg} / \mathrm{cm}^{2}\right)$ dans un bac intermédiaire et poussé dans un premier Votator (de ro pouces) où sa température est abaissée à $24^{\circ}$. Il passe devant une pompe à injection continue de la semence ( 7 à Io p. roo) et ainsi ensemencé arrive dans un deuxième Votator double, comportant deux cylindres de refroidissement, en série. Dans ce Troin Votator, le mélange homogène miel-semence est assuré, et le refroidissement puursuivi. Le miel en masse devenue plus visqueuse encore, sort à $\mathrm{I} 4^{\circ}$. Le médium de refroidissement est l'eau glacée. Le débit reste de l'ordre de $2000 \mathrm{~kg} / \mathrm{h}$.

Les appareils utilisés en industrie alimentaire, en Europe, pour refroidir des corps visqueux (crèmes, huiles épaisses) sont construits par la Société Astra. $\left({ }^{2}\right)$ D'un prix élevé, ils ne se justifient que dans des usines de format important et spécialisées dans la fabrication du miel-crème.

Des appareillages plus simples, mais sans doute moins rationnels, ont été imaginés :

Refroidisseur à cylindre, de la Coopérative de l'Ontario. - C'est un cylindre métallique à axe horizontal (1ongueur $2 \mathrm{~m}$, diamètre $0,80 \mathrm{~m}$ ) refroidi intérieurement par de l'eau à la température de $10^{\circ}$ environ. Le miel, pris à la base du cylindre, par trempage, est réparti uniformément et entraîné sur la surface entière, dans un mouvement lent de rotation. Il est raclé en fin de course le long d'une génératrice inférieure et s'écoule dans la cuve à mélange. Température I $8^{\circ}$. Débit I $500 \mathrm{~kg} / \mathrm{h}$. Deux de ces ensembles sont utilisés. Les cuves à mélange de la semence, sont dotées d'un arbre horizontal supportant des palettes de brassage.

Cuve de refroidissement et de mélange de la Coopérative Finger Lake. - Il s'agit d'une cuve cylindrique de $2 \mathrm{~m}$ de diamètre et $\mathrm{I}, 30 \mathrm{~m}$ de hauteur, dans laquelle le refroidissement est assuré par un agitateur tubulaire en forme de tambour à l'intérieur duquel circule l'eau froide. Température obtenue : $25^{\circ}$.

Le miel-crème est empaqueté, ensuite placé en chambre froide à $5^{\circ}$ pendant $24 \mathrm{~h}$ et entreposé dans des chambres à $\mathrm{I}^{\mathrm{O}}$.

Les chaines d'embouteillage. - Sur le plan technique, leur présentation ne présente qu'un intérêt relatif car un tel matériel existe sur le marché français. Elles diffèrent les unes des autres par un automatisme plus ou moins poussé. Les postes

(1) The Girdler Corporation - 224 East Broadtay - Louisville - Kenturky.

(P) Filiale en Allemagne, de la Sociétí Alfa-Laval. 


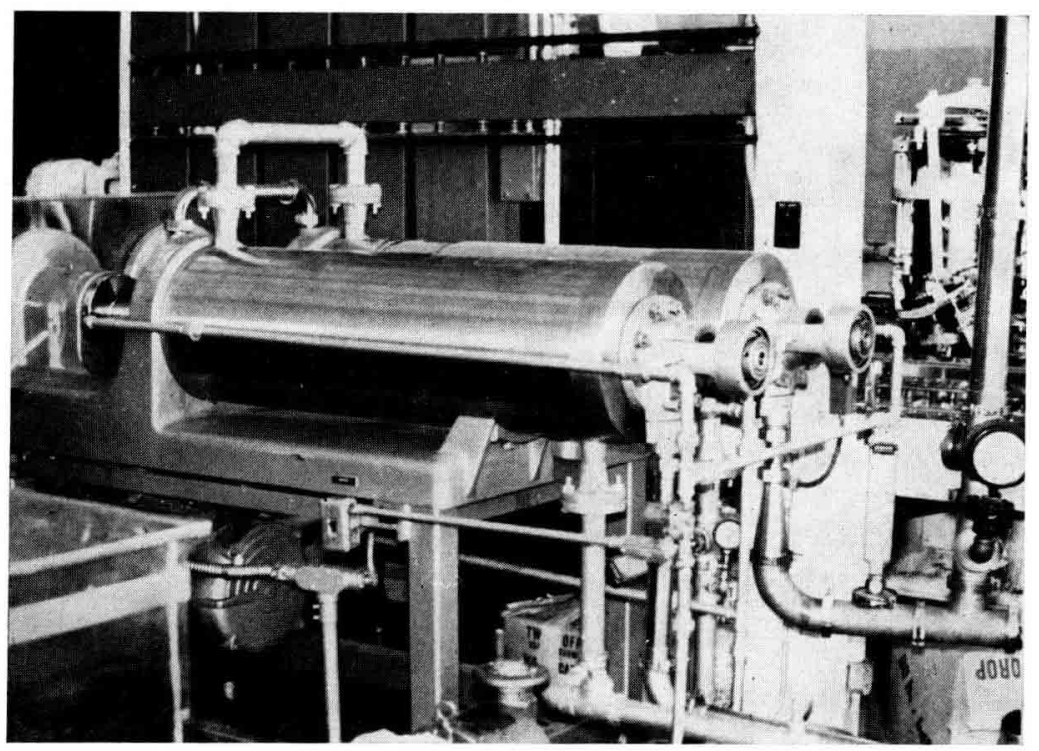

Fic. zा. - Volator double wilisé à la "Clozer Cirest" pour la prépuralion du miel-crème

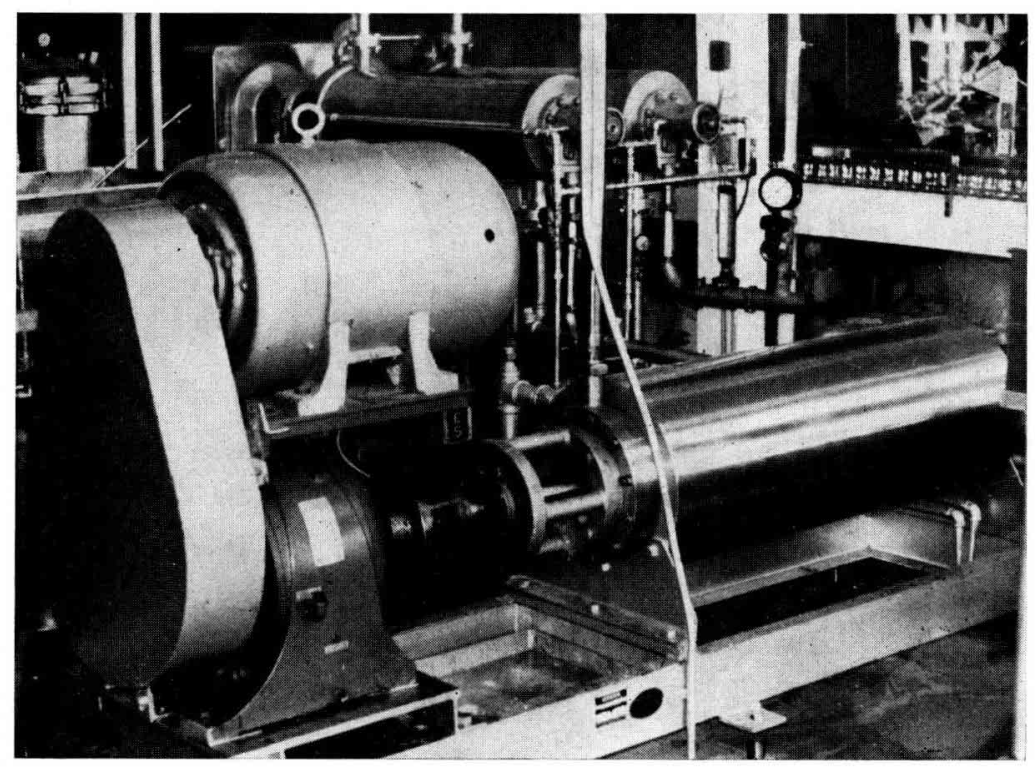

FIG. 22. - Enstmble des deux votators milisés à la "Clover Crest n pour la préparalion du mid crème. Le inatar du premier phu sert uniquement au refroidissement du miel pasteurisé. Le secunt assure le mélans arec la semence en mime temps que le refrohitissement, jusqu'd $14^{\circ}$ 


\begin{tabular}{|c|c|c|c|c|c|c|c|c|}
\hline No & Firmes & $\begin{array}{l}\text { Caractéris- } \\
\text { tiques } \\
\text { générales }\end{array}$ & $\begin{array}{l}\text { Matériaux } \\
\text { de cons- } \\
\text { truction }\end{array}$ & $\begin{array}{l}\text { Plan- } \\
\text { chers }\end{array}$ & $\begin{array}{l}\text { Surface } \\
\text { stockage }\end{array}$ & $\begin{array}{c}\text { Quais } \\
\text { des } \\
\text { véhicules }\end{array}$ & Bureaux & $\begin{array}{l}\text { Labor } \\
\text { toir }\end{array}$ \\
\hline 1 & $\begin{array}{c}\text { Doyon et Doyon } \\
\text { (Montréal) }\end{array}$ & $\begin{array}{l}\text { A étages } \\
\text { et sous-sol }\end{array}$ & Maçonnerie & Bois & & & $\begin{array}{l}\text { Petits } \\
\text { et sombres }\end{array}$ & $15 \mathrm{n}$ \\
\hline 2 & $\begin{array}{c}\text { Fred Lallemand } \\
\text { (La Prairie) }\end{array}$ & $\begin{array}{l}\text { A étages } \\
\text { et sous-sol }\end{array}$ & Maçonnerie & Cinment & & & $\begin{array}{l}\text { Rez-de- } \\
\text { chaussée }\end{array}$ & 10 \\
\hline 3 & $\begin{array}{c}\text { Billy BEE } \\
\text { Honey (Toronto) }\end{array}$ & $\begin{array}{l}\text { Un seul } \\
\text { niveau }\end{array}$ & Métal & Ciment & $2000 \mathrm{~m}^{2}$ & $\begin{array}{l}\text { Encastrés } \\
\text { Largeur : } \\
\quad 8 \mathrm{~m}\end{array}$ & $\begin{array}{l}\text { A l'étage, } \\
\text { modernes }\end{array}$ & 10 \\
\hline 4 & $\begin{array}{r}\text { BEE KIST } \\
\text { (Toronto) }\end{array}$ & $\begin{array}{l}\text { Plusieurs } \\
\text { niveaux }\end{array}$ & Maçonnerie & Bois & $1000 \mathrm{~m}^{2}$ & & Très grands & \\
\hline 5 & $\begin{array}{c}\text { Clover Crest } \\
\text { Honey } \\
\text { (Winnipeg) }\end{array}$ & $\begin{array}{c}\text { De plain-pied } \\
\text { sous-sol } \\
\text { partiel }\end{array}$ & Métal & $\begin{array}{l}\text { Métal } \\
\text { et sol } \\
\text { cintent }\end{array}$ & $900 \mathrm{~m}^{2}$ & $\begin{array}{l}\text { Enterrés } \\
3 \text { hauteurs }\end{array}$ & $\begin{array}{c}\text { Modernes } \\
\text { insonorisés } \\
\text { bien éclairés }\end{array}$ & 19 \\
\hline 6 & $\begin{array}{l}\text { SIOUX BeE } \\
\text { Honex } \\
\text { (Sioux City) }\end{array}$ & $\begin{array}{l}\text { Plusieurs } \\
\text { niveaux }\end{array}$ & Maçonnerie & Bois & $400 \mathrm{~m}^{2}$ & Norniaux & A l'étage & 50 \\
\hline 7 & $\begin{array}{c}\text { W. F. Strad B } \\
\text { (Chicago) }\end{array}$ & $\begin{array}{l}\text { Plusieurs } \\
\text { niveaux }\end{array}$ & Maçonnerie & Bois & Exiguë & & $\begin{array}{l}\text { Au rez-de- } \\
\text { chaussée }\end{array}$ & \\
\hline 8 & $\begin{array}{l}\text { M. DUNHAM } \\
\text { (London) }\end{array}$ & $\begin{array}{l}\text { Un seul } \\
\text { niveau }\end{array}$ & $\begin{array}{c}\text { Haçonnerie } \\
\text { et bois }\end{array}$ & $\begin{array}{l}\text { Sols } \\
\text { ciment }\end{array}$ & $80 \mathrm{~m}^{2}$ & Sans & $4 \mathrm{~m}^{2}$ & ?a \\
\hline 9 & $\begin{array}{c}\text { FINGER LAKE } \\
\text { HONEY }\end{array}$ & $\begin{array}{l}\text { R. de ch. } \\
\text { et étage }\end{array}$ & Bois & Bois & $\begin{array}{c}200+\text { em- } \\
\text { ballages } \\
\text { vides } \\
\text { au } 1^{\text {er }}\end{array}$ & $\begin{array}{l}1 \text { route } \\
1 \text { voie }\end{array}$ & $\begin{array}{l}\text { Séparés } \\
\text { au rez-de- } \\
\text { chaıssée }\end{array}$ & \\
\hline 10 & $\begin{array}{l}\text { HONEY } \\
\text { PROCESSORS } \\
\text { INC }\end{array}$ & $\begin{array}{l}\text { R.-de-ch. } \\
\text { Sous-sol } \\
\text { partiel }\end{array}$ & $\begin{array}{c}\text { Maçonnerie } \\
\text { et bois }\end{array}$ & $\begin{array}{l}\text { Sols } \\
\text { ciment }\end{array}$ & $200 \mathrm{~m}^{2}$ & $\begin{array}{c}\text { Trés } \\
\text { petit quai }\end{array}$ & $9 \mathrm{n}^{2}$ & $\mathrm{~d}$ \\
\hline
\end{tabular}




\section{bâtiments}

\begin{tabular}{|c|c|c|c|c|c|c|}
\hline \multirow{2}{*}{ haufferie } & \multicolumn{2}{|c|}{ Salles de : } & \multirow{2}{*}{$\begin{array}{l}\text { Chambres } \\
\text { froides }\end{array}$} & \multirow{2}{*}{$\begin{array}{l}\text { Chanubre } \\
\text { de chauffe }\end{array}$} & \multirow{2}{*}{$\begin{array}{l}\text { Bonte- } \\
\text { charges }\end{array}$} & \multirow{2}{*}{ Observations } \\
\hline & Traitement & $\begin{array}{c}\text { Condition- } \\
\text { nement }\end{array}$ & & & & \\
\hline & \multicolumn{2}{|c|}{$100 \mathrm{~m}^{2}$} & & $\begin{array}{l}30 \mathrm{~m}^{2} \\
\dot{a} \text { l'étage }\end{array}$ & \multirow[t]{2}{*}{$\begin{array}{c}\text { oui } \\
1500 \mathrm{kr}\end{array}$} & $\begin{array}{l}\text { Construction ancienne : adaptation } \\
\text { compliquée: mauvais éclairage naturel. }\end{array}$ \\
\hline $14 \mathrm{~m}^{2}$ & $3 \pm \mathrm{m}^{2}$ & $\begin{array}{c}60 \mathrm{~m}^{2} \\
1 / 2 \text { à l'étage } \\
1 / 2 \text { aur } \\
\text { r.-de-ch. }\end{array}$ & & $3 \times 1 \mathrm{~m}^{2}$ & & $\begin{array}{l}\text { Ancien bureau de poste. Interpéné- } \\
\text { tration du traitement de miel (accessoire) } \\
\text { et des jus de fruits et contitures. }\end{array}$ \\
\hline \multirow[t]{2}{*}{$10 \mathrm{~m}^{2}$} & \multicolumn{2}{|c|}{$120 \mathrm{~m}^{2}$} & $\begin{array}{l}100 \mathrm{~m}^{2} \\
\text { sur } \\
\mathrm{H}: 5 \mathrm{~m}\end{array}$ & $\begin{array}{c}110 \mathrm{~m}^{2} \\
\text { attenante } \\
\text { au traitement }\end{array}$ & & $\begin{array}{l}\text { Construction assez moderne mais } \\
\text { sombre. }\end{array}$ \\
\hline & $180 \mathrm{~m}^{2}$ & $100 \mathrm{~m}^{2}$ & $\begin{array}{c}2 \mathrm{de} \\
150 \mathrm{~m}^{2}\end{array}$ & $36 \mathrm{~m}^{2}$ & $1500 \mathrm{kgg}$ & $\begin{array}{l}\text { Bàtiment ancien, dont l'adaptation au } \\
\text { miel fut difficile. }\end{array}$ \\
\hline \multirow[t]{3}{*}{$55 \mathrm{~m}^{2}$} & \multicolumn{2}{|c|}{$260 \mathrm{~m}^{2}$} & \multirow[b]{2}{*}{$500 \mathrm{~m}^{2}$} & $140 \mathrm{~m}^{2}$ total & & $\begin{array}{l}\text { Très moderne. Trìs bien conçue. Murs } \\
\text { rideaux pour façarle bureaux et traite- } \\
\text { ment. Construction cossue et élégante. } \\
\text { Propreté méticuleuse. }\end{array}$ \\
\hline & $80 \mathrm{~m}^{2}$ & $180 \mathrm{~m}^{2}$ & & $\begin{array}{l}\text { A l'étage, } \\
\text { ' de } 6 \mathrm{~m}^{2} \\
\text { (bidons), } \\
1 \text { de } 1: 3 \mathrm{~m}^{2} \\
\text { (fûts) }\end{array}$ & $\begin{array}{l}\text { oui } \\
1500 \mathrm{kgr}\end{array}$ & $\begin{array}{l}\text { Ancienne construction. Étages de } \\
\text { faible hauteur. Poteaux très rapprochés. } \\
\text { Un projet nowveau est en cours. }\end{array}$ \\
\hline & \multicolumn{2}{|c|}{ Encombrées } & & & & $\begin{array}{l}\text { Cohabitation et promiscuité, dans un } \\
\text { ancien bátiment, du miel, du jus de } \\
\text { fruits et du savon mou. }\end{array}$ \\
\hline \multirow[t]{2}{*}{$12 \mathrm{~m}^{2}$} & \multicolumn{2}{|c|}{$70 \mathrm{~m}^{2}$} & $20 \mathrm{~m}^{2}$ & $\begin{array}{l}\text { (i) } \mathrm{m}^{2} \text { bidons } \\
15 \mathrm{~m}^{2} \text { fûts }\end{array}$ & & $\begin{array}{l}\text { Réalisation particulière, simple, mais } \\
\text { complete. Très propre. }\end{array}$ \\
\hline & \multicolumn{2}{|c|}{$90 \mathrm{~m}^{2}$} & $\begin{array}{rl}2 & \mathrm{de} \\
15 \mathrm{~m}^{2} \\
\mathrm{II} & : \geq, \geq 0\end{array}$ & $\begin{array}{l}36 \mathrm{~m}^{2} \\
\text { a l'otage }\end{array}$ & $\begin{array}{c}\text { oui } \\
1500 \mathrm{kgr}\end{array}$ & $\begin{array}{l}\text { Adaptation à une construction exis- } \\
\text { tante. 'Traitement très encombré. }\end{array}$ \\
\hline $2 \mathrm{~m}^{2}$ & 65 & $\mathrm{~m}^{2}$ & $50 \mathrm{~m}^{2}$ & $15 \mathrm{nt}^{2}$ & & $\begin{array}{l}\text { Conception simple mais logique d'une } \\
\text { petite installation peu onéreuse. }\end{array}$ \\
\hline
\end{tabular}


d'une chaîne complète seraient les suivants : alimentation de la chaîne en pots vides, dépoussiérage des pots à l'air comprimé, remplissage rotatif, pose et serrage des couvercles, collage de l'étiquette, transfert des pots pleins, mise en cartons. Seuls le premier et le dernier postes nécessitent des opérations manuelles. Les chaînes utilisant l'emballage verre sont entièrement automatiques ; lorsque le miel est empaqueté dans le carton ou plutôt la matière plastique (miel-crème), diverses opérations sont parfois exécutées manuellement (fermeture des pots).

Les chambres froides. - Conçues de façon économique (isolation en laine de verre ou polystyrène, sols avec couche d'usure au carborandon, portes isothermes construites sommairement avec dispositif de protection métallique dans le bas), leur hauteur varie de $3,50 \mathrm{~m}$ à $6,09 \mathrm{~m}$. Leur coefficient de brassage est faible.

Chauffage. - Le moyen le plus utilisé est la vapeur circulant dans des aérothermes asservis par thermostat. Les aérothermes sont également utilisés pour apporter des frigories et assurent le conditionnement de l'air, été comme hiver. On notera le développement important de ce genre d'installation dans des locaux industriels et le soin apporté à la mise en œuvre de cette technique.

Éclairage. - Éclairage fluorescent dans la plupart des cas, et largement dispensé.

\section{LES BÂTIMENTS}

Nous donnons leurs caractéristiques sous forme de tableau (tab1. 3), l'ordre de présentation étant celui de la visite.

Ils peuvent se diviser en deux catégories : ceux qui existaient avant leur utilisation comme lieu de stockage et conditionnement du miel; ceux qui, au contraire, ont été conçus en fonction de leur destination.

Dans le premier groupe, entrent les numéros I, 2, 3, 4, 6, 7 et 9. Cependant, le $n^{\circ} 3$ est assez moderne pour pouvoir être classé en même temps dans les deux catégories, la seconde comprenant alors les $n^{\circ} 3,5,8$ et ro.

L'adaptation des premiers ne permet pas en général une implantation du matériel assurant une exploitation facile et économique, son emplacement étant toujours fonction des dispositions existantes.

Dans les seconds, l'appareillage a été conçu suivant une disposition rationnelle; c'est lui qui a conditionné la forme et le parti du bâtiment.

\section{E. - LE PERSONNEL}

L'importance numérique dı personnel employé dans les diverses entreprises (coopératives ou affaires privées) que nous avons visitées en Amérique du Nord est essentiellement variable. Elle dépend, évidemment, de la quantité de miel traitée journellement mais il ne semble pas qu'il existe une proportionnalité rigoureuse entre les deux facteurs. Ceci signifie que selon les entreprises, la productivité est plus ou moins élevée. D’une façon générale, les coopératives semblent employer proportionnellement plus de main-d'œuvre que les affaires particulières.

Nous avons regroupé dans le tableau 4 les données que nous avons pu recueillir sur la question du personnel mais nous désignerons seulement par une lettre les différentes entreprises, ceci par simple discrétion. 


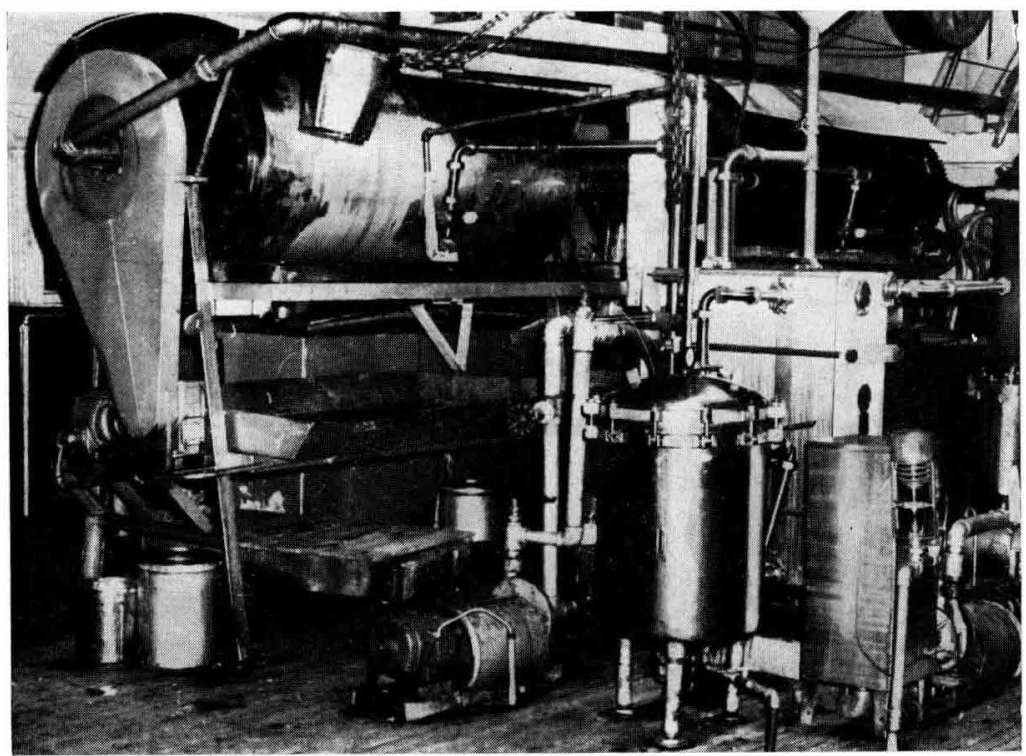

FIG. 23. - Appareil pour le refroidissement du miel pustruisé arant son mélange avec la semence pour la préparation die miel-crème. Cet appareil qui appartient à la Coopératize de l'Ontario est d'un modèle ancien. Au premier plan un ensemble de fillotion el pasteurisation

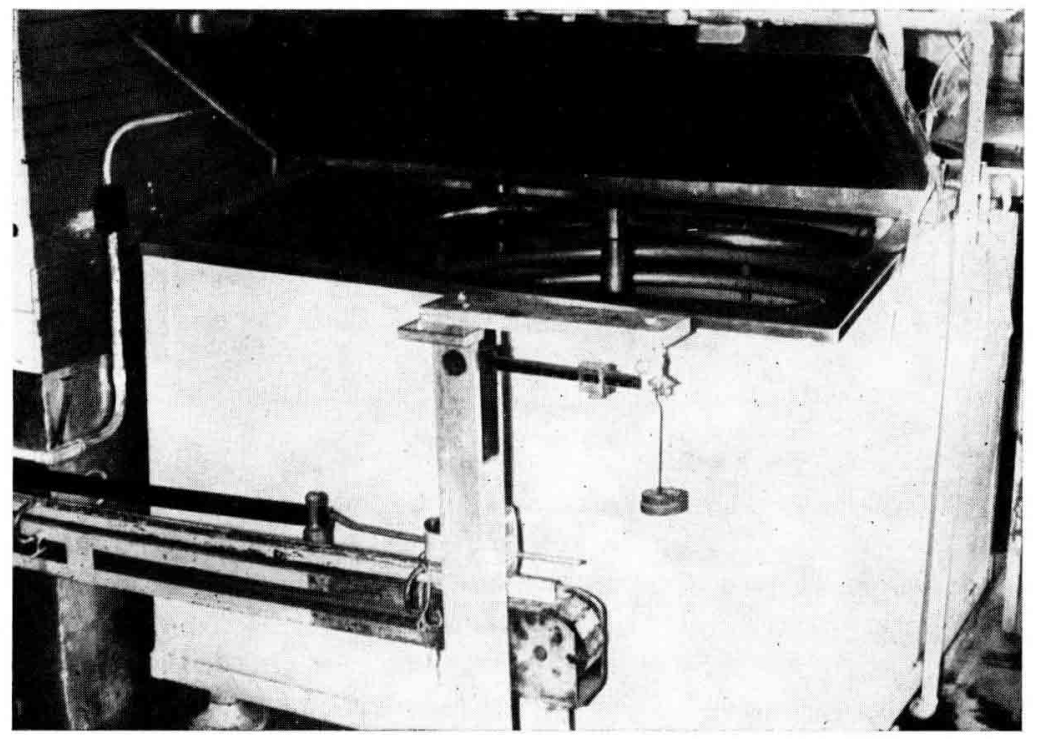

Ftc. 24. - Cuve ulilisée pour refroidir le miel pasteurisé el assurer le mélange de la semence en vue de la préparation du miel-crème. Le serpentin du refroidisseur sert en même lemps d'agitaleur (Coopérative des Finger Lake) 
Nos renseignements restent d'ailleurs assez fragmentaires et le tableau que nous avons tenté de dresser présente des lacunes importantes. Nous n'y avons pas fait figurer la "Sioux Bee» pour la raison que cette Coopérative emploie à Sioux-City un important personnel administratif qui travaille pour l'ensemble des succursales réparties dans tous les $\mathrm{U}$. S. A. Nous savons toutefois que cette Coopérative se signale par une chaîne de mise en pots de miel liquide qui est susceptible de livrer 28280 doses de $700 \mathrm{~g}$ environ par journée de $8 \mathrm{~h}$. avec 4 personnes seulement. C'est là un cas exceptionnel ; en moyenne on évalue la capacité de conditionnement entre $700 \mathrm{~kg}$ et $\mathrm{I} 400 \mathrm{~kg}$ par ouvrier et par journée de $8 \mathrm{~h}$.

La qualification du personnel est presque toujours la même. L'équipe-type affectée au conditionnement du miel comprend un contremaître, un chef de quai, un mécanicien et un technicien pour le laboratoire. Le reste de la main-d'œuvre est sans spécialisation et constitué principalement par des femmes.

TABLEAU 4

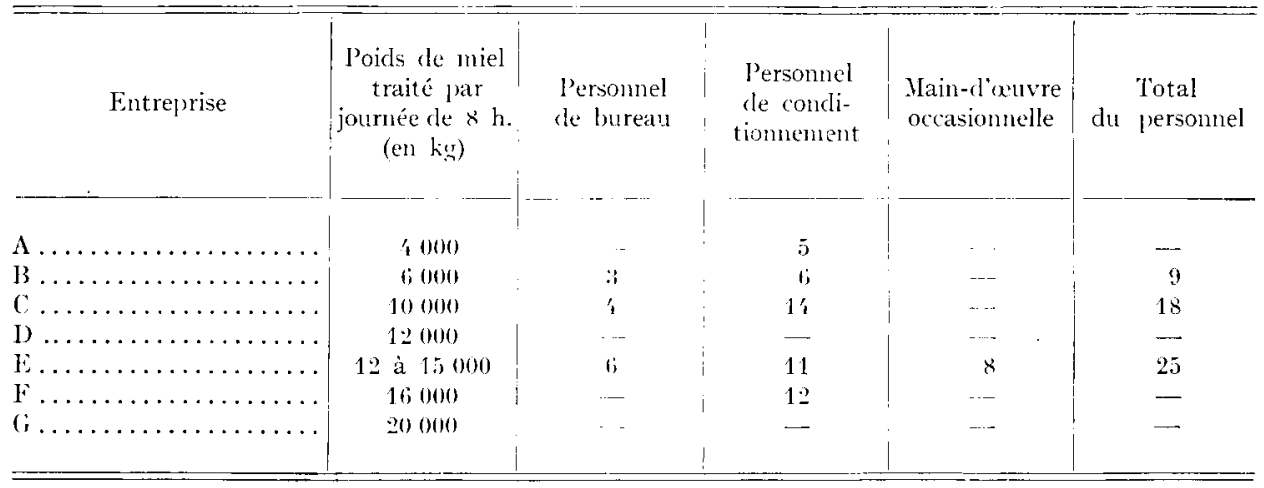

Les salaires horaires sont de $I, 60 \$$ pour les manœuvres et de $I, 75 \$$ pour le personnel de bureau. Rappelons par ailleurs que les régimes de sécurité sociale américains sont assez différents du nôtre.

\section{F. - Plannings de FONCtionnement}

Le fait de disposer d'un matériel perfectionné pour le conditionnement du miel ne résout pas tous les problèmes d'organisation du travail qui se posent aux Coopératives ou aux industriels. La fourniture rapide des commandes qui, tout comme sur le marché européen, se présentent avec une assez grande irrégularité constitue une difficulté majeure. Un autre obstacle provient de la multiplicité des types d'emballages ; la "Clover Crest " à elle seule en utilise une quinzaine. Il est donc nécessaire que chaque entreprise organise ses fabrications d'une façon rationnelle pour répondre à la demande sans qu'il en résulte une irrégularité exagérée du fonctionnement des chaînes. Il convient de noter que la complexité des problèmes de planning est toutefois moins grande qu'en France où la multiplicité des qualités de miel vient s'ajouter à celle des emballages; les qualités de miel américaines sont très peu nombreuses, ce qui simplifie le travail. 
La souplesse du fonctionnement des chaînes de conditionnement est assurée en premier lieu par le stockage. Nous avons vu que chaque entreprise dispose généralement d'un vaste local où peuvent être entreposées des centaines de tonnes de miel. Par ailleurs, le miel conditionné est conservé en chambre froide à $I 4^{\circ}$ et la capacité de stockage de ces chambres est, elle aussi, parfois très élevée.

Sur les chaînes de conditionnement proprement dites, les possibilités de réglage du débit horaire sont peu importantes. On peut toutefois jouer sur l'intensité du chauffage dans les chambres de refonte et sur la mise en service de chambres de secours. Certaines entreprises disposent de plusieurs unités de pasteurisation dont certaines ne sont pas utilisées en permanence. Le goulot d'étranglement est alors constitué par les machines à empoter et les étiqueteuses dont il est difficile de modifier les cadences de travail de façon importante. Nous avons noté dans quelques entreprises 1'existence de systèmes perfectionnés permettant de passer rapidement d'un type d'emballage à un autre. Dans ce cas, des cuves tampons permettent de poursuivre le traitement du miel malgré l'interruption de la mise en pots.

Pour la fabrication du miel-crème, on procède généralement par lots et non pas en continu. En effet, la consommation du miel-crème est assez en retrait par rapport à celle du miel liquide. Seule la "Clover Crest " est équipée pour la fabrication continue.

\section{G. - LA " CLOVER CREST "- MANITOBA COOPÉRATIVE OF HONEY PRODUCERS I.TD, WINNIPEG}

Ayant examiné les caractéristiques générales du matériel et des méthodes en usage dans l'industrie du miel américaine, il nous a paru intéressant de regrouper les divers renseignements d'ordre technique et économique relatifs à une Coopérative déterminée. Nous avons choisi pour cette petite monographie la "Clover Crest" qui est, sans aucun doute, la Coopérative la plus moderne et la mieux équipée qu'il nous ait été donné de visiter.

La "Clover Crest", dont le siège est à Winnipeg (Manitoba) a été fondée en I922. Elle groupe 700 coopérateurs, tous apiculteurs dans le Manitoba ou à proximité dans les deux provinces voisines, l'Ontario et l'Alberta, et collecte chaque année 2300 à 2500 t. d'un miel d'excellente qualité provenant essentiellement des Trèfles. Sur les 700 coopérateurs, 75 possèdent de 600 à I 200 ruches et l'ensemble de leurs livraisons représente $90 \mathrm{p}$. Ioo du tonnage traité. La récolte moyenne est de $75 \mathrm{~kg}$ par ruche.

\section{Bâtiments et installations.}

Le bâtiment de la "Clover Crest» offre une surface couverte de $2600 \mathrm{~m}^{2}$. Sa hauteur est de $6 \mathrm{~m}$. C'est une construction récente, d'aspect très moderne, comportant une ossature et une charpente métalliques, des murs rideaux, une couverture en tôle reposant sur des fermettes avec isolation en polystyrène et étanchéité en multicouche.

On distingue trois niveaux :

a) Sous-sol. - Sa surface est très réduite puisqu'il n'occupe que I8 $\times 7 \mathrm{~m}$. On y trouve exclusivement les cuves de mélange. 


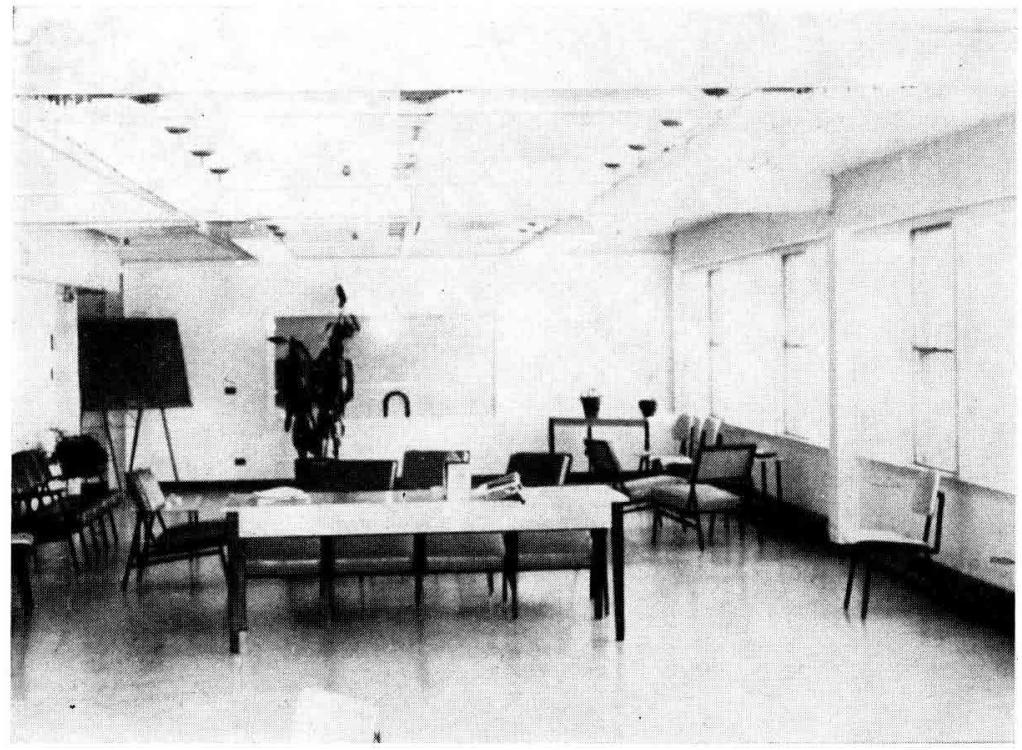

FIG. 25. - Salle de réunion du Conseil d'administration de la "Clover-Crest à Winnipeg. Le panneau vitre qui est au fond de la salle donne directement sur la grande salle de conditionnement du mi el

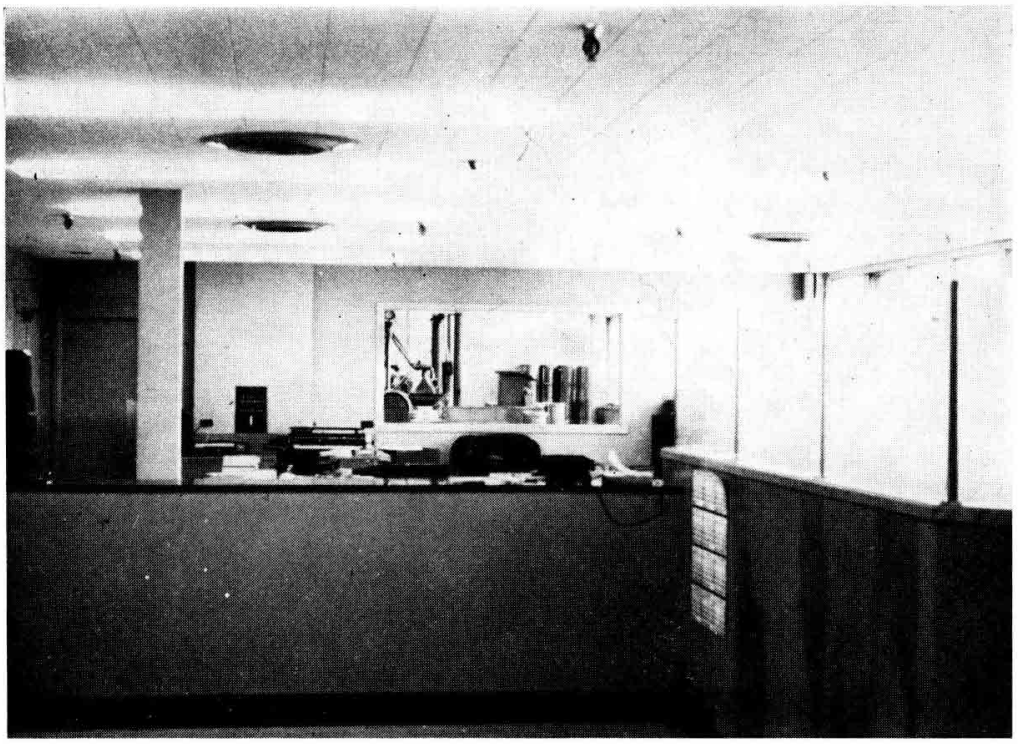

Fig. 26. - Hall de réception des coopérateurs à la "Clover-Crest "(Winnipeg) 

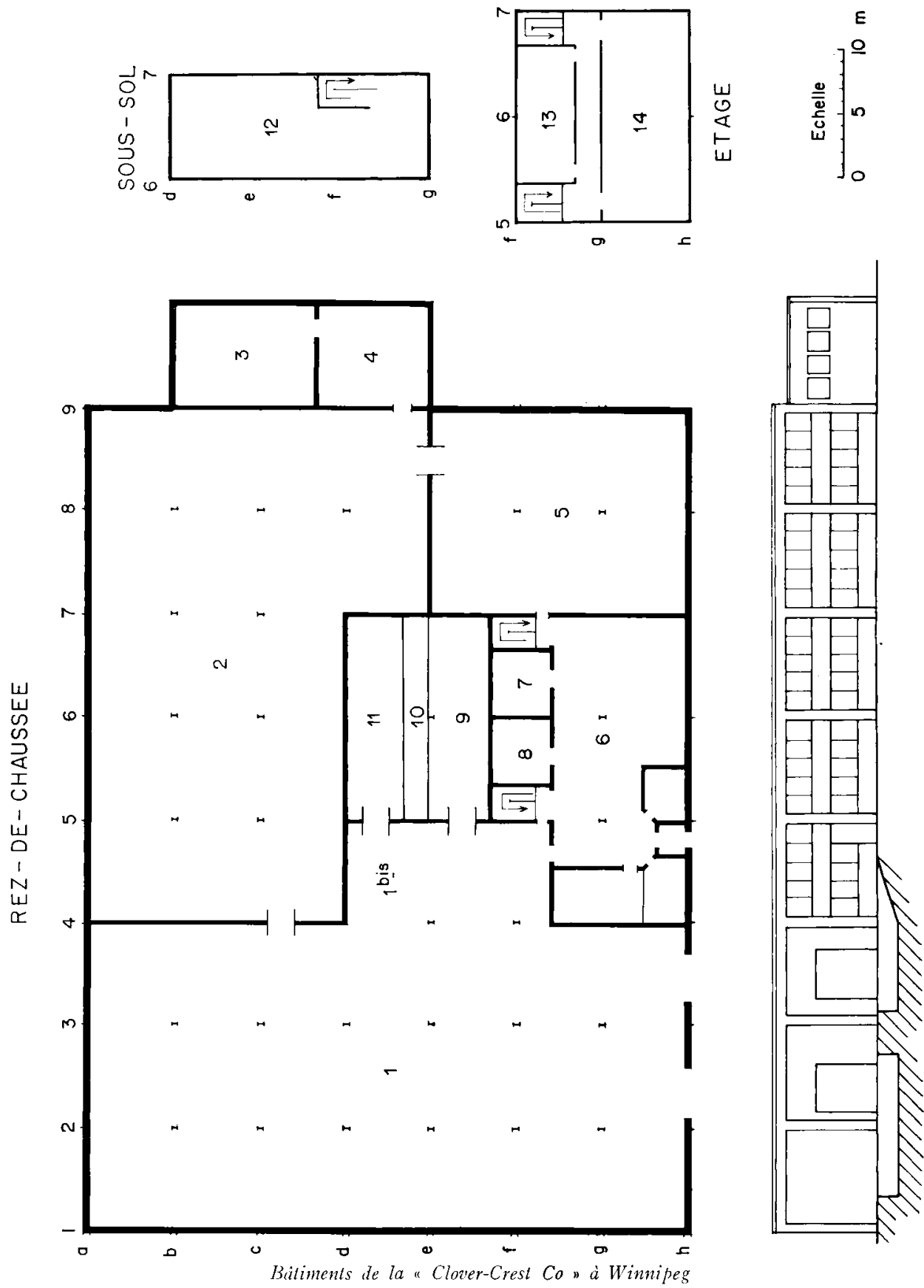

I. - Aire de stockage.

I bis. - Poste de lavage des fûts.

5. - Salle de conditionnement du ro. - Couloir de refonte du miel miel.

2. - Chambre froide.

6. - Bureaux.

3. - Salle de traitement des cires. 7. - Bloc sanitaire.

4. - Chaufferie.

8. - Laboratoire.

9 et 1 I. - Pré-chauffage. cristallisé.

I2. - Réception du miel fondu.

I3. - Bloc sanitaire et vestiaire

I4. - Salle de rúunion. 
b) Rez-de-chaussée. - Il comprend le stockage (40 $\times 2 \mathrm{I} \mathrm{m})$, la chambre froide $(38 \times$ I $8 \mathrm{~m})$, la chambre de fonte $(\mathrm{I} 5 \times$ Io $\mathrm{m})$, les bureaux $(2 \mathrm{I} \times$ Io $\mathrm{m})$, le laboratoire $(5 \times 4 \mathrm{~m})$, l'atelier de conditionnement $\left(\mathrm{I} 8 \times \mathrm{x}_{4} \mathrm{~m}\right)$, la chaufferie $(8 \times 7 \mathrm{~m})$, le local de refonte des cires ( $10 \times 7 \mathrm{~m}$ ).

c) Étage. - Il ne couvre qu'une partie de la surface du bâtiment. Il comprend une salle de réunion ( $5 \times 6 \mathrm{~m}$ ), un bloc sanitaire (Io $\times 4 \mathrm{~m}$ ) et un local de stockage des emballages $\left(22 \times I_{5} \mathrm{~m}\right)$.

Le diagramme de fonctionnement ci-dessous résume les différentes opérations portant sur le miel. Il ne nécessite aucun commentaire, tous les appareils et toutes les opérations ayant été décrits antérieurement. Les produits fabriqués sont le miel liquide et le miel-crème.

\section{Aspect juridique.}

La "Clover Crest" est un organisme ouvert à tous les apiculteurs et dont les statuts correspondent à ceux des Coopératives françaises. Chaque part sociale de $20 \$$ correspond à une livraison de 2 ooo livres de miel par an. Ces parts sociales ne portent pas d'intérêt. Pendant les 5 premières années, les coopérateurs ne sont pas tenus de livrer la totalité de leur miel à la Coopérative ; celle-ci conditionne et commercialise les quantités qui lui sont confiées par les apiculteurs. En fin d'exercice, les profits sont répartis proportionnellement aux livraisons de chaque coopérateur.

\section{La collecte du miel.}

Ia coopérative fournit les emballages aux coopérateurs et assure le ramassage du miel par des transporteurs privés. Les emballages sont consignés. Pour la campagne I962-63, le miel était payé environ I4 cents la livre à la production (environ $\mathrm{I}, 44 \mathrm{~F}$ le $\mathrm{kg}$ ). L,es coopérateurs reçoivent un accompte de 4 conts par livre à la livraison. Le complément est versé au fur et à mesure des possibilités de la trésorerie de la coopérative. Une retenue de 2 cents par livre pendant 5 ans permet d'alimenter un fond de roulement.

Le prix du miel à la production subit des abattements suivant le taux d'humidité et suivant la coloration :

- Humidité : si le taux est inférieur à I7,I p. I00, pas d'abattement. De I7,I à 18,7 p. Ioo, I/4 de cent d'abattement par livre.

\section{- Couleur: (mesurée au Pfund grader) :}

De o à I3, pas d'abattement.

De I4 à $30, \mathrm{I} / 2$ cent d'abattement par livre.

De 3 I à 47 , I cent d'abattement par livre.

Au-delà de 47 , I I/2 cent d'abattement par livre.

Iin outre, I/ 2 cent à I cent de pénalité est prévue pour les miels malpropres, chauffés de façon excessive, ou contenant un excès d'air. La Coopérative peut refuser purement et simplement les miels de mauvaise qualité.

\section{Personnel.}

Le personnel comprend environ 25 personnes soit : un directeur, un directeur adjoint, une secrétaire de direction, trois secrétaires, un contremaître, un chef de quai, un mécanicien, un laborantin, 4 à 6 ouvriers temporaires, 3 à 8 femmes chargées de 1'emballage. 
Aspect économique.

Les documents qui nous ont été aimablement communiqués nous permettent de présenter comme suit l'activité économique de la "Clover Crest " (en dollars et cents).

Montant des investissements :

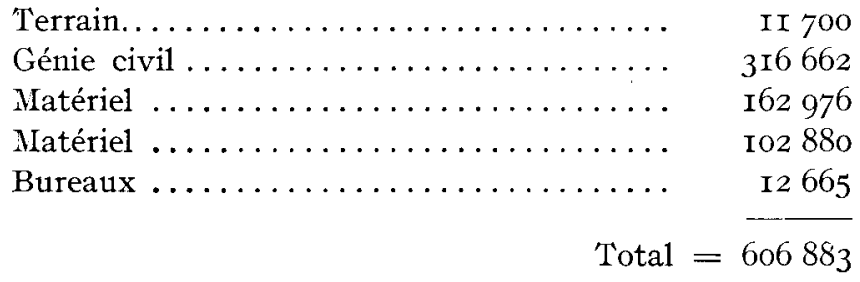

Financement : entièrement assuré par la Coopérative par emprunt à 5,25 p. Ioo. Essai de bilan annuel :

Amortissement des emprunts $(606883 \times 0,082)$ 48000

Renouvellement et entretien :

- Bâtiments (3I6 $662 \times 0,02)$

- Matériel (262000 $\times 0,05)$

$\left.\begin{array}{r}6300 \\ \text { I3 } 100\end{array}\right\}$ I9 400

Personnel (Estimation pour 25 personnes)

80000

Charges par livre (pour 5 ooo livres par an).

Amortissement........... I cent soit 0 , ro $F / \mathrm{kg}$

Renouvellement du matériel ...... 0,40 soit $0,04 \mathrm{~F} / \mathrm{kg}$

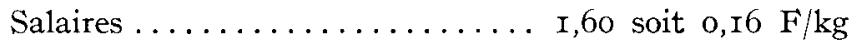

Emballages............. 3,25 soit $0,32 \mathrm{~F} / \mathrm{kg}$

Frais proportionnels........ 0,75 soit $0,07 \mathrm{~F} / \mathrm{kg}$

$$
\text { Total }=7,00 \text { cents soit } 0,69 \mathrm{~F} / \mathrm{kg}
$$

Prix de vente du miel: 2 I cents la livre.

Prix d'achat au coopérateur : I4 cents la livre.

Marge : $2 \mathbf{I}-\mathrm{I}_{4}=7$ cents la livre.

Les frais ressortent donc à $3^{\circ} \mathrm{p}$. Ioo du prix de vente et à $50 \mathrm{p}$. Ioo du prix payé à l'apiculteur.

\section{Conclusion}

La “Clover Crest " est une entreprise bien équipée, parfois même d'une façon un peu somptuaire. Sur le plan de la fabrication du miel-crème en particulier, elle présente le matériel le plus moderne et le mieux adapté pour une usine d'un tel format. La distribution logique des bâtiments, 1'organisation rationnelle des circuits, constituent des éléments intéressants dont on pourrait s'inspirer avec profit dans l'étude d'un projet sur le plan français. 


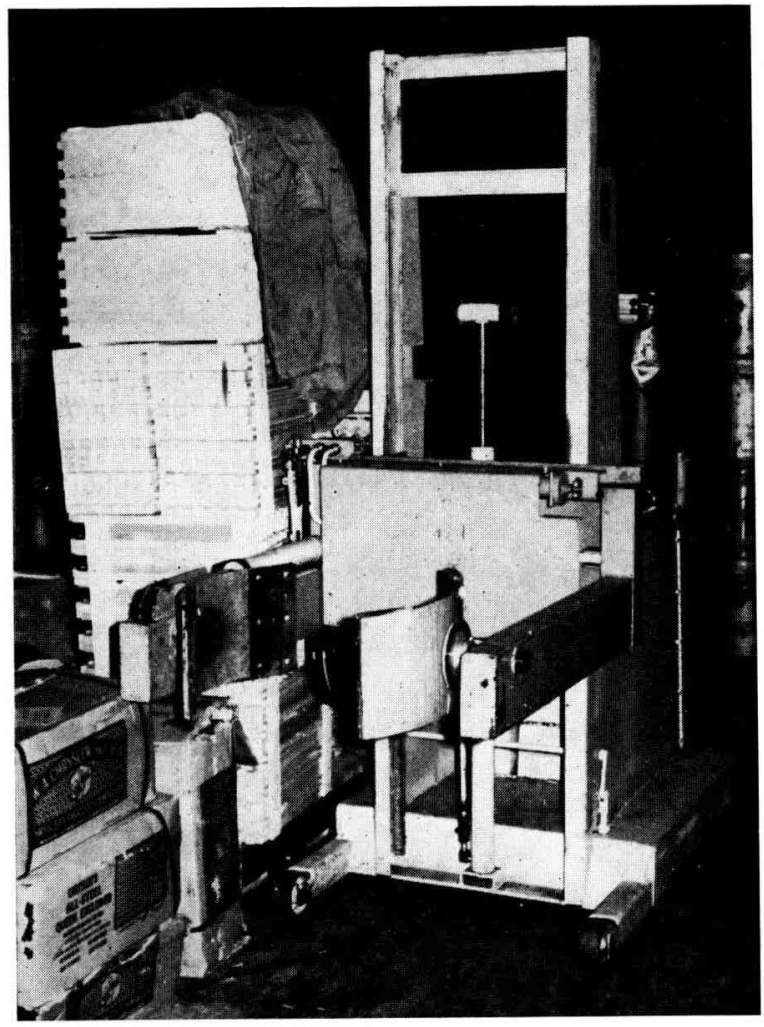

FIG. 27. - Manulention micanique des füts de mill de $300 \mathrm{~kg}$ "Cloner Crest"

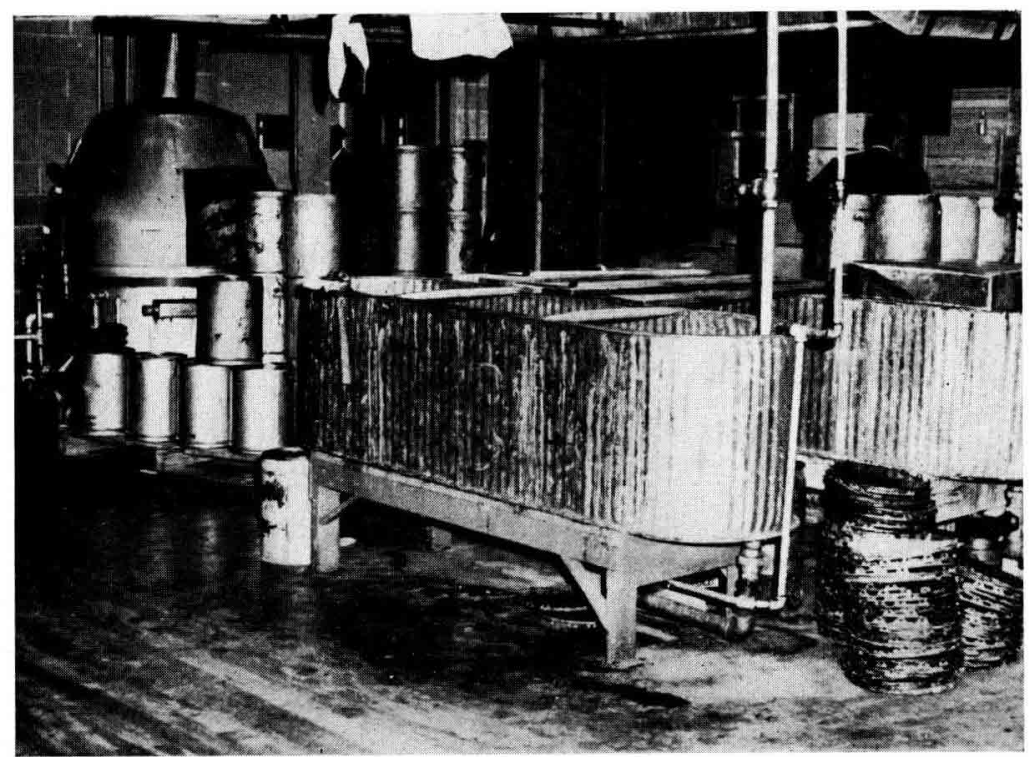

FIri. 28. -..- Poste de lavage des futs a miel it le "Clover Crest" 
Iiagramme

Réception (Miel brut)

Pesce

l'rólivement d'échantilloms

Stockage d'attente

Constitution des lots

Fonte

Melange

Préfiltration

Pastenrisation

Filtration

Refroidissement

Miel liquide $\left\{\begin{array}{l}\text { Embouteillage } \\ \text { Stockage } \\ \text { Pesage expédition }\end{array}\right.$ Misc en pression
Scmence broyagre
Mélange refroidis-

Micl-crime

$\mid \begin{aligned} & \text { Injection } \\ & \text { Refroidissement } \\ & \text { secondaire }\end{aligned}$

Mise en pots

Stockage

Expédition
Quai à hauteur variable. Tendance à l'emballage en fûts de $300 \mathrm{~kg}$.

Bascule automatique. Enregistreuse "Toledo".

Détermination au laboratoire du clegré d'humidité et de la coloration.

Gerbaune cles fûts sur 5 niveaux. Densité de stockagge : $3 \mathrm{t}$ au $\mathrm{m}^{2}$ brut.

Choix des miels en fonction des résultats des analyses, en vue d'obtenir un produit final moyen (coloration et teneur en eau).

Chambre de fonte. (apacité : 15 tomes par jour; température $75^{\circ} \mathrm{C}$.

Au sous-sol : ' ${ }^{4}$ cuves mélangeuses, 3 de 4 tomnes, 1 de 7 tonnes. Tenpérature $\$ 30 \mathrm{C}$. Iompe de reprise $2000 \mathrm{l} / \mathrm{h}$. P'ression $=6 \mathrm{~kg} / \mathrm{cm}^{2}$.

Filtre "Siparkler".

Pasteurisateur A.P.V. Température à $77^{\circ}$. Débit : $20001 / \mathrm{h}$.

2 filtres célite fonctiomant alternativement. I'réparation des filtres par circulation de niel chargé en célite.

Température ${ }^{\prime} 0^{\circ}$. I.e miel est dirigé soit vers un bac tampon pour embouteillage liquide, soit vers un bac tampon de reprise pour la fabrication du micl-crime.

Chaine d'embouteillage sous bar tampon. Pots verre.

Chambre froide $\left(+8^{\circ}+15^{\circ}\right)$.

Quai.

Reprise par pompe à engrenage du bac tampon, vers un échangeur nólangeur.

Broyeur à palette.

Échangeur mélangeur. Refroidissement par eau froide jusqu'à $28^{\circ} \mathrm{C}$

Ponjuarge du bas. Tampon vers l'échangeur. Pompe à engrenage.

Échangeur "Votator ". Refroidissement par eau glacée jusqu'à 150; le miel est dirigé vers un bac tampon.

A partir du bac tampon placé alı-clessus de la chaîne.

Chambre froide $\left(+8^{\circ}+15^{\circ}\right)$.

Quai.

\section{III. - LA COMMERCIALISATION DES MIELS}

\section{A. - LES CIRCUITS COMMERCIAUX}

Les circuits commerciaux sont de quatre types plus ou moins complexes. Nous distinguerons :

\section{I) Le circuit court.}

C'est la vente directe de l'apiculteur au consommateur. Ce type de vente, loin d'avoir disparu aux U. S.A., s'est transformé et modernisé depuis un certain nonıbre 


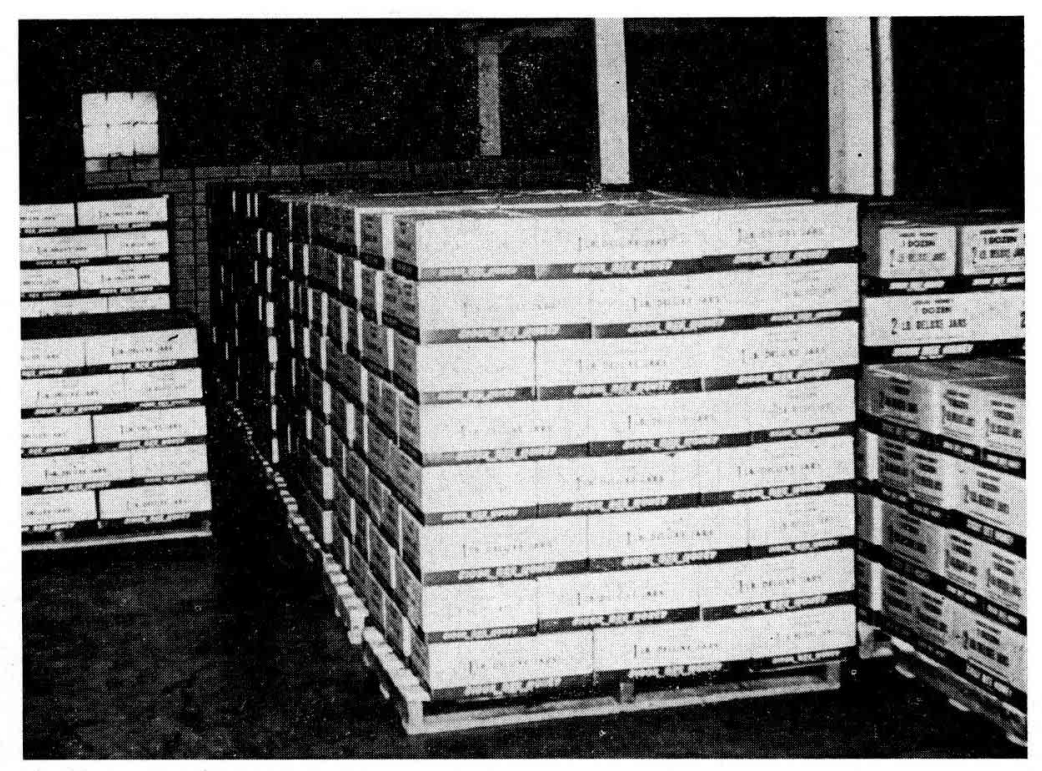

FIr. 29. - Stockage du miel conditionné à la Coopérative "Sioux-Bee"

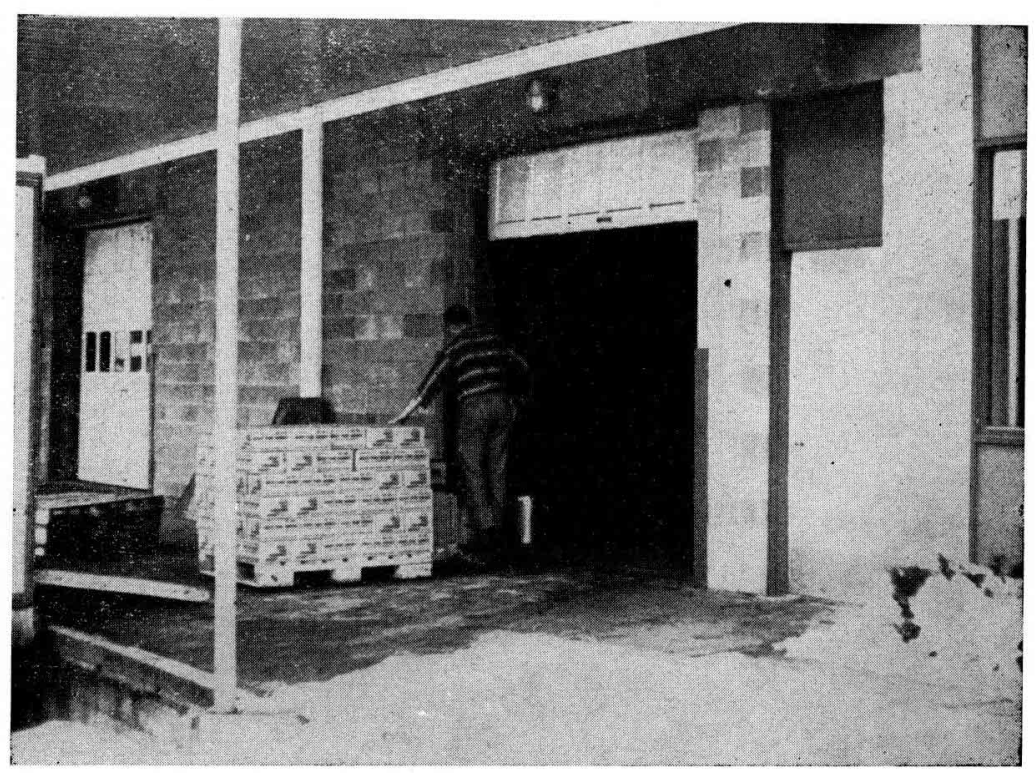

Fic. zo. - Le quai d'expédition à la "Sioux-Bee" 
d'années. Beaucoup d'apiculteurs installés à proximité de sites touristiques écoulent une partie importante de leur récolte dans des chalets de vente et de dégustation dont la présentation est particulièrement soignée. C'est ainsi qu'un apiculteur de la région de Saint-Paul-Minneapolis vend ro tonnes de miel chaque année au bord de la route. Très souvent, le chalet de vente est laissé sans surveillance directe; les clients de passage se servent et déposent la monnaie dans la caisse. Il résulte de ce système une économie de main-d'œuvre appréciable.

Lorsqu'un apiculteur est membre d'une coopérative, un arrangement intervient avec celle-ci pour que la vente en bordure de route reste possible. On considère d'ailleurs que ces ventes constituent une excellente publicité.

\section{2) Le circuit moyen.}

L'apiculteur lui-même conditionne son miel et vend directement à des grossistes ou à des détaillants. Cette formule est assez courante, surtout chez les apiculteurs professionnels importants qui vendent à une clientèle locale.

\section{3) Le circuit long.}

L'apiculteur vend son miel en gros à une entreprise qui le conditionne. Le miel passe ensuite par le grossiste et le détaillant. Cette formule présente pour le producteur l'avantage de ne nécessiter aucun investissement en matière de conditionnement mais elle le prive incontestablement d'une part appréciable de ses revenus.

\section{4) Le circuit coopératif.}

Ce circuit est le même que le précédent mais l'organisme qui conditionne le miel est une coopérative de producteurs. Ce système laisse généralement un profit supérieur à l'apiculteur, moyennant d'ailleurs quelques sacrifices au moment oì s'établit la coopérative. Le circuit coopératif intéresse 33 p. Ioo de la production de miel des U. S. A. et 50 p. Ioo de la production canadienne.

Les trois derniers types de circuits commerciaux utilisent presque toujours pour la vente un système de représentants et, plus particulièrement, de voyageurs-représentants à cartes multiples. Leurs commissions sont de 5 à 7,5 p. Ioo selon que les affaires traitées concernent le commerce de gros ou de détail. Il n'existe d'exception que pour les affaires traitées directement avec les chaînes de magasins à succursales multiples, les supermarchés, etc. Ces affaires donnent lieu souvent à des arrangements entre les représentants et les directeurs d'entreprises privées ou de Coopératives.

Aux États-Unis, certains centres sont devenus particulièrement actifs et importants pour la vente du miel. Ce sont, par ordre d'importance, Los Angeles, New York, Chicago, Kansas-City, Cleveland, Portland, Detroit, Philadelphie et Pittsburgh.

\section{B. - LE CONSOMMATEUR}

On sait que le consommateur américain recherche volontiers les produits standardisés et qu'il attache une asse z grande importance à la présentation des produits alimentaires. Par ailleurs, il est très préoccupé par des questions d'hygiène. On comprendra donc aisément que les efforts accomplis au cours des dernières décades 


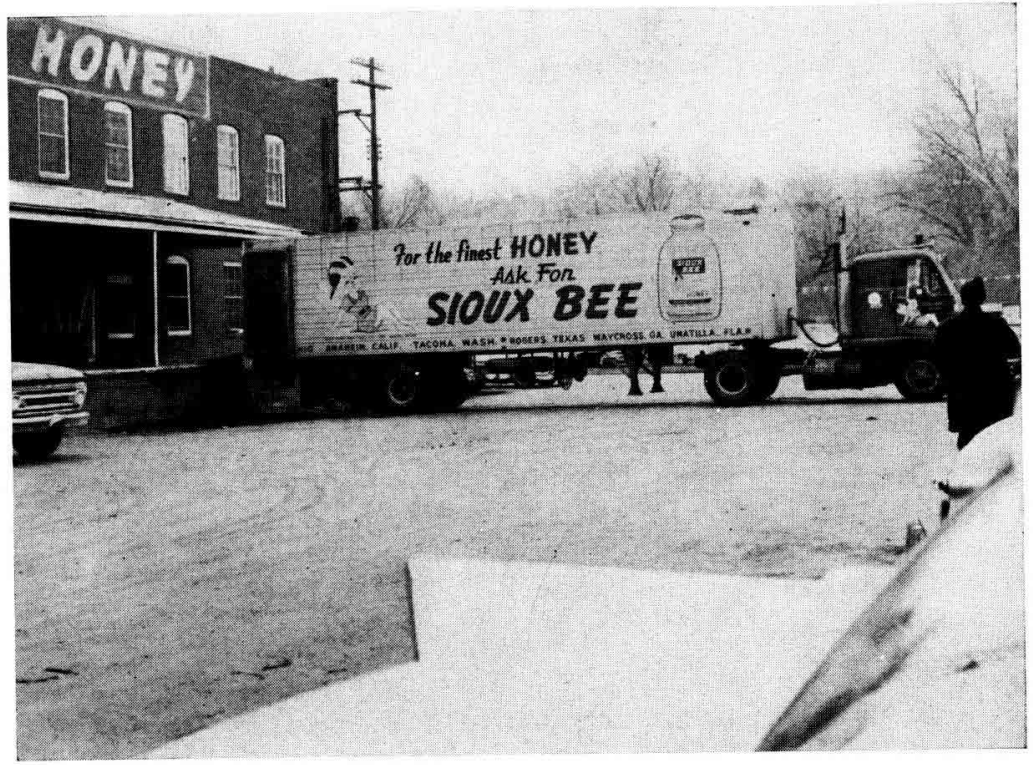

FIG. 3r. - Un camion de livraison de la "Sioux-Bee". on remarquera l'utilisation publicitaire du camion par la Coopérative

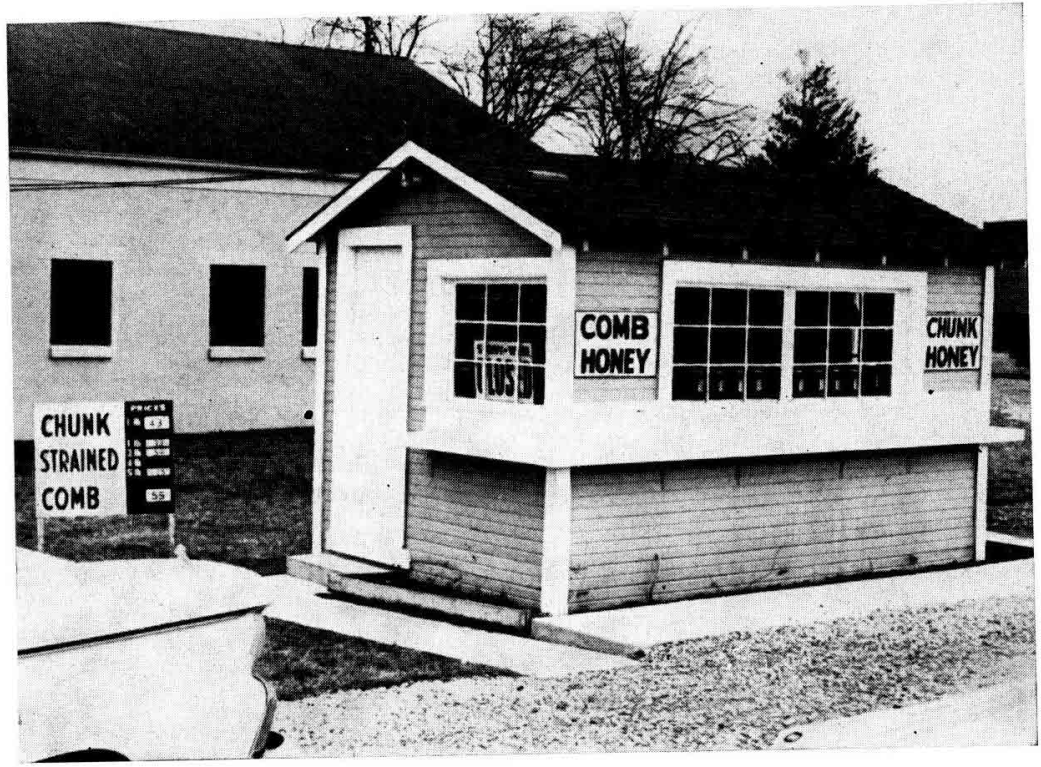

FIG. 32. - Stand de vente du miel en bordure de route. (Établissements Dunham à London, Ohio) 
aient porté sur la préparation de miels, non seulement propres mais pasteurisés, filtrés et conditionnés dans des emballages de plus en plus attrayants. Malgré tout, le miel reste dans l'esprit du consommateur nord-américain un produit sucrant ordinaire ; son prix est d'ailleurs comparable à celui d'un sucre de luxe. Seul un changement de mentalité, qui d'ailleurs s'opère actuellement et qui oriente une partie du public vers les magasins de vente de produits diététiques, pourra modifier la position du miel sur le marché des produits alimentaires en Amérique.

\section{C. - LES EMBALLAGES}

Les emballages constituent un élément important de la vente. C'est pourquoi nous avons trouvé dans les emballages, aux U. S. A. comme au Canada, une grande variété de formes et de matériaux.

Le verre reste le matériau le plus employé. Il représente 80 p. Ioo des emballages utilisés. Les récipients présentent des formes très variées : bouteilles plates et ovales, vases cylindriques ou parallélépipédiques, sans compter les formes originales qui sont la propriété des diverses firmes. Les capacités courantes sont de 8 onces, I livre, 2 livres et 4 livres soit $226 \mathrm{~g}, 453 \mathrm{~g}, 907 \mathrm{~g}$, I $8 \mathrm{I} 5 \mathrm{~g}$.

Les pots de matière plastique opaque de forme tronconique et de contenances variées sont plus courants au Canada qu'aux U. S. A. Les seaux métalliques de $2,5^{-5}$ Io livres sont plus rares.

Depuis quelques années, on utilise des emballages de fantaisie en matière plastique translucide et souple épousant la forme d'animaux ou de personnages variés. I1 existe également des emballages plus onéreux fonctionnant comme distributeurs.

Chaque industriel s'efforce d'apporter dans la présentation du miel le maximum de variété et d'agrément. Notons encore une présentation inconnue en France : un morceau de rayon est placé au centre d'un pot de verre au milieu de miel limpide. Dans d'autres cas, c'est une fleur en matière plastique qui est enrobée dans le miel et qui évoque son origine florale.

\section{D. - LA PUBIICITÉ}

Dans l'ensemble, les apiculteurs américains sont inquiets quant à l'avenir de leur production, Le public ne paraît guère favorable à une augmentation importante de la consommation du miel, ceci en dépit d'un effort publicitaire qui n'est certes pas négligeable mais qui reste sans doute insuffisant compte tenu de l'immensité du marché. Cet effort se traduit par des expositions des produits de l'apiculture. A l'occasion de ces manifestations régionales, on procède à l'élection d'une "Reine du miel " (Honey queen), jeune personne choisie pour son esthétique et que l'on charge d'informer les visiteurs sur la valeur alimentaire du miel et sur ses utilisations culinaires. La campagne publicitaire est appuyée par la presse, la radio et la télévision.

Les frais de publicité sont couverts par le Comité de 1'Industrie du Miel qui établit un programme annuel de propagande. Il existe par ailleurs depuis I928, une organisation sans caractère commercial, l'Institut du Miel, dont la principale activité est de faire connaître les informations intéressantes sur le Miel. Cet Institut 
travaille en liaison avec la radio et la télévision et il met également à la disposition des apiculteurs à des prix très modiques tout un matériel de propagande et de publicité.

Bien entendu, cette publicité collective n'exclut pas la publicité particulière des différentes firmes.

\section{E. - LES PRIX DU MIEL}

Comparativement aux prix européens, les prix américains paraissent très bas. Voyons ce qu'il en est exactement.

Prix de gros.

En mars I 960 , les prix variaient entre I I et $\mathrm{I} 5$ cents la livre ( $\mathrm{I}, 22$ à $\mathrm{I}, 60 \mathrm{~F}$ le $\mathrm{kg}$ ). Les Coopératives avaient réglé les apports de leurs adhérents en moyenne sur la base de 13 cents. Ces prix s'entendent pour des marchandises nues mais en général rendues. Le miel conditionné atteint chez le grossiste 25 à 28 cents la livre. Il passe chez le détaillant à 25 ou 30 cents. La marge est faible mais il faut tenir compte des quantités traitées qui sont souvent considérables.

Prix de détail.

La plupart des miels sont vendus 33 à 45 cents la livre au consommateur aussi bien dans les magasins de détail que chez l'apiculteur. Cependant, certains miels atteignent un prix plus élevé tels le miel de Tupelo ( $N y s s a$ sp.) en provenance de Virginie et qui se vend I $\$$ la livre à New York. D'une façon générale, les prix sont d'ailleurs beaucoup plus élevés à New York où ils arrivent parfois au double de ce qu'ils sont habituellement dans le reste du pays. Un même miel de Trèfle peut être vendu à New York 35 ou 53 cents la livre. Certains magasins d'alimentation ont un grand choix; des magasins spécialisés présentent des miels d'importation de tous les pays du monde. Nous avons visité un commerce new-yorkais présentant 46 variétés de miel différentes dont 8 en provenance de France et atteignant $2,17 \$$ la livre. En dépit de ces prix très élevés, il faut reconnaître honnêtement que nos miels français, mal présentés et à cristallisation défectueuse, font piètre figure, à quelques rares exceptions près, à côté des miels américains.

\section{F. - LES VARIATIONS DE LA CONSOMMATION}

Malgré les quelques efforts publicitaires, l'utilisation d'emballages attrayants et modernes, la grande pureté, le haut standard des produits présentés au consommateur, la consommation du miel n'a pas augmenté aux États-Unis comme l'indiquent clairement les statistiques officielles. Ces mêmes statistiques soulignent qu'elle est restée régionale. L'Ouest du pays consomme beaucoup plus de miel que l'Est (Wyoming 6,3 livres par habitant, Massachusetts I livre). Sauf en ce qui concerne la Californie, elle est restée très saisonnière dans tout le pays où les deux tiers des ventes de détail s'opèrent pendant les 5 mois les plus froids de l'année. Le miel ne semble donc pas être devenu un produit de consommation courante. 
On enregistre, cependant, une augmentation continue des ventes de miel-crème ou miel à tartiner. Elles augmentent chaque année d'un petit pourcentage et constituent déjà, pour bien des établissements, environ ro p. Ioo du total des ventes.

En conclusion de ce bref aperçu sur la commercialisation du miel en Amérique du Nord, on peut dire que, comme presque tous les produits agricoles, le miel connaît des difficultés. La régularité relative de la production, les hauts rendements à la ruche, la mécanisation et l'organisation rationnelle de la production, l'existence de coopératives puissantes permettent à l'apiculteur de vivre du produit de son activité mais avec une marge bénéficiaire qui est à la limite des possibilités. Seule la politique de soutien des prix agricoles permet encore de subsister à une industrie qui a pourtant en main tous les éléments de la prospérité.

\section{IV. - LE FONCTIONNEMENT ADMINISTRATIF}

\section{DES COOPÉRATIVES APICOLES AU CANADA E'T AUX ÉTATS-UNIS}

La coopérative agricole est une organisation commerciale capitaliste créée par les agriculteurs pour leur bénéfice mutuel. Les coopératives apicoles répondent à cette définition et, que ce soit au Canada, aux États-Unis ou en France, leur but est d'accroître l'efficience du producteur, de diminuer les frais de commercialisation et de distribution en même temps que d'élargir les débouchés. En mettant en commun dans une telle organisation leur pouvoir commercial, les producteurs bénéficient à la longue d'un débouché régulier pour leur miel. Par ailleurs, dotée de moyens modernes de conditionnement, la coopérative garantit au producteur une présentation de ses produits compétitive sur tous les marchés. Cependant, les coopératives ne peuvent ni contrôler les prix, ni obtenir un prix très supérieur aux prix moyens du marché; elles ne peuvent pas non plus garantir que les frais de production seront couverts, ni éliminer les intermédiaires. Enfin, elles ne sont pas en mesure, comme le disent les Américains, de "faire de l'argent " pour les producteurs de miel de basse qualité.

Voyons maintenant comment, sur le plan pratique, fonctionnent les coopératives apicoles américaines, ce que sont leurs statuts et comment sont réglés les différents problèmes administratifs.

\section{Statuts.}

I1 n'existe pas aux États-Unis de statut fédéral des coopératives agricoles. Cependant, les coopératives tombent pour leur contrôle, donc pour leur création, sous le coup de certaines lois, telles que la loi sur les marchés agricoles et en particulier le Copper Volstead Act passé en I922 et qui autorise les associations de producteurs de denrées agricoles. Les trois règles principales édictées par cet acte sont :

$\left.I^{0}\right)$ qu'aucun membre de l'association n'ait droit à plus d'un vote, quel que soit le nombre des parts de capital qu'il possède ;

$\left.2^{\circ}\right)$ que l'association ne paie en aucun cas des dividendes supérieurs à 8 p. Ioo par an sur le capital ou le capital social ; 
$\left.3^{\circ}\right)$ que l'association ne commercialise en aucun cas les produits de producteurs non membres pour une somme supérieure à celle provenant de la commercialisation des produits de ses propres membres.

Par ailleurs, les coopératives sont soumises à toutes les lois concernant la commercialisation des produits agricoles et, dans le cas où elles s'engageraient dans des actions de concurrence déloyale, à la juridiction de la Commission Fédérale de Commerce. Elles fonctionnent souvent avec des statuts particuliers aux divers États mais, la plupart du temps, elles doivent rendre compte de leur activité à un fonctionnaire de 1'État.

\section{Règlements intérieurs.}

Les lois générales régissant les coopératives étant très incomplètes, il s'ensuit que ces dernières édictent des règlements intérieurs longs et précis et qui couvrent tous les aspects de leur fonctionnement. Nous n'avons pas l'intention de détailler l'ensemble de ces dispositions mais simplement d'énumérer celles qui sont prises d'une façon générale. Nous reprenđrons celles qui nous ont paru les plus intéressantes.

Dans la plupart des cas, les règlements intérieurs traitent successivement des sujets suivants :

Le nom de la coopérative.

Liobjet.

Le sceatr.

L'adhésion des membres.

Les administrateurs.

Les pouvoirs des administrateurs.

Les devoirs des administrateurs.

Le directeur commercial (manager).

Les devoirs du président.

Les devoirs du secrétaire-trésorier.

Les votes.

Les commissaires aux comptes.

Le capital.

L'année fiscale.

Les assemblées.

Les obligations contractuelles (apports et règlements).

I,es modifications du règlement intérieur.

Nous examinerons plus particulièrement :

l'adhésion des membres, le manager, le capital, les obligations contractuelles.

\section{L'adhésion des membres.}

Dans la plupart des coopératives que nous avons visitées, tout apiculteur peut devenir membre dela coopérative par souscription d'une ou plusieurs parts de capital. Le conseil des directeurs accepte ou refuse les demandes d'adhésion. Sa décision est sans appel.

Chaque membre possède une part de capital social au moins et au plus un nombre bien déterminé. En général, la valeur nominale de ces parts est peu élevée 
(5 dollars à la Finger Lake, $25 \$$ à la Coopérative de 1'Ontario). Le peu d'importance de ces parts permet des transferts faciles et rapides (ex. : Coopérative de l'Ontario : 824 membres en $1922 ; 300$ membres en I963).

\section{Le Directeur commercial (manager).}

Le Conseil de direction des Coopératives emploie toujours un directeur commercial appointé. Celui-ci a la charge de toutes les affaires de la coopérative. Il a la garde de tous les bâtiments et de tout ce qu'ils contiennent; il en est responsable. Il doit chaque année, en liaison avec le secrétaire-trésorier, présenter un inventaire de tous les biens de la Coopérative. Il remet au trésorier toutes les sommes d'argent qu'il a reçues pour le compte de la Coopérative. Il est la clef de voûte de l'édifice. Sur ses capacités commerciales et sa valeur humaine, repose le succès de l'entreprise. En fait, il est non seulement à la tête de la partie commerciale mais il est en rapport constant avec les membres.

\section{Le capital.}

Les Américains ont eu à cour de résoudre le problème du capital social ou plus simplement du capital dans leurs coopératives. Nous avons indiqué plus haut l'une des formules utilisée, celle de la part sociale ou common stock. Flle ne l'est cependant qu'avec beaucoup de restrictions puisque les coopératives que nous avons visitées ne la considèrent guère que comme une formule purement administrative sanctionnant l'adhésion d'un nouveau membre. Parfois cette souscription n'existe même pas.

En fait, le problème de la constitution du capital de la coopérative de telle sorte que le capital fourni par chaque membre soit en relation directe avec ses apports et lui soit en définitive rendu, semble avoir été résolu au mieux par le revolving Fund Plan of Financing c'est-à-dire le plan de financement par fond tournant. Ce système a l'avantage d'éviter les inégalités et les dissentiments entre coopérateurs et souvent entre générations de coopérateurs.

Dans les coopératives apiccles visitées, ce capital tournant est constitué de la manière suivante. La coopérative effectue sur la valeur des apports de miel une retenue de $15 \mathrm{p}$. Ioo, maximum. Cette retenue est sanctionnée par l'émission d'un certificat de retenue, souvent négociable, portant intérêt à 6 p. Ioo maximum. Elle est effective sur une période de 6 ans et de io ans au maximum. Le remboursement des premières sommes retenues intervient dès que le capital nécessaire est atteint. On assiste alors à un renouvellement continuel du capital. Pour mieux fixer les idées, nous citerons le bilan (I962) de la "Sioux Bee ":

Parts sociales : I6 I25 \$.

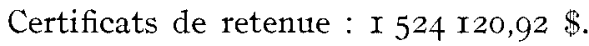

Les retenues représentent donc environ cent fois la valeur des sommes souscrites en parts sociales.

Ce système fonctionne à la satisfaction de tous et assure une juste répartition des charges d'investissements. Les remboursements sont chronologiques. Nous n'avons pas trouvé de coopératives employant le système du preferred stock qui peut également se transformer en capital tournant. Nous n'avons pas rencontré non plus le système du non stock. 
Pour les aider dans leur financement, les Coopératives ont à leur service depuis la passation du Credit Act en I933, I2 banques régionales et une banque centrale qui leur sont destinées.

\section{Les obligations contractuelles.}

Nous avons réuni, sous ce titre, les différentes dispositions qui lient les Coopérateurs à la Coopérative dans le processus des apports et de leur règlement. Ces dispositions peuvent être contenues dans deux documents différents ou bien elles font partie intégrante du règlement intérieur, ou bien elles sont exposées dans un Marketting Agreement signé par la coopérative et le producteur, valable un an, reconductible ou dénonçable dans des conditions prévues. Cette deuxième formule est adoptée par les coopératives qui exigent des apports totaux (iix. : "Sioux Bee," encore qu'il faille introduire des correctifs à la notion d'apport total puisqu'en fait la politique de la "Sioux Bee» est très souple à ce sujet et qu'elle peut permettre la vente au détail par l'apiculteur dans sa localité et même l'approvisionnement de l'épicerie voisine).

Dans la plupart des cas, et sans aucune mesure de rétorsion, les coopérateurs restent fidèles à leur coopérative.

Les apports sont soumis à des règles en ce qui concerne l'époque de la livraison, la qualité et les emballages. Ceux-ci sont presque toujours la propriété de la coopérative et, dans tous les cas, d'un type parfaitement déterminé.

Le règlement des apports se fait par le jeu des avances avec un règlement final intervenant presque toujours avant la campagne suivante. Le montant du premier règlement n'est jamais inférieur à $60 \mathrm{p}$. roo de la valeur marchande des apports (certaines coopératives telle que la "Sioux Bee" payent en deux fois seulement).

Chaque année, les coopératives peuvent prélever sur les comptes des coopérateurs les sommes d'argent nécessaires au financement de leur " capital tournant ". Il arrive que cet emprunt ne porte pas intérêt (Coopérative de 1'Ontario). Les sommes empruntées sont restituées aux coopérateurs selon des règlements propres à chaque Coopérative mais toujours en tenant compte de la chronologie des emprunts.

Parallèlement aux apports des coopérateurs, rappelons que les coopératives peuvent, aux États-Unis, acheter à des non membres des marchandises pour une valeur égale à celle des apports des coopérateurs. Il est rare que ces achats atteignent une telle ampleur. Cependant les coopératives font appel à cette possibilité pour équilibrer la vente de certaines qualités et c'est ainsi que nous notons dans le rapport annuel de la "Sioux Bee " pour I962 que sur un total de 4 I 353 ooo livres de miel la coopérative en avait acheté I 509 ooo livres à des non-membres.

\section{V. - LES SERVICES DE RECHERCHES}

Il est banal de constater que la technologie du miel est une science à peu près exclusivement américaine. Alors que les chimistes allemands et suisses du $\mathrm{xIx}^{\mathrm{e}}$ et du début du $\mathrm{xx}^{\mathbf{e}}$ siècle ont mis au point la plupart des méthodes d'analyse du miel et de recherche des fraudes, on ne connaît pour ainsi dire aucun travail européen ancien sur les méthodes de préparation et de conservation du miel. Cela provient sans doute du fait que les pays d'Europe centrale, qui se sont de tout temps distin- 
gués par l'importance et la valeur de leurs recherches sur l'abeille, sont des pays de petits producteurs n'ayant à écouler, chaque année, qu'une récolte minime ne posant pas de bien grands problèmes technologiques. L'Amérique, au contraire, possède beaucoup de très gros producteurs et une véritable industrie du miel qui s'intéresse vivement à tous les problèmes de conditionnement et de conservation. D'autre part, les habitudes alimentaires de l'Américain moyen. les lois qui le protègent contre les produits malsains ou pollués, ont constitué des éléments favorables à des études poussées dans le domaine de la technologie du miel, science que 1'Europe commence à peine à découvrir.

Au cours de notre voyage, nous avons visité trois laboratoires dont deux au moins ont contribué de façon décisive à faire évoluer les techniques dans le sens qu'elles suivent actuellement. Au Canada, le laboratoire d'apiculture du Collège agricole de 1'Ontario, situé à Guelph est à l'origine des procédés de pasteurisation et d'épuration des miels actuellement appliqués d'une façon générale dans tout le pays. Sous la direction du Pr TowNSEND, ce laboratoire a, en particulier, mis au point tout un matériel industriel ou semi-industriel qui a fait ses preuves. Nous ne reviendrons pas sur cette question qui a été traitée abondamment aussi bien dans cette revue que dans la Revue trançaise d'A piculture.

Aux E.tats Unis, nous avons visité le laboratoire apicole de l'Université Cornell à Ithaca où le Pr DycE continue ses recherches sur le miel. Son nom est attaché au procédé bien connı qui permet de contrôler la recristallisation des miels pour préparer le miel-crème. Ce procédé est trop connu pour que nous en reprenions la description.

Avec ces deux laboratoires, celui de Guelph et celui d'Ithaca, nous avons un exemple magnifique de collaboration des chercheurs avec la profession pour laquelle ils travaillent. On ne sait d'ailleurs pas qui l'on doit féliciter le plus de cette réussite, des chercheurs qui ont su résoudre les problèmes ou des apiculteurs qui ont eu confiance en la science et qui ont suivi les conseils reçus.

Dans un tout autre domaine, le laboratoire du pr HAYDAK à Saint-PaulMinneapolis nous a montré ce que sont les services de recherches des universités américaines. Les travaux du $\mathrm{P}^{\mathrm{r}}$ HAYDAK portent surtout sur la nutrition des abeilles et ils ont beaucoup contribué à l'extension de nos connaissances sur la composition des aliments nécessaires à tous les habitants de la ruche. Il est inutile de souligner que ces travaux revêtent une très grande importance pour les apiculteurs.

Nous regrettons que le peu de temps dont nous disposions ne nous ait pas permis de visiter d'autres laboratoires américains, en particulier celui où se poursuivent actuellement de fort intéressantes recherches sur la composition du miel, nous voulons parler du laboratoire de J. W. White à Philadelphie (Pa.) et celui du Dr FARRAR à Madison, Université du Wisconsin, qui s'est spécialisé dans le matériel apicole,

\section{VI. - PERSPECTIVES DE TRANSPOSITION}

\section{AUX CONDITIONS FRANÇAISES}

Au terme d'un voyage qui nous a permis en deux semaines de visiter une dizaine d'installations industrielles de conditionnement $\mathbf{d u}$ miel et trois laboratoires, et de converser avec les personnalités les plus qualifiées dans le domaine apicole tant au 
Canada qu'aux U. S. A., nous devons faire le bilan des connaissances acquises et poser le problème des possibilités de transposition en France des réalisations d'outreAtlantique.

Le problème est complexe et comporte plusieurs aspects, les uns techniques et les autres économiques.

\section{A. - Aspects TECHNIQUES}

Il importe tout d'abord de savoir si les principes généraux mis en application en Amérique pour le conditionnement du miel sont valables pour la France. En admettant qu'ils le soient, en totalité ou partiellement, comment peut-on concevoir, sur le plan des bâtiments et de l'outillage, une coopérative française de conditionnement du miel et quel format doit-on prévoir pour un fonctionnement optimum? C'est à ces questions que nous allons tenter de répondre.

\section{Principes généraux.}

I,es exposés précédents nous ont familiarisés avec les grandes lignes du processus de conditionnement utilisé en Amérique, ce qui nous permettra de ne pas y revenir. I1 semble superflu par ailleurs d'examiner la valeur intrinsèque des opérations de pesée et de contrôle de la qualité des miels livrés. On ne peut concevoir une coopérative moderne digne de ce qualificatif sans un système de prélèvement d'échantillon et d'analyse, au moins sommaire.

Les opérations de refonte du miel cristallisé, qui sont absolument inéluctables pour une Coopérative qui veut travailler toute l'année, nous semblent avoir été étudiées avec tout le soin voulu par les Américains. Le principe de l'écoulement progressif des miels au sortir des chambres de refonte est le seul qui garantisse le produit contre un chauffage excessif et prolongé. L'utilisation de vastes cuves mélangeuses pour la préparation de véritables cuvées de miel, parfaitement homogènes, bien contrôlées à tous les points de vue, constitue un facteur indéniable d'amélioration de la qualité. Nous ne relèverons non plus aucune objection contre toutes les opérations de pompage, de mise en pots, ni même de préparation du miel-crème. Restent deux points très importants sur lesquels il convient de se pencher quelque peu : la pasteurisation et la filtration sur terre de diatomées.

Notre expérience personnelle de la pasteurisation des miels porte maintenant sur plusieurs années. Nous savons qu'une installation bien conçue utilisant un pasteurisateur à plaques, dotée de tous les moyens de contrôle de température et de débit souhaitables permet de préparer un miel qui se conserve à l'état liquide pendant environ 6 mois, sous réserve que les récipients recevant le miel pasteurisé soient parfaitement lavés au préalable. Toute fermentation ultérieure est exclue. L'augmentation de la teneur du miel en HMF est négligeable, l'amylase n'est que très partiellement détruite. Seule l'invertase, diastase très thermolabile, souffre de l'opération et se trouve détruite à $80 \mathrm{p}$. Ioo environ. L'inhibine est à peine affaiblie.

Ces données ont été vérifiées abondamment sur les échantillons de miel que nous avons pu ramener d'Amérique ou qui nous ont été expédiés après notre retour en France. Nous avons dosé l'HMF, l'amylase et l'invertase et nous avons mesuré la teneur en eau. Certains miels présentent des signes évidents de chauffage excessif mais nous avons remarqué qu'ils proviennent d'entreprises qui ne contrôlent pas 
rigoureusement les conditions de pasteurisation. N'oublions pas d'ailleurs que la loi américaine n'a rien prévu pour sanctionner des excès qui ne sont considérés comme tels que par les lois européennes. On aurait donc mauvaise grâce de reprocher aux Américains des pratiques qui, dans leur pays, sont considérées comme valorisantes.

Nous ne pensons pas que l'inactivation partielle des diastases du miel par la pasteurisation soit un argument suffisant pour la faire rejeter en tant que moyen de préservation du miel et de conservation de longue durée à l'état liquide. Aucun argument sérieux, reposant sur des bases scientifiques, ne peut actuellement être avancé contre la pasteurisation. On ne dispose, en particulier, d'aucun test physiologique permettant de mettre en évidence une diminution quelconque de la valeur alimentaire ou thérapeutique du miel pasteurisé. On connaît, par contre, parfaitement les avantages que l'on peut tirer de la pasteurisation sur le plan de la conservation et de la présentation.

En ce qui concerne la filtration sur terre de diatomées, nous pensons, par contre, que de très sérieuses réserves sont à faire. Une bonne filtration est certes indispensable pour donner au miel une présentation avantageuse et la décantation seule est insuffisante pour éliminer toutes les particules solides qui souillent le miel extrait par centrifugation. De là à filtrer le miel au point d'en enlever tous les constituants solides et colloïdaux, il y a une marge qu'il semble bien imprudent de franchir. Peut-on considérer encore comme du miel un produit dont on a extrait des constituants qui font que, précisément, le miel se distingue des autres produits sucrants? Nous ne le pensons pas et nous jugeons qu'il serait dangereux de laisser s'introduire dans notre pays une technique qui ne présente aucun avantage sérieux pour la valorisation du miel et qui risque, au contraire, de lui faire perdre ses clients les plus fidèles.

\section{B. - Aspects ÉCONOMIQUES}

Il ne suffit pas que les principes appliqués en Amérique au conditionnement du miel soient valables, à quelques détails près, sur le plan technique ; encore faut-il que sur le plan économique la transposition des données soit possible, dans la mesure où elle apparaîtrait comme souhaitable, voire nécessaire.

La création en France, au cours des trois dernières années, de nombreuses Coopératives apicoles, semble bien apporter la preuve qu'il existe un courant d'opinion favorable à la coopération en apiculture. Il est urgent, si l'on veut éviter un développement irrationnel de ces Coopératives, de poser clairement les problèmes et de déterminer les bases sur lesquelles elles sont susceptibles de fonctionner à la satisfaction de tous. Il nous semble que les informations recueillies au Canada et aux U. S. A. sont de nature à nous faciliter ce travail. Voyons donc, à la lumière de ces informations, comment on peut envisager les problèmes français.

Il est certain que le volume de la production française de miel ne peut pas être comparé à celui de la production américaine. Il n'en reste pas moins vrai que ce sont chaque année Io à I5 millions de kilogrammes de miel qui sont livrés à la consommation par l'intermédiaire d'un circuit commercial normal, le reste de la production échappant à la commercialisation d'une façon plus ou moins complète. Une telle masse de produits est très suffisante pour justifier la mise sur pied d'un système coopératif pour le conditionnement et la vente. D'ailleurs, la tendance 
actuelle du marché paraît favorable à l'instauration d'un tel système. En effet, les producteurs perdent d'année en année leurs anciens marchés régionaux. Sous l'influence des nouvelles chaînes commerciales de supermarchés et de magasins à succursales multiples, la vente des produits devient parfois très difficile. La psychologie du consommateur évolue elle aussi. L'acheteur se tourne de plus en plus vers des produits standardisés auxquels il demande d'être à la fois savoureux et de qualité constante. Il semble donc bien que la création de coopératives du type américain soit tout à fait dans la ligne actuelle de l'évolution du marché et soit seule capable d'assurer à l'apiculture cette évolution qui lui permettra de vaincre ses difficultés.

Il n'est pas non plus sans intérêt de noter que le groupement des producteurs constitue, pour eux, le seul moyen d'accéder aux avantages commerciaux de la publicité qu'il est impossible de concevoir à l'échelon du producteur moyen isolé. L'organisation coopérative peut enfin faciliter le stockage et le report d'éventuels excédents d'une année sur l'autre. Elle peut donc contribuer efficacement à la stabilité des cours.

En conclusion, nous pensons que l'organisation coopérative des apiculteurs, dans des conditions comparables à celles qui existent en Amérique, constitue à 1'heure actuelle une formule parfaitement adaptée aux besoins, à la fois du producteur et du consommateur français, voire européen. Il resterait à déterminer quel est le format le plus satisfaisant pour une coopérative apicole dans les conditions actuelles du marché.

Le calcul effectué par des experts a montré qu'au-dessous de 300 tonnes par an, une coopérative est dans l'incapacité de couvrir les frais occasionnés par l'emploi d'un directeur commercial. Si l'on tient compte de la nécessité de couvrir des frais d'investissement importants dans le domaine des constructions et du matériel de conditionnement, on s'aperçoit que c'est un volume de 800 à I ooo tonnes qui serait nécessaire pour assurer un fonctionnement rentable. On retombe sur les chiffres relevés en Amérique où les plus petites affaires traitent précisément un tonnage de cet ordre. Doit-on considérer comme utopique la création, en France, de coopératives apicoles d'une telle importance? Nous ne le pensons pas mais nous estimons cependant qu'il ne peut y avoir place dans notre pays pour un grand nombre de ces entreprises. Ceci nous amène à envisager la coexistence de petites Coopératives régionales traitant, sans moyens industriels importants, quelques dizaines de tonnes chaque année et des Coopératives de grand format disposant à la fois d'installations industrielles modernes et d'un directeur commercial.

Notons enfin qu'il nous paraîtrait de bonne politique que l'apiculteur coopérateur puisse conserver, comme en Amérique, une certaine liberté pour vendre directement au détail une partie de sa production. Ces ventes directes constituent une excellente publicité, notamment pendant les mois d'été lorsqu'elles atteignent les citadins en vacances. Elles ne devraient pas gêner les coopératives mais au contraire favoriser les ventes de miel dans les grandes villes pendant les mois d'hiver. Mais on touche là à un principe fondamental de la Coopération, celui de la livraison intégrale des produits à la coopérative. On soulève alors d'autres problèmes qu'il nous paraît difficile d'évoquer ici. 


\section{CONCI,USION}

Bénéficiant d'une expérience qui porte maintenant sur plusieurs dizaines d'années, l'industrie américaine du conditionnement du miel a atteint un stade d'évolution très avancée qui la place au premier rang dans le monde à la fois par son efficacité et par la qualité des produits commercialisés. Notre retard n' en apparaît que plus important mais nous sommes persuadés que l'apiculture française, l'une des premières d'Europe par le volume de sa production, peut si elle manifeste suffisamment d'esprit d'entreprise le combler rapidement.

Par la coopération, par l'installation de chaînes de conditionnement modernes et bien équipées, notre apiculture peut, en quelques années, mettre sur le marché français et européen des miels de qualité répondant aux nécessités du marché. Elle peut assurer aux producteurs des prix de vente satisfaisants et moins soumis qu'actuellement aux fluctuations économiques. Elle peut aussi apporter au consommateur la garantie, qu'il exigera de plus en plus énergiquement, de trouver partout des produits de qualité suivie et hautement satisfaisante.

Notre voyage d'étude n'aurait pas eu son aboutissement normal sans la publication du présent rapport. Nous souhaitons qu'il constitue désormais pour les apiculteurs français un document de référence en dépit des inévitables lacunes qu'il comporte. Nous sommes loin d'avoir rédigé ici toutes nos observations et nous n'avons pas donné non plus la totalité des renseignements d'ordre technique qui nous ont été fournis. Nous nous en excusons mais nous pensons qu'ils auraient alourdi un texte déjà très copieux. Ils restent à la disposition des apiculteurs sous certaines conditions et ils formeront, avec les archives photographiques de la mission, un dossier très complet que les coopérateurs auront intérêt à consulter.

Il nous reste à formuler le vocu que dans un proche avenir, des réalisations concrètes viennent administrer la preuve que notre voyage ne fut pas inutile et qu'il a pu contribuer quelque peu à faire progresser l'apiculture française.

$$
\text { Reçu pour publication en fétrier } 1964 .
$$

\section{REMERCIEMENTS}

Il est bien évident que la mission d'étude dont nous venons de rendre compte n'aurait jamais pu être mise sur pied et menée à bien, comme elle le fut, sans le concours efficace et désintéressé de nos divers hôtes américains dont nous avons pu, à tout moment, apprécier l'amabilité, le dévouement et le sens de l'organisation.

Aussi, nous est-il particulièrement agréable de leur exprimer notre reconnaissance et de les remercier chaleureusement en notre nom et au nom de tous les organismes officiels et professionnels représentés au sein de la mission.

Reprenant notre itinéraire et espérant ainsi éviter toute omission involontaire, nous adresserons tout d'abord nos remerciements au $\mathrm{D}^{\mathrm{r}} \mathrm{J}$. I. HAMBLEToN, ancien chef du Département d'Apiculture des services de recherches du Ministère de l'Agriculture des U. S. A., grand ami de la France et bien connu des apiculteurs français, qui s'est chargé, avec M. le Professeur G. Townsend, Chef du service d'apiculture du Collège d'Agriculture de l'Ontario, d'établir le plan de notre visite et de prendre tous les contacts nécessaires pour assurer notre introduction auprès des organismes apicoles acceptant de nous recevoir 
A Montréal, nos remerciements iront à M. René Brasseur, Assistant-chef du Service de l'Apiculture et à son épouse pour leur si cordiale réception, à M. PLOURDE, Chef de l'A piculture de Québec pour son exposé sur l'organisation de la lutte contre les maladies des abeilles, et aux dirigeants des établissements " Doyon and Doyon » et des Établissements Lallemant qui nous ont aimablement fait visiter leurs installations apicoles.

A Guelph, où le $\mathrm{D}^{\mathrm{r}}$ TownsEND dirige l'excellent Laboratoire de recherches apicoles, nous avons l'agréable devoir de remercier toute l'équipe de chercheurs qui nous a reçus si aimablement et nous a consacré tout son temps.

De Toronto, nous gardons le souvenir du manager de la Coopérative apicole de l'Ontario, de son prédécesseur M. 'Tom Shear et du Dr BuRke, assistant du Pr Townsend qui fut notre sympathique pilote. Nous n'oublions pas non plus les dirigeants de la "Billy Bee ». A tous, nous adressons nos plus vifs remerciements.

Si nous gardons de Winnipeg le souvenir d'une ville balayée par un vent glacial, la chaleur de l'accueil de M. F. R. Garlant, Directeur de la "Clover Crest Iloney Coopérative", nous le fait facilement oublier. Nous rendons hommage à sa patience et à l'infatigable bonne volonté avec laquelle il a répondu à nos questions. Nous remercions également bien vivement $\mathrm{M}$. URHIN, président de la Coopérative, le Dr R. Robertson, conseiller technique apicole du Manitoba et tout le personnel de la Coopérative.

M. le Professeur M. Haydack, de l'Lniversité de Saint-Paul, M. C. D. Floyd, leurs assistants et leurs dévouées compagnes ont droit à toute notre reconnaissance pour leur généreuse hospitalité ainsi que M. Banker, Président des Apiculteurs du Minnesota, et sa famille. A tous, nous devons le souvenir d'un bien sympathique dimanche.

Nous remercions également M. Remer, manager de la "Sioux-Bee" qui a bien voulu nous consacrer une journée en dépit des charges écrasantes de l'affaire qu'il dirige, la plus importante des U.S. A. Nous n'oublions pas non plus M. H. SCHAEFFER, qui fut notre pilote pendant une partie du voyage et à qui nous adressons notre amical souvenir.

Sur le chemin du retour, nous remercions encore bien vivement M. J. STraub de Chicago, le Dr DUNHAM et sa famille de London (Ohio) pour les précieux renseignements que nous a apportés la visite de leurs installations.

Enfin, de notre dernière escale à Ithaca, nous gardons le souvenir des précieux renseignements de M. le Professeur Dyce de l'Université Cornell et celui de notre instructive visite à la Coopérative des Finger Lakes et à la firme "Honey Butter Co". Qu'ils soient chaleureusement remerciés. Nous leur associerons encore dans notre reconnaissance tous ceux, et ils sont nombreux, qui à un moment quelconque nous ont aidés, conseillés ou pilotés dans ce monde américain avec lequel beaucoup d'entre nous venaient tout juste de faire connaissance.

Nous remercions enfin tous les organismes qui, en France, ont contribué au succès de notre entreprise, notamment par leur aide financière : le Service du Commerce extérieur, le Ministère de l'Agriculture et plus particulièrement l'Institut national de la Recherche agronomique ainsi que les organisations apicoles qui ont pris sur leur modeste budget les sommes nécessaires au voyage.

\section{SUMMARY}

REPORT ON TIE TRIP TO TIE L. S. A.

The authors present the results of their investigations as members of a study group sent to the U.S.A. and Canada in March 1963. In both these countries, the Cooperatives account for approximately one third of the harvest. American legislation aims at protecting the consumer against certain defects (excessive water content, dirt, tastes, parasites etc.) which may be found in honey. It pays no regard to the H.M.F. content nor to the diastase content and considers geographic and floral origin to be of minor importance. It seeks to obtain a standardized product of unvarying quality. A roughly filtered honey is delivered by the producer to the cooperatives, where the barrels are stored in accordance with the category of their contents (colour and water content). On maturing, the honey is repeatedly melted down in special chambers and is then fermented in mixing vats. The maturing process strictly speaking consists of prefiltering, pasteurization at $78^{\circ} \mathrm{C}$, and filtering through diatomite. American honey is put on the market in two principal forms : liquid pasteurized honey, and cream honey (mixed with fine crystalline honey which serves as a seed). Preservation is carried out at $14^{\circ} \mathrm{C}$. A variety of plants can be used for all these operations, depending on the size of the cooperative (various plants, techniques, and buildings are described). "Clover Crest " in Winnipeg was the most modern and best-eruipped plant that the authors visited. Four types 
of commercial outlets are used : short, medium, long, and cooperative. In spite of constant publicity, the use of attractive modern packings, and the purity of the products, the consumption of honey has not risen in the United States. Certain laws govern the running of the cooperatives which, furthermore, give out a considerable number of their own regulations.

The authors also visited 3 laboratories, among them the Laboratory of Apiculture of the Agricultural College of Ontario, in Canada, and the Apicultural Laboratory of the Cornell University, in the United States. 